SAND90-8224

Unlimited Release

DE9 1000883

Printed September 1990

\title{
DESIGN OF A DUAL PORT VOLUME MEASURING SYSTEM
}

\author{
Paul A. Klevgard \\ Measurement Standards, Calibration, \& \\ Photography Division \\ Sandia National Laboratories \\ Livermore, California
}

\begin{abstract}
A volume measuring system is described which uses the ideal gas law and pressure measurements to determine an unknown vessel's volume when a gas expands into that vessel from a known volume. The design, the engineering principles, the calibration, and the accuracy of this computercontrolled system are all discussed. A set of electrical and mechanical drawings of the system is included.
\end{abstract}

\section{MASTER}




\section{CONTENTS}

Introduction

Pressure and Tubing Ratios

Helium Metering Manifold

Hardware Design

Software

Calibration

Test Results

Drawings

Bibliography

APPENDIX A - SOFTWARE

APPENDIX B - PVMS DRAWINGS
Page

7

11

13

15

20

21

22

23

23

A 1

$\mathrm{B} 1$ 


\section{ILLUSTRATIONS}

No.

Page

$1 \quad$ Simplified System

8

2 Full System 10

3 Helium Metering System . 14

$4 \quad$ Water Bath $\quad 16$

$5 \quad$ Valve Drivers and Manifold $\quad 17$

$6 \quad$ PVMS Computer, Instrument Rack, and Vacuum Pump 18

A1 Software Flowchart A3 


\title{
DESIGN OF A DUAL PORT VOLUME MEASURING SYSTEM
}

\author{
Introduction
}

The component development groups of Department 8440 at Sandia National Laboratory-Livermore are often required to measure the internal volumes of a variety of pressure vessels, valves, and manifold assemblies. To expedite these measurements, a computer-driven, automated, volume measuring system was designed, fabricated, and calibrated.

A precision volume measuring system (PVMS) uses a gas ratioing systern to measure the pressure of the gas in a known volume and the pressure of that same gass expanded into an unknown volume. Using helium at sub-ambient pressure levels ensures that the ideal gas law applies in this process. The volume of the known and the unknown vessels are then related by their respective pressures through Boyle's law, $\mathrm{P} 1 \times \mathrm{V} 1$. $=\mathrm{P} 2 \times \mathrm{V} 2$, where $\mathrm{P} 1$ is the initial pressure in the initial volume V1, and P2 is the final pressure in the final volume V2.

In schematic form, Figure 1, the PVMS may be regarded as a helium supply connected to a vacuum pump by a valved manifold from which projects a known volume and the unknown test volume. The "forward" measuring cycle begins with valves $B$ and $C$ open, evacuating $V_{\text {ref }}$ until the vacuum gage reads less than 100 millitorr (100 microns of $\mathrm{Hg}$ ) of pressure. Valves $\mathrm{B}$ and $\mathrm{C}$ are then closed and A and D opened. Valve D is closed when the pressure equals 10 psia. A delay interval of 6 to 8 minutes then follows, allowing the thermal effects of charging to dissipate. At the end of this interval a pressure reading $\mathrm{P} 1$ is taken. Valve $\mathrm{C}$ is then opened, admitting the gas from $V_{t}$ and $V_{u n k}$. After another delay interval, a second pressure reading, $\mathrm{P} 2$, is taken. This gives a single equation with two unknowns:

$$
\mathrm{P} 1 \times\left(\mathrm{V}_{\mathrm{t}}+\mathrm{V}_{\text {unk }}\right)=\mathrm{P} 2 \times\left(\mathrm{V}_{\mathrm{t}}+\mathrm{V}_{\text {unk }}+\mathrm{V}_{\text {ref }}\right)
$$

The "reverse" measuring cycle then begins by evacuating $\mathrm{V}_{t}$ and $\mathrm{V}_{\text {unk. }}$. When the vacuum level is lower than 100 millitorr, valves $\mathrm{B}$ and $\mathrm{A}$ are closed. Valves D and $\mathrm{C}$ are opened to admit helium up to $10 \mathrm{psia}$, at which time valve $\mathrm{D}$ is closed. After a delay interval, a pressure reading P3 is 


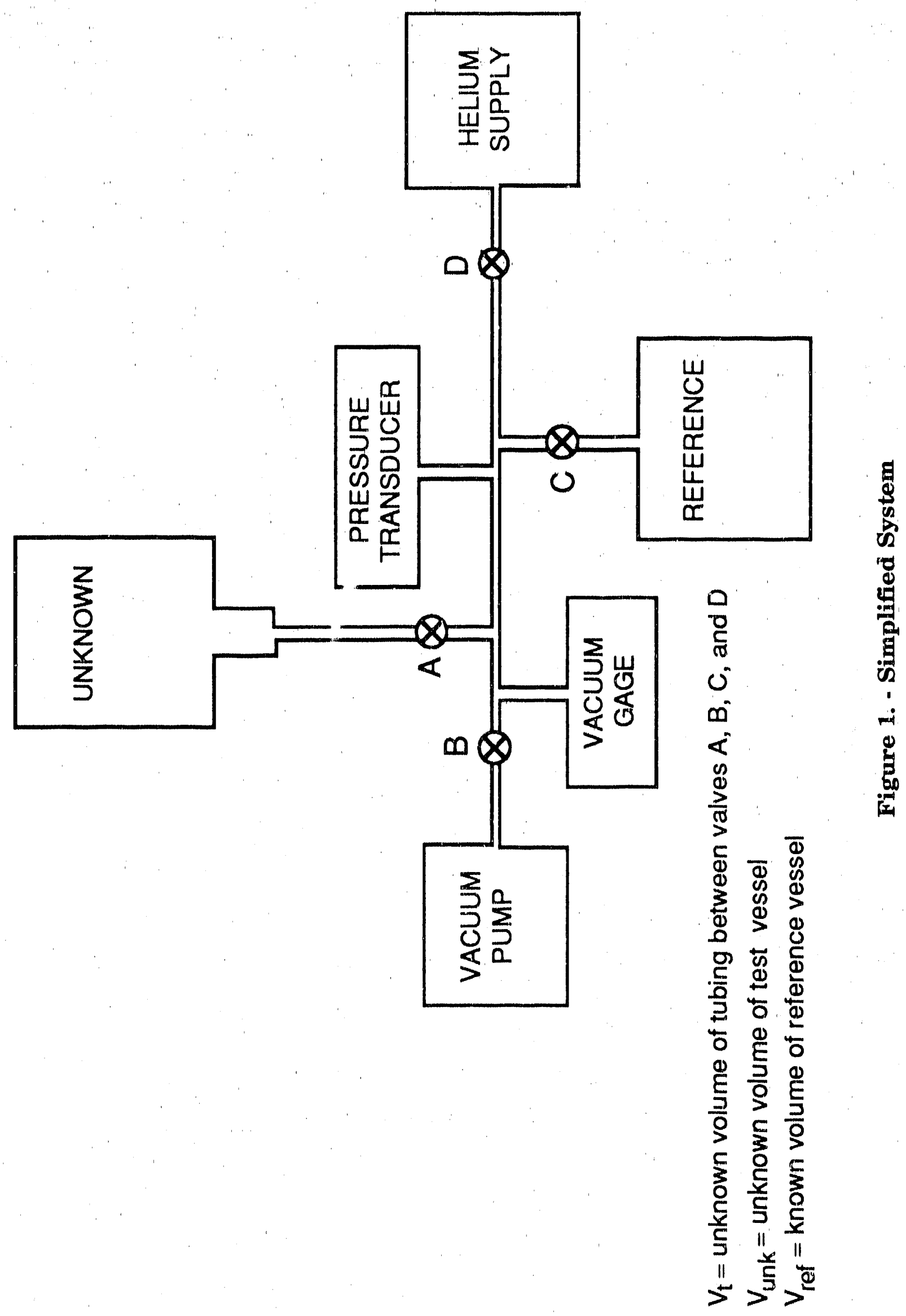


taken. Valve $\mathrm{A}$ is then opened and, after another delay, pressure reading P4 is taken. A second equation with two unknowns may then be written:

$$
\mathrm{P} 3 \times\left(\mathrm{V}_{\mathrm{t}}+\mathrm{V}_{\text {ref }}\right)=\mathrm{P} 4 \times\left(\mathrm{V}_{\mathrm{t}}+\mathrm{V}_{\text {ref }}+\mathrm{V}_{\text {unk }}\right)
$$

Eliminating $V_{t}$ between the two equations then yields $V_{u n k}$ in terms of 4 pressure readings and $\mathrm{V}_{\text {ref. }}$.

$$
\mathrm{V}_{\text {unk }}=\mathrm{V}_{\text {ref }} \times \frac{\mathrm{P} 3(\mathrm{P} 1-\mathrm{P} 2)}{\mathrm{P} 1(\mathrm{P} 3-\mathrm{P} 4)}
$$

A complete description of the operation and the calibration of a PVMS is set forth in a previous report ("Precision Volume Measuring System", SAND84-8014) by the same author. The algebraic derivation of the equation for $V_{\text {unk }}$ from Boyle's law is also included in this report.

Since Boyle's law assumes that the temperature of the gas involved stays constant throughout the measurement cycle, some care must be taken to preserve isothermal conditions. There are two sources of gas temperature change within the manifold and the reference and test volumes: 1) changes of ambient conditions, and 2) heating and cooling effects during vessel filling and during the gas expansion processes. A constant temperature water bath will ensure that ambient conditions do not change during the test. And agitating the bath water will even out the inevitable heating and cooling effects of the helium gas.

Submerging the manifold assembly in the water does not present any great difficulties. The pressure transducer used was a submersible model 8010 depth sensor from Paroscientific, Inc. of Redmond, Washington. The valve bodies themselves may be submersed, although their pneumatic drivers should be kept above the water line by means of stand-off couplers. The vacuum gage may be located just outside the bath on the tubing leading to the vacuum pump. Because the vacuum gage and its connecting tubing sees small temperature changes due to air currents, a valve within the bath is used to isolate this section from the manifold itself. To allow the testing of a wide range of unknowns, reference volumes of various sizes are connected to the manifold. Adding a computer which reads temperature, pressure, and vacuum, and which controls temperature and valve operation, completes the system. The resulting schematic is shown in Figure 2.

What the system regards as the "test unknown" is everything after the last valve leading to the test vessel. The operator must subtract any connecting tubing volume to find the actual volum' of his vessel. This is normally done by running the test a second time with the vessel removed and the tubing capped off. This external tubing must be distinguished from the internal tubing, $\mathrm{V}_{\mathrm{t}}$. The latter is never assigned a value, although it plays its role in the gas expansion process characterizing both the forward and the reverse cycles. 


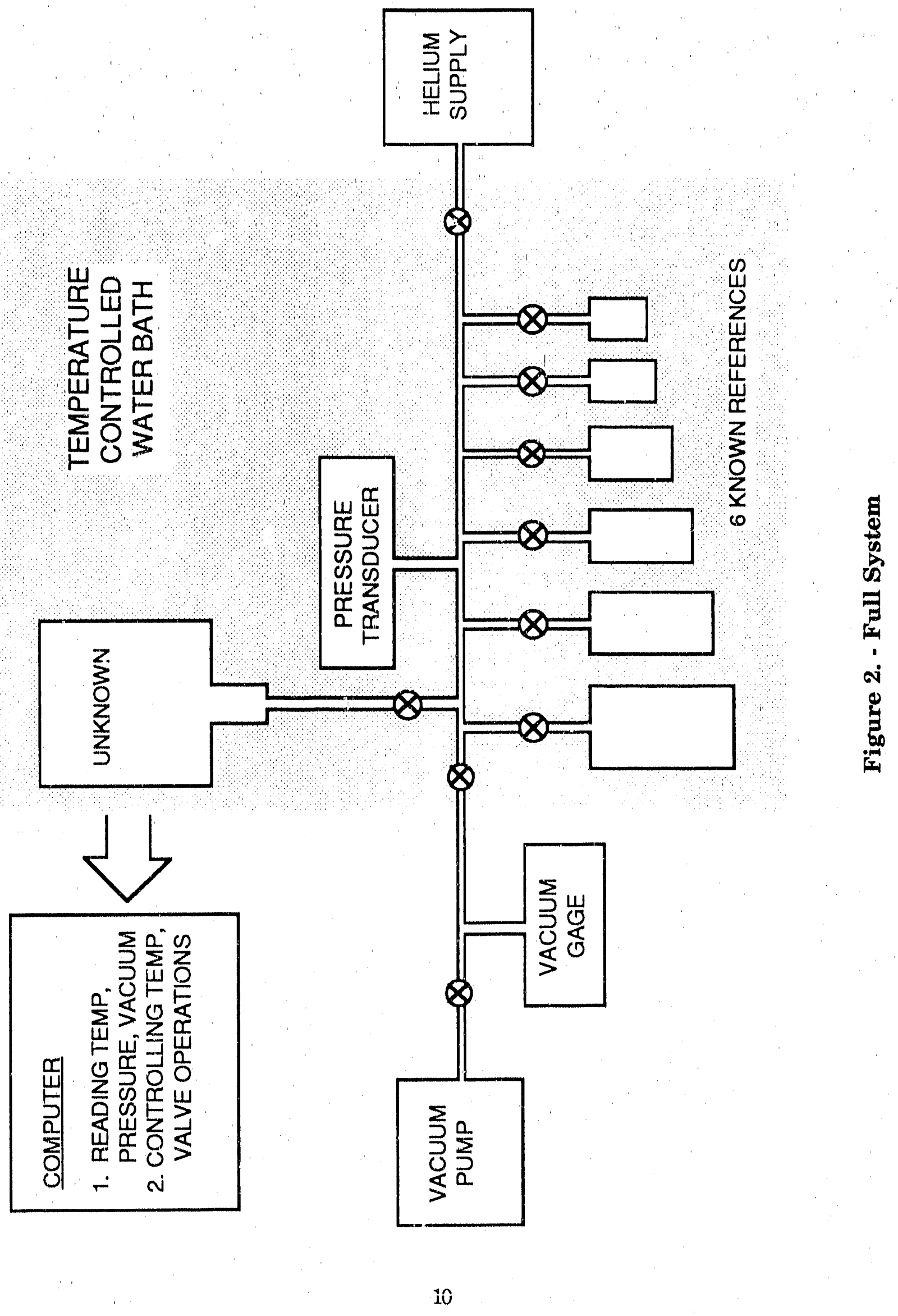




\section{Pressure and Tubing Ratios}

All volume calculations are based on the equation cited above:

$$
\mathrm{V}_{\text {unk }}=\mathrm{V}_{\text {ref }} \times \frac{\mathrm{P} 3(\mathrm{P} 1-\mathrm{P} 2)}{\mathrm{P} 1(\mathrm{P} 3-\mathrm{P} 4)}
$$

$\mathrm{P} 1$ is the starting pressure for the forward ratioing cycle and P3 is the starting pressure for the reverse ratioing cycle. Both are software controlled to be a nominal 10 psia, which means that the ratio of $\mathrm{P} 3$ over P1 is simply 1 . As a result, the volume calculation actually depends upon the ratio of two pressure differences, (P1 - P2) and (P3 - P4). This provides one advaritage and imposes one constraint.

The advantage of ratioing pressure differences is that offsets do not affect the calculations. If the pressure transducer reads 1 psi high throughout its range, the pressure differences are unaffected and the accuracy of the volume calculation is preserved. The constraint involves the relative values of the two differences: neither the numerator nor the denominator should be a small value. The ratio is especially unstable and susceptible to error magnification if the denominator is a small value and the numerator is not, or vice versa. The system, both in hardware and in software, must be designed to permit a significant pressure drop from P1 to P2 and from P3 to P4. A couple of examples may best illustrate this.

Suppose that an unknown plus tubing totals about $350 \mathrm{cc}$, the internal tubing is about $80 \mathrm{cc}$, and the reference selected is about $300 \mathrm{cc}$. If the expansion goes into the reference vessel and the beginning pressure is 10 psia, then P2 is:

$$
\begin{gathered}
10(80+350)=\mathrm{P} 2(80+350+300) \\
\mathrm{P} 2=5.89 \mathrm{psia}
\end{gathered}
$$

For the reverse cycle, if $\mathrm{P} 3$ is 10 then $\mathrm{P} 4=10(380) / 730=5.2$ psia.

As a second example, suppose that an unknown plus tubing totals only $10 \mathrm{cc}$, the internal tubing is still $80 \mathrm{cc}$, and the reference selected is 10 cc. For the forward cycle:

$$
\begin{gathered}
10(80+10)=\mathrm{P} 2(80+10+10) \\
\mathrm{P} 2=9 \text { psia }
\end{gathered}
$$

For the reverse cycle, $\mathrm{P} 4$ also equals 9 psia. 
In the first example the ratio of (P1 - P2) over (P3 - P4) is 4.11/4.8. Both numerator and denominator are large enough so that random errors have little effect upon the ratio value. In the second example, where the ratio is $1 / 1$, both random errors and resolution errors can play a much larger role. The problem in this latter case is that the internal tubing value, $V_{t}$, is too large relative to the volume of the unknown. A similar effect obtains if the reference volume is very much larger than the unknown vessel. From these examples, two conclusions follow: 1) the internal tubing volume must be proportioned to the smallest reference volume of the manifold system, and 2) any test unknown should be ratioed against a known reference vessel of approximately equal size.

For this particular PVMS the measurement requirements were an accuracy of better than $0.3 \%$ over a range of 2 liters down to $3 \mathrm{cc}$. This necessitated two differently sized internal tubings and a total of six references from $1000 \mathrm{cc}$ down to $10 \mathrm{cc}$. The internal tubing connecting all the reference vessels was split into two sections by a valve: one section had the larger vessels, 1000,$300 ; 150$, and $75 \mathrm{cc}$, and the other section had the two smaller reference vessels, 40 and $10 \mathrm{cc}$. The valve dividing these roferences remained open when testing large unknowns and closed when testing small unknowns.

A schematic of the entire system is shown in Appendix B, Drawing 99626. All the reference vessels are labeled with their nominal volume values and all vessels and their valves are submerged in the water bath. Valves 106, 108, 202, 109, 200, 201 plus their connecting tubing are also submerged; all remaining valves and tubing are outside of the bath. Valve 200 is a three-way valve which is open toward valve 201 when testing large unknowns. The internal tubing volume delimited by valves 106, 202, and 201 is $37 \mathrm{cc}$. When testing small unknowns, valve 200 is open toward valve 109 and valve 108 is closed during all gas fills and gas expansions. The internal tubing volume delimited by valves 108,202 , and 109 is only $6.4 \mathrm{cc}$. This is achieved by using eighth-inch diameter tubing in this section.

The volume system measures (ratios) any volume after its last valve, 201 for large vessels, 109 for small vessels. Extending from this valve therw must be a length of tubing which connects to the operator's unknown vessel. When the test vessel is removed, the capped off "external" tubing represents the smallest volume the system effectively measures. Working through the mathematics of desired pressures after gas expansion, one finds that the optimum external tubing volume is simply the equal of the internal tubing volume. Hence, after valve 201 there is a "tag-along" volume of $37 \mathrm{cc}$ before the fitting which connects to the unknown. This takes the form of about 13 inches of half-inch diameter tubing which is joined to the external tubing at one end and sealed off at the other end. The tag-along volume after valve 109 is $6.4 \mathrm{cc}$ (about 9 inches of quarter-inch diameter tubing). 
The differing external tubing volumes for testing large versus small vessels is what creates the need for two test ports and a throe-way valve. The same effect can be achieved with a single port if one is willing to connect fittings to the last valve with different tag-along volume values for large versus small vessel tests. The design used here imposes fewer plumbing connections upon the operator and requires but a single decision: connect the vessel directly to the large port or to the small port.

\section{Helium Metering Manifold}

Any PVMS is likely to be used to test vessels whose size differs greatly. In this case, the smallest "vessel" would be the capped off tubing of the small port, namely $6.4 \mathrm{cc}$. The largest vessel might be two liters; vessels even larger than two liters could be tested, although with decreasing accuracy. If the helium system consists simply of a bottle, a regulator, and a single metering valve, then problems appear. If the metering valve is closed down to a flow rate appropriate to small vessels, then large vessels, either reference or test, will take too long to fill: And if the metering valve is set to a flow rate appropriate to large vessels, then the small vessels tend to overfill well beyond the 10 psia target value. The best solution is to have a variable helium metering system under computer control. 'T'his avoids both overfills and long fill times. Without overfills, both '1' and P3 are nearly identical, which has some advantages as mentioned above.

A variabla helium metering system is depicted in Figure 3. Two regulators are used for safety considerations. The first regulator is on the gas bottle and it reduces the pressure down to 100 psig. Valve 207 is an electric solenoid valve, helium leak tight, that only opens when the computer calls for helium. Downstream from this valve comes the second regulator which reduces the pressure to about $5 \mathrm{psig}$. A relief valve set to 10 psig follows which serves to protect the pressure transducer down line. Three electrically operated solenoids follow, valves 204 through 206 , mounted on a single manifold. Up to the manifold the tubing used is onequarter inch diameter; after the manifold the tubing is one-eighth inch until pneumatically-actuated ball valve 203. This smaller tubing reduces the helium reservoir downstream from the throe solenoid valvos; this in turn eliminates a helium surge when valve 203 opens to an evacuated internal tubing. 


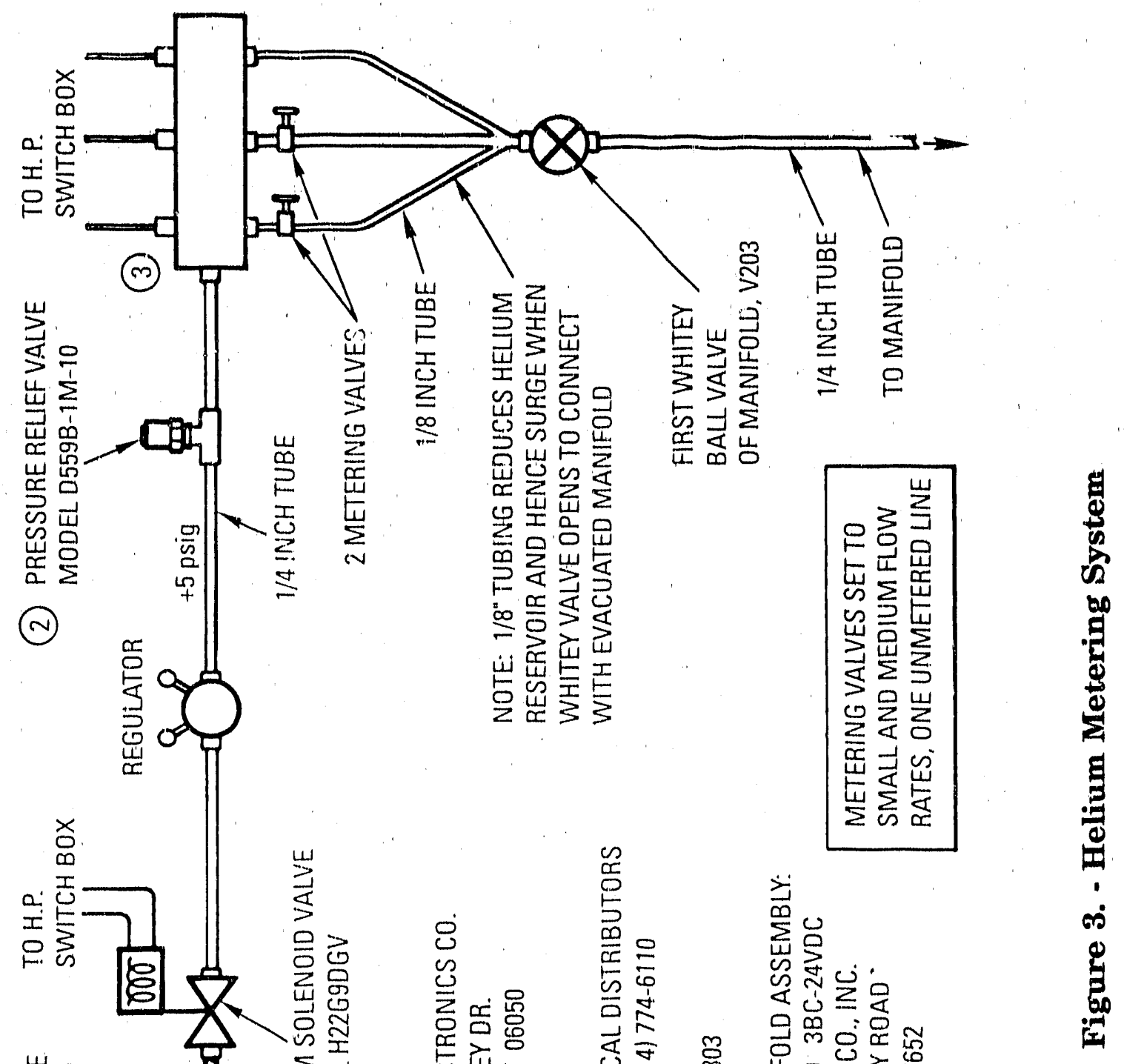


Each of the metering manifold's three exits are only open if the corresponding solenoid is energized. One of these exit lines allows free flow, a second exit line is partly constricted by a metering valve, and the third exit line is severely restricted. The result is a flow system that is variable through the computer's choice of opening any combination of the three solenoids. The software can do this by using the size of the reference vessel selected as an indication of flow rate. An alternative software approach is to start with a default flow rate and adjust it on the basis of the rate of pressure rise over the course of executing a measurement loop.

\section{Hardware Design}

The bath used for this PVMS is an old calorimetry bath fabricated by Mound Laboratory (Figures 4 and 5). It holds about 200 gallons of water, the level of which can be raised or lowered by reversing the rotation of the agitator impeller. The bath and all of the submerged manifold hardware are stainless steel; a small amount of "Rust Raider" by Radiator Specialty Company of Charlotte, N.C., is nevertheless added in case a test item is subject to corrosion. The bath's original fast heater $(220 \mathrm{vac})$ failed and wo $\mathrm{s}$ replaced with a similar model, CNBS1-352, from Proheco Manufacturing Company of Pomona, California. The latter is protected from overheating by a meltable fuse. Both heaters are under simple off-on control from the computer. Cooling is achieved by heat loss to the room; heating comes from the energy of the impeller, as well as the two heater elements. A stable operating temperature of $27.0^{\circ} \mathrm{C}$ was found to be ideal for the thermodynamics of the system.

Exclusive of the computer, all the electronics are housed in a 19 inch rack about 4 feet high (Figure 6). This rack has an instrument panel (drawing title "PVMS Front Panel Parts Layout" in the appendix) featuring a manifold schematic displaying the location and status of the vario's manifold valves. A lit green LED indicates an open valve; a lit red LED indicates a closed valve. The three-way valve, V200, has two green LEDs which indicate the direction in which the valve is open. Since pressure, temperature, vacuum, and valve status are all displayed on the instrument panel, the operator is given complete information on the state of the system.

For ease of communication, all instrumentation should be selected which offers IEEE-488 bus connections to the computer. The Newport RTD temperature readout is so equipped. When the Granville-Phillips vacuum gage was ordered an IEEE-488 option was not available; output was in BCD format. Rather than install a BCD card in the IBM computer, a converter box was used (model 4833 from ICS Electronics Corp., San Jose, California) to get from BCD to IEEE-488. This would now be unnecessary; GranvillePhillips offers : "Convectron" vacuum gage and readout with an IEEE-488 


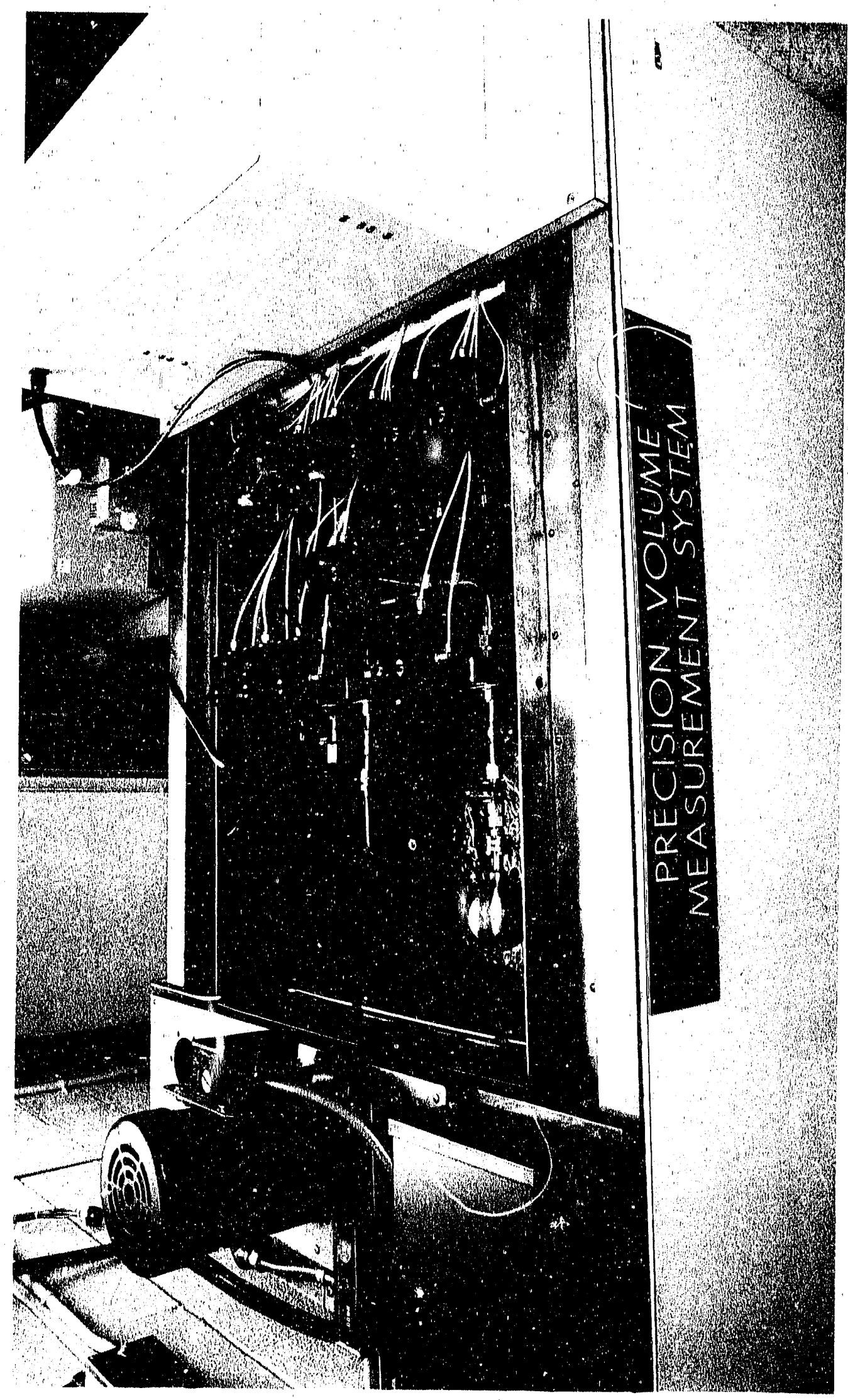

ن 


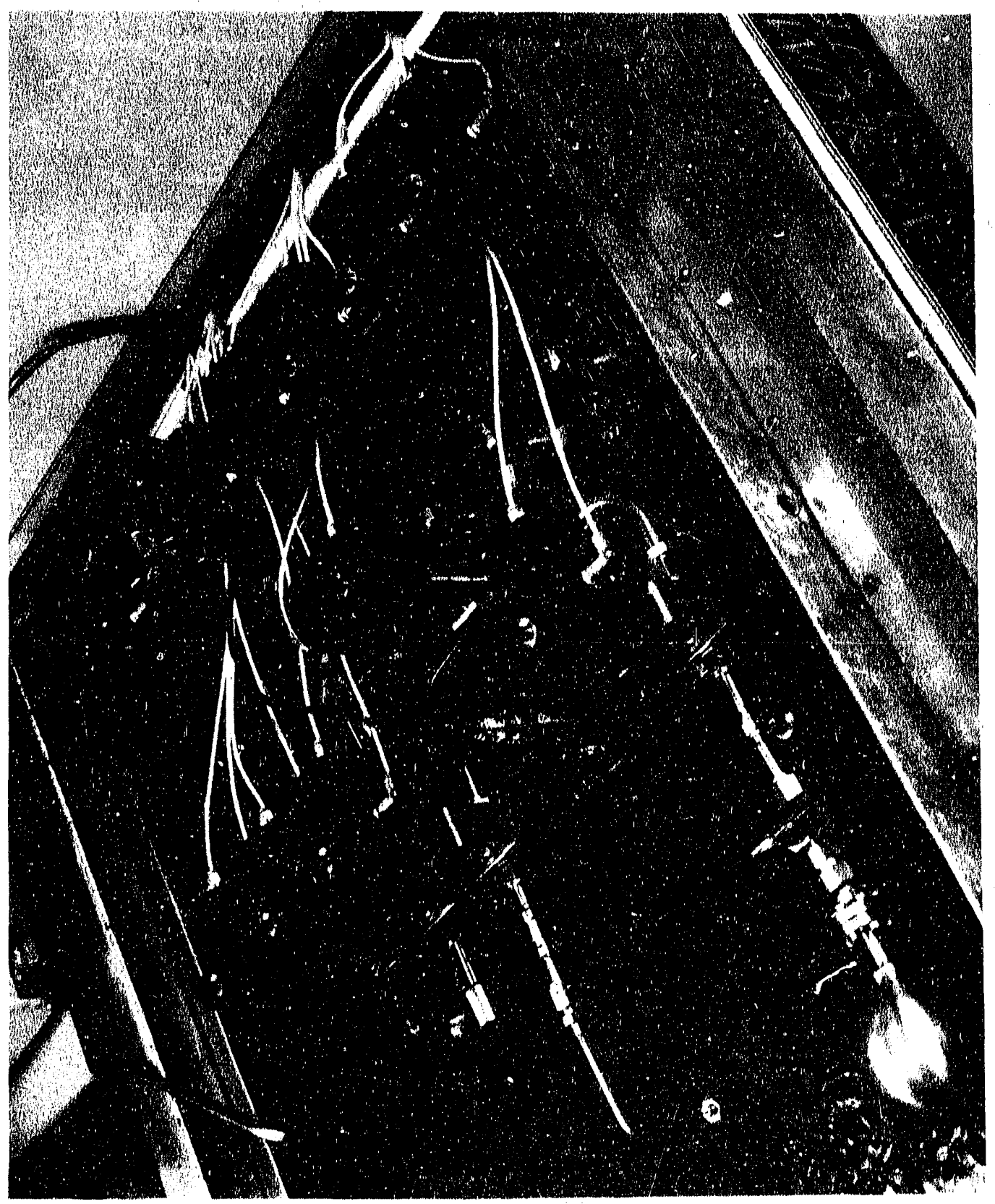

 


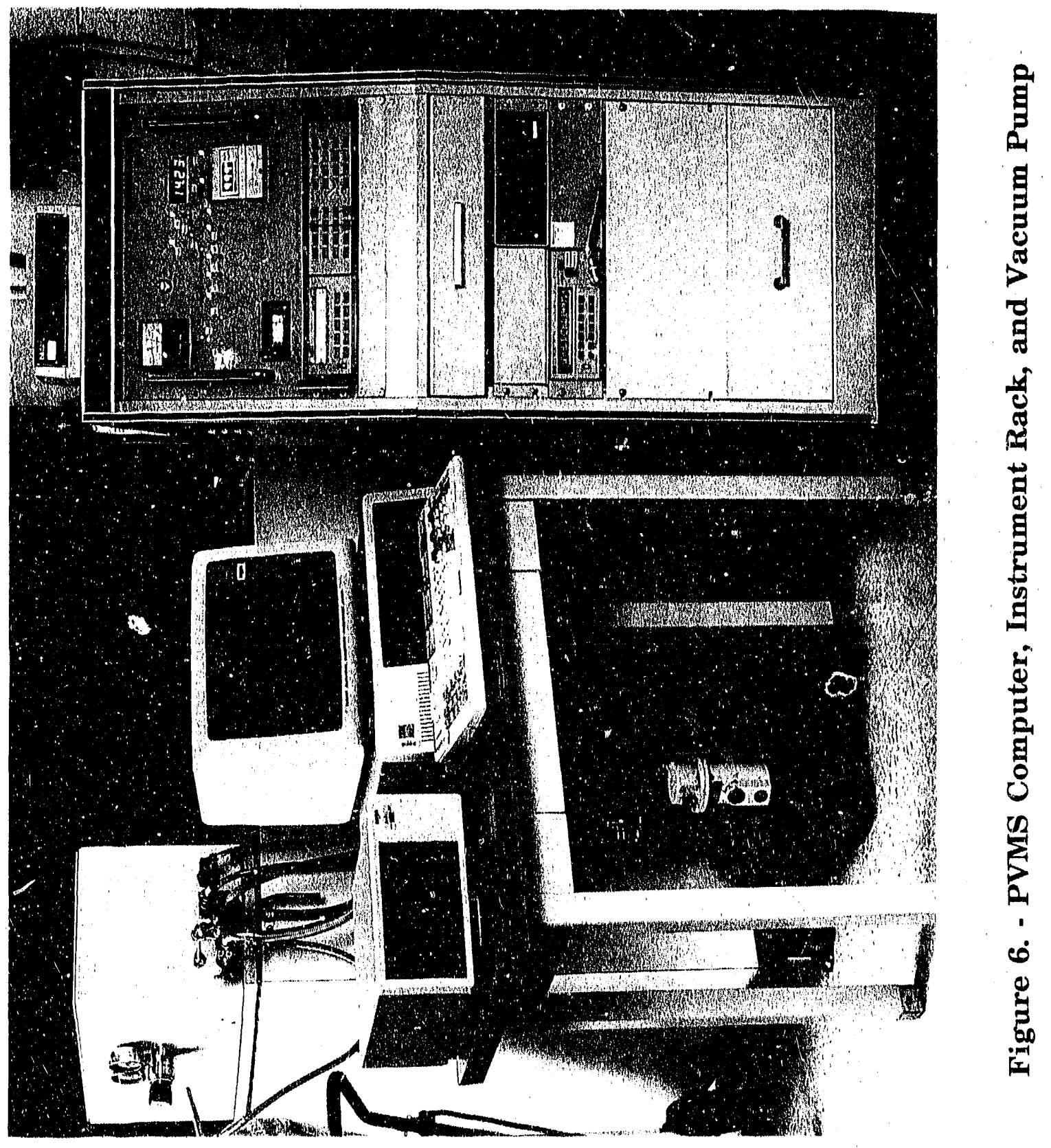


option (model 316 for up to thrce sensors). 'The secend vacuum gage on the manifold is not read by the computer. It is used to help isolate any leaks which occur in the manifold.

The Hewlett-Packard model 3488A Switch/Control Unit is a versatile interface box whose function depends upon the specific module plugged into one of its five available slots. For the PVMS, three slots are filled with option 011 cards, a ten-channel general purpose relay. Upon computer command. via the IEEE- 488 bus, these cards actuate relays operating at $24 \mathrm{vdc}$. Electric solenoid valves, V204-V207, are operated directly by these relays; pneumatic valves (V100-V106, and V108-V203) are operated via the Tyna_Mite valves which control house air (50 psig). Relays (channels) 208, 209, and 301 actuate remote high current relays which in turn control the two heater circuits and the vacuum pump motor.

The bath agitator must be turned on manually. All other electric power is through an off-on key switch on the instrument panel. Once this key is turned to "on", all the electronics have power and the computer boots itself from a hard disk. An autoexec.bat file loads and runs the appropriate software, and the operator is presented with a graphics screen listing his choices. One of the choices presented is that of "shutdown". When the test is finished or aborted and shutdown is selected, the computer shuts off the heaters and vacuum pump and closes all valves. Once the vacuum pump is off, the helium inlet valves are opened to bring the vacuum line up to atmospheri. pressure. This prevents any migration of pump oil into the vacuum line and hence to the manifold. Once the vacuum line and manifold are at $14.3 \mathrm{psia}$, the helium inlet valves are closed and the computer screen tells the operator to turn the key switch to "off".

The vacuum line from the pump has an internal diameter of about 0.75 inches and the fittings are $\mathrm{KF} 16$ couplings. Just before valve V107 the line switches to quarter-inch tubing. It would have been better to run this section in half-inch tubing up to valve V106 (in the bath). The larger pneumatic drivers required for half-inch valves would have been more awkward to install, but the vacuum characteristics of the manifold would have been improved. One quarter-inch tubing could have begun on the manifold side of V106. As presently built, the quarter-inch and eighth-inch tubing sections tend to slow down the vacuum response somewhat.

Except for the helium inlet valves, V203 through V207, all valves used are quarter-inch ball valves. These valves are ordered with Cajon-VCR fittings for two reasons: 1) this fitting is superior to Swagelok for vacuum service, and 2) the zero clearance of this fitting permits the easy replacement of valves if that becomes necessary. Those four valves, V106, V107, V202, and V203, which either terminate the ratioing manifold or isolate vacuum gages, have the standard configuration (unforted) ball, Whitey part number SS43-VCR4. The remaining valves, with one exception, have the ported ball, SS43HL-VCR4. This porting configuration creates a constant-volume valve: the manifold volume is not changed by ball rotation 
(see SAND84-8014). The exception is valve V108 which does not have to be constant-volume: it remains open when ratioing large vessels, and closed when ratioing small vessels. Unported ball valves have an extra sealing surface compared to ported ball valves and where possible they should be used.

That section of the manifold plumbed with one-eighth inch tubing also features one-quarter inch valves because Whitey does not make a oneeighth inch, constant-volume, ball valve. Cajon-VCR male weld glands must be used between these valves and the eighth-inch tubing. Cajon makes such a reducing gland (part \# SS-2-VCR-3); an unbored (blind) gland, SS-4-VCR-3-.75LG-BL, may also be modified for this purpose. If modification is chosen, a shoulder should be cut into the gland to reduce the metal masa at the weld junction. If this is not done, the weld heat may burn through the tubing before melting the gland surface.

\section{Software}

A regular IBM-PC was available at the beginning of this project and was chosen as the controller. Cards provide for extra memory, graphics (Hercules graphics card), and IEEE-488 interface (National Instruments card). The software is a compiled BASIC; namely, Microsoft QuickBASIC, version 4.5. The graphics package is HALO 88, QuickBASIC, version 1.00 .12 , from Media Cybernetics. The custom software code, ent tled "Volume", must be linked with an object file for the IEEE-488 interface, plus a graphics object file, plus a graphics library: LINK VOLUME.OBJ+QBIB1. OBJ+HALODVQB.OBJ,,HALOQB.LIB.

A software flowchart and the code itself is provided in Appendix A. The software was adapted from a previous project and includes only three subprograms: Close1, and Open1 to actuate valves, and Textcall to refresh the graphics screen. Both "close" and "open" are reserved words for QuickBASIC, hence the use of the numeral "1". All other functions are accomplished by "GOSUB" commands which branch to a named line label and then return. Most of these subroutines are self explanatory by their name, but some comments are appropriate. "Measure" controls the entire sequence of function gosubs and prints out the test results. "Volume" contains the loop which defines the forward and reverse cycles. "Evac", "Fill", and "Expand" all call valve sequences to fulfill the functions their names imply. "Refselect" does a quick ratioing of the unknown against a default reference and selects the appropriate set of reference vessels, depending upon the unknown's volume. Valves (and hence their reference vessels) are assigned integer numbers in "Refselect" on a binary basis: $\mathrm{V} 100=1, \mathrm{~V} 101=2, \mathrm{~V} 102=4, \mathrm{~V} 103=8, \mathrm{~V} 104=16, \mathrm{~V} 105=32$. In the routine "Decode", these integers are converted to channel strings which the HP 3488A can interpret. "Presdsp" takes the value for pressure (Pres), rounds 
it to' two decimal places, converts each digit to a string of zeros and ones, and sums each string according to the place value of its ones. The resulting integer values are sent to the I/O module of the HP 3488A and hence to the seven-segment displays on the display panel.

\section{Calibration}

The first phase of calibration involves assigning yolume values to the different reference vessels. The second phase of calibration involves testing the accuracy and precision of the system by measuring traceable, known, standard volumes.

The five larger reference vessels $(40,75,150,300,1000 \mathrm{cc})$ along with their constant-volume valves were measured on the PVMS in the SNLL Standards Lab. The smallest reference of around $10 \mathrm{cc}$ had to be measured by ratioing against a known standard. For this purpose, a precision cylinder (Drawing A42128) was fabricated and measured very precisely in the Dimensional Standards Lab. The cylinder was made of invar $(70 \%$ iron, $30 \%$ nickel) to achieve a zero coefficient of thermal expansion. Two end caps were also made (of stainless steel), Drawings A42130 and A42131. The assembled cylinder plus end caps, and the connecting tubing, were then ratioed 12 times against the $10 \mathrm{cc}$ reference. This gave an expression relating the unknown reference to the known standard plus the unknown connecting tubing. The cylinder was then disassembled and the brass plug (Drawing 782019) was then screwed into the ported end cap. This subtracted the known cylinder but did not change the connecting tubing. This tubing was then ratioed 12 times, the average of which gave an expression relating the unknown reference to the unknown tubing. Two unknowns (connecting tubing and reference) were then related by two independent equations; combining yielded a value for the reference, namely $10.309 \mathrm{cc}$ (see line 17510 in the software).

With all of the reference vessels assigned a volume value, the accuracy and precision phase of the calibration could proceed. The testing was spread over some four months and yielded the test data below. Six precision reference standards of known dimensions were used for the accuracy testing. A seventh standard was generated by placing a ball bearing of known volume inside of Std. B. All measurements are traceable to local dimensional standards which in turn are traceable back to the Albuquerque Primary Standards Lab and hence to NIST. 


\section{Test Results}

Item Test Value Actual (cc) Err Err\%

Tested on Small Port:

$\begin{array}{lrrrr}\text { Std.B Minus Ball } & 3.933 & 3.9336 & -.00058 & -.015 \% \\ \text { Std.B } & 7.118 & 7.1259 & -.0079 & -.11 \% \\ \text { Std.C } & 7.976 & 7.9817 & -.0057 & -.07 \% \\ \text { Std.50 } & 49.692 & 49.7030 & -.011 & -.022 \% \\ & & & & \\ \text { Tested on Large Port: } & & & & \\ \text { Std.155 } & 155.23 & 155.2197 & +.010 & +.007 \% \\ \text { Std.300 } & 299.31 & 299.4428 & -.133 & -.044 \% \\ \text { Std.500 } & 500.84 & 500.606 & +.234 & +.047 \%\end{array}$

An average of 24 tests (repetitions) were performed on each standard volume listed above. The volume uncertainty of the dimensionally measured standards is a maximum of $0.001 \mathrm{cc}$. The possible error in the mean for a series of test runs is typically $0.0006 \mathrm{cc}$. Hence, when adding the bias to the error in the mean to the reference uncertainty to get the total systematic uncertainty, the bias overwhelms the other contributions. Assuming the customary three repetitions for any volume measurement, from $2000 \mathrm{cc}$ down to $10 \mathrm{cc}$, the total systematic uncertainty of a measurement is $+/ / 0.1 \%$, or one part in one thousand. For a measurement of $10 \mathrm{cc}$ the uncertainty is $0.01 \mathrm{cc}$ which is close to the absolute minimum uncertainty of the system. Hence, below $10 \mathrm{cc}$ the systematic uncertainty is taken as a constant $0.01 \mathrm{cc}$. This high accuracy at th w low range is made possible by the unique design of two separate manifolds in the measuring systom. For a single measurement at a $90 \%$ confidence level, the 3 sigma random uncertainty over the entire range is less than $0.1 \%$ (e.g., $0.31 \mathrm{cc}$ at $500 \mathrm{cc}$ volume).

All calibration measurements were made on vessels in a water bath at $27.0^{\circ} \mathrm{C}$. Future users will have the option of running a test: 1 ) in the bath but without temperature control, 2) outside the bath. Either method will increase the scatter without greatly affecting the accuracy. Nevertheless, 
when used under these non-ideal conditions, the system should be assumed to have a systematic uncertainty of $0.2 \%$ of reading or $0.02 \mathrm{cc}$, whichever is larger.

\section{Drawings}

The drawings (Appendix B) are functionally complete for the electronics rack and for the manifold assembly. Since the bath was preexisting, it was not drawn in any detail. Some of the bath's ancillary equipment was also omitted, namely the heaters and the pump-filter system. The heater relays, mounted on the bath, are only shown schematically.

\section{Bibliography}

R. L. Jones, "Precision Volume Measurement System," Sandia National Laboratories, SAND79-8057, October 1979.

P. A. Klevgard, "Precision Volume Measuring System," Sandia National Laboratories, SAND84-8014, November 1984.

R. L. Shaffer and D. A. Homan, "Computerized Automated Pressure/ Volume Calibration System," Presented at The 1975 Monsanto Process Computer Symposium, Springfield, Massachusetts. 
APPENDIX A

SOFTWARE

$\hat{A} \hat{I} / \hat{A} \bar{Z}$ 


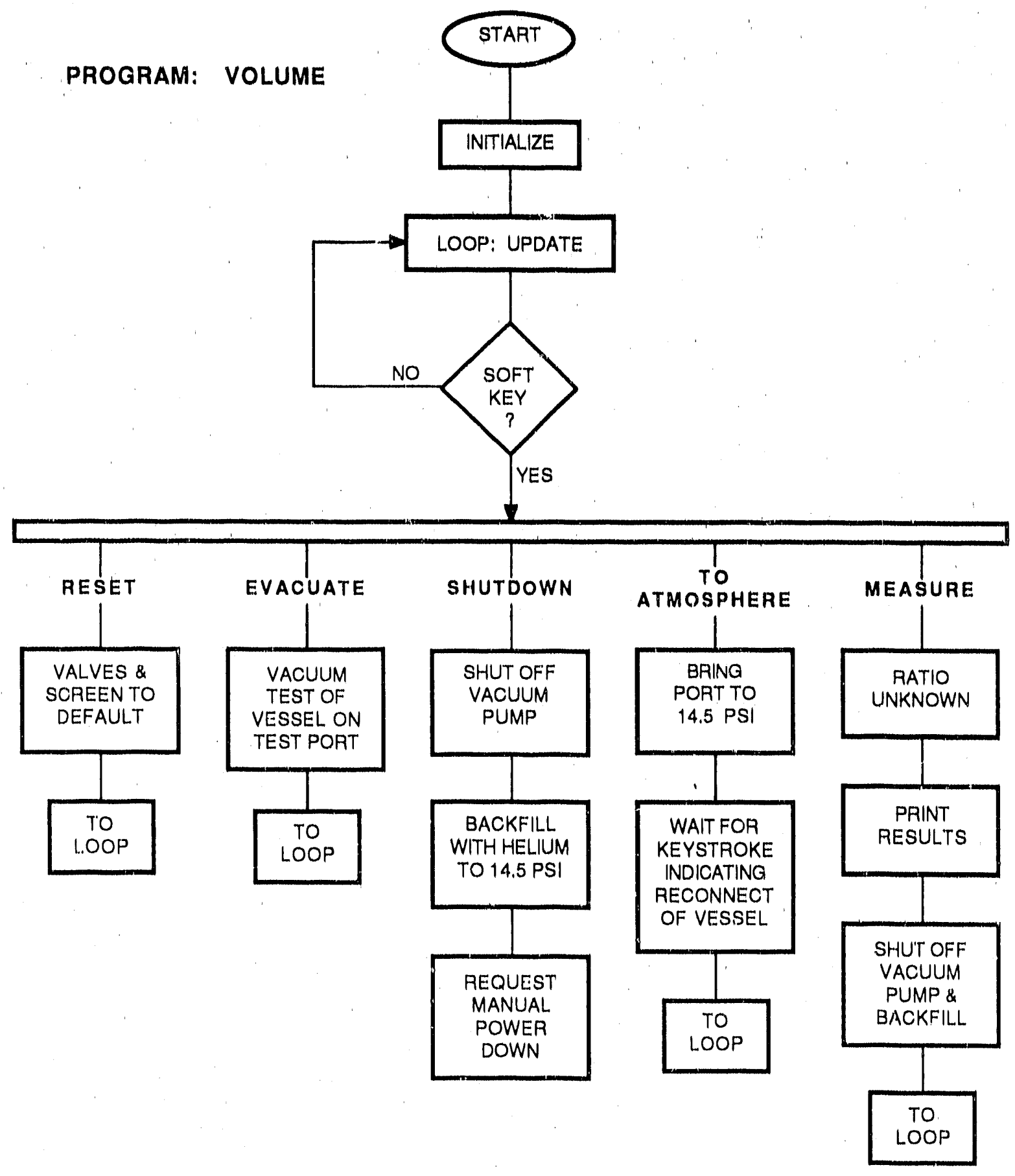

Figure A1. - Software Flowchart

$\mathrm{A} 3 / \mathrm{A} 4$ 
Volume Measurement Software: MicroSoft QuickBasic for IBM-PC

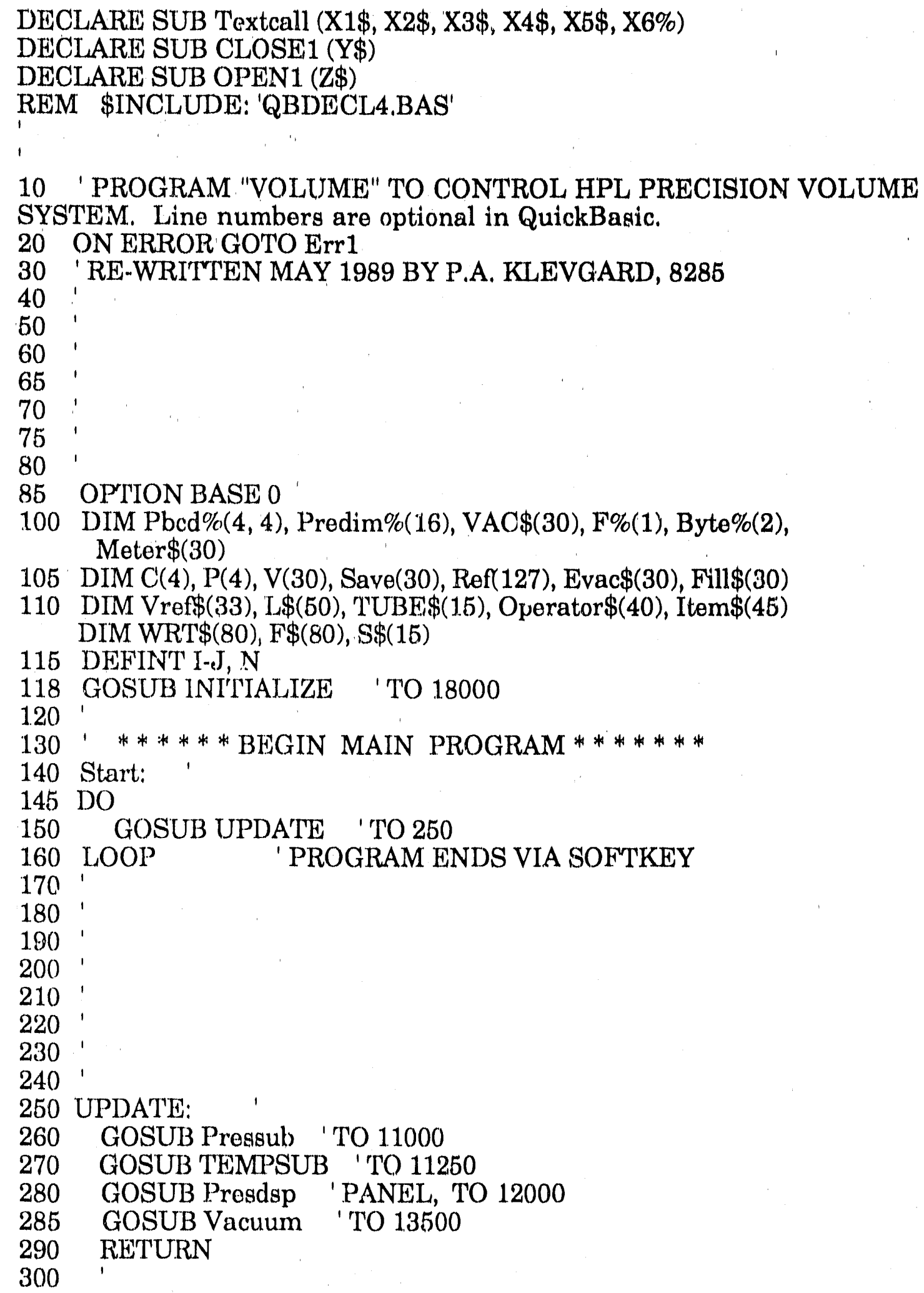




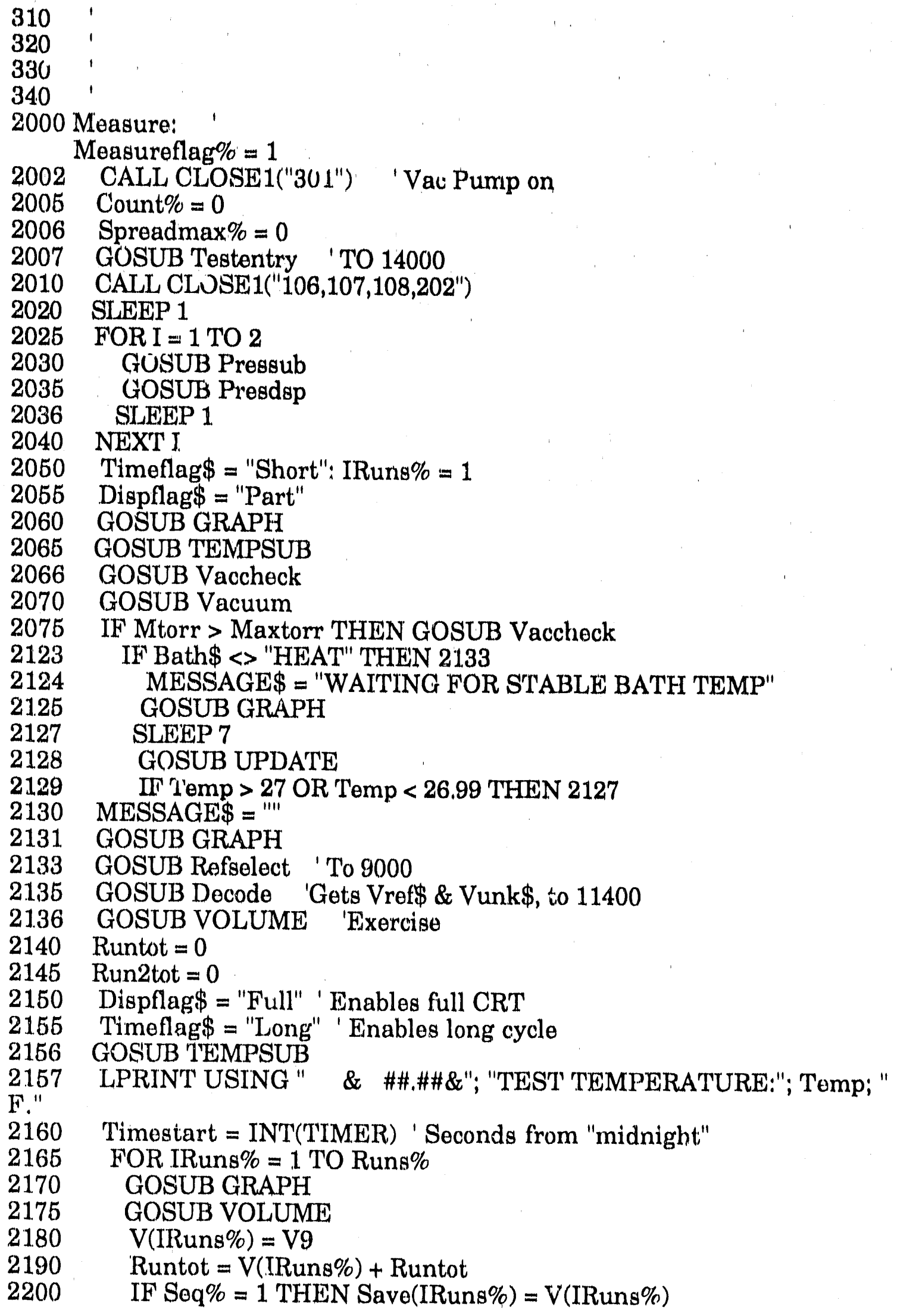


IF Seq\% $=2$ THEN

Save $($ IRuns $\%)=A B S($ Save $($ IRuns $\%) \cdot V($ IRuns $\%))$

Run2tot $=$ Run2tot + Save $($ IRuns $\%)$

END IF

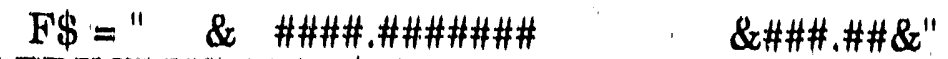

LPRINT USING F\$; "VOLUME ="; V(IRuns\%); "Temp= "; Temp;

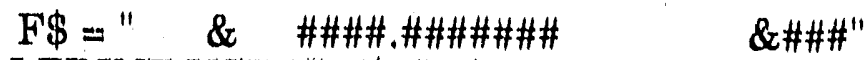

LPRINT USING F\$; "RATIO ="; Ratio; "Spread="; Spread\%

NEXT IRuns\%

Avg $=$ Runtot $/$ Runs $\%$

IF Runs $\%>2$ THEN GOSUB Stddev 'To 6000

LPRINT USING "\& \&\#\#\#\#,\#\#\#\#\#\#\#\#"; LF\$; "AVERAGE IS: ";

IF Seq $\%<2$ THEN 2305

\section{SUBTRACTED VOLUME ROU'TINE}

$2265 \quad$ Avg $=$ Run2tot $/$ Runs $\%$

$2267 \quad \mathrm{~F} \$="$ * SUBTRACTED VOLUME CALCULATION FOLLOWS *"

2270 LPRINT USING "\&\&\& \&"; LF\$; LF\$; LF\$; F\$

$2275 \quad$ TOR $J=1$ TO Runs\%

$2280 \quad \mathrm{~V}(\mathrm{~J})=\operatorname{Save}(\mathrm{J})$

$2283 \quad \mathrm{~F} \$=$ " \& \#\#\#\#,\#\#\#\&"

2285

2290

2295 LPRINT USING F\$; " * SUBTRACTED VOLUME AVERAGE IS: ";

Avg; "cc."

2296

2300

2301

2303

2304

2305

2310

2311

2312

2313

2316

2320

2325

2330

2335

2340

2500 VOLUME:

2510 IF Timeflag\$ = "Long" THEN

2520

2530

S $\$=$ "SUBTRACT" ' Flag for Stddev

IF Runs $\%>2$ THEN GOSUB Stddev

$\mathrm{S} \$=$ "'"'

LPRINT USING "\&"; CHR\$(12) ' Formfeed

IRuns $\%=0$

Vol1 $=0$

Shutdown\$ = "PARTIAL"

GOSUB Shutdown

Shutdown\$ = "FULL"

Measureflag\% = 0: Evac $\$="+1$

GO'TO Start

'

,

,

Min $=1$

ELSE 


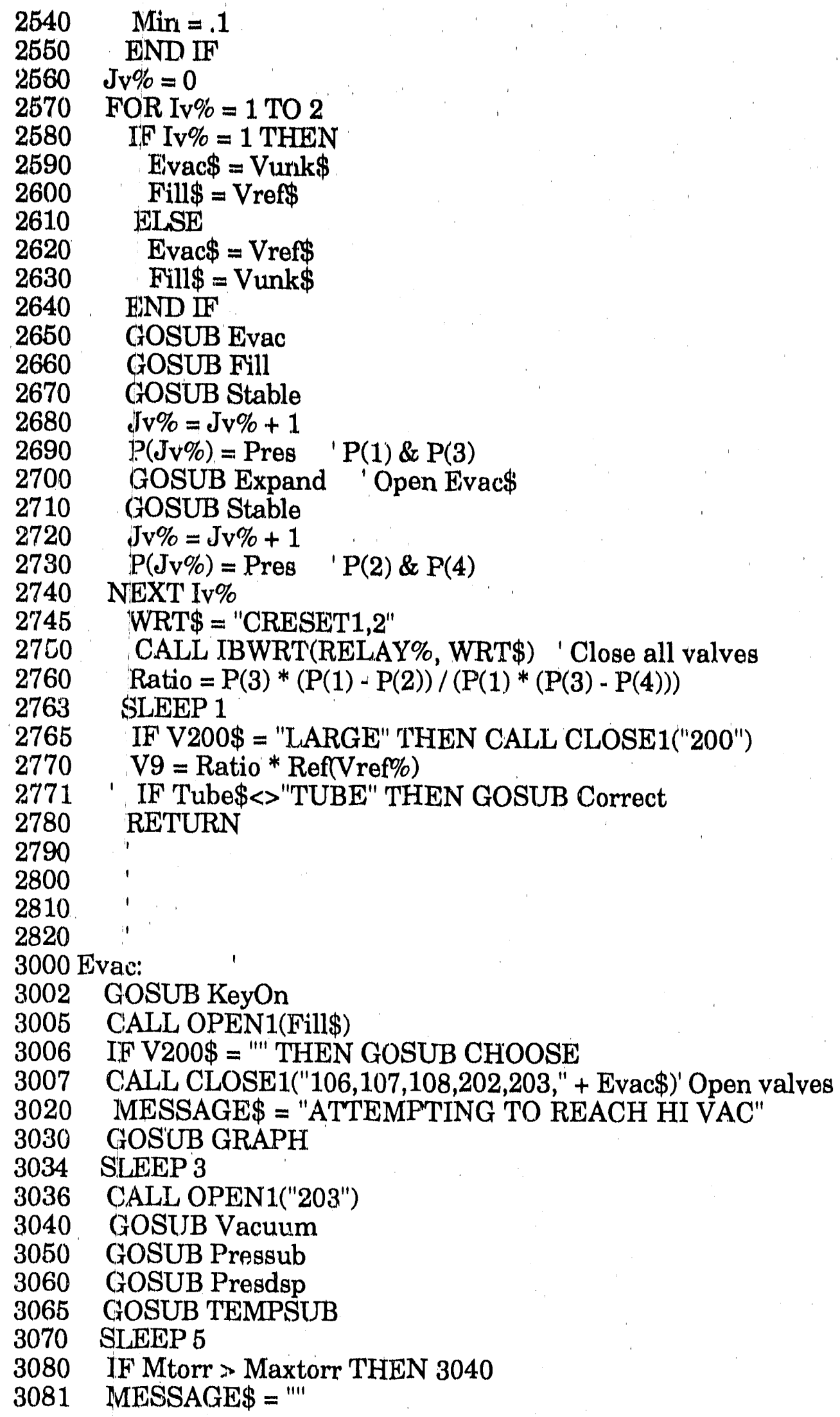




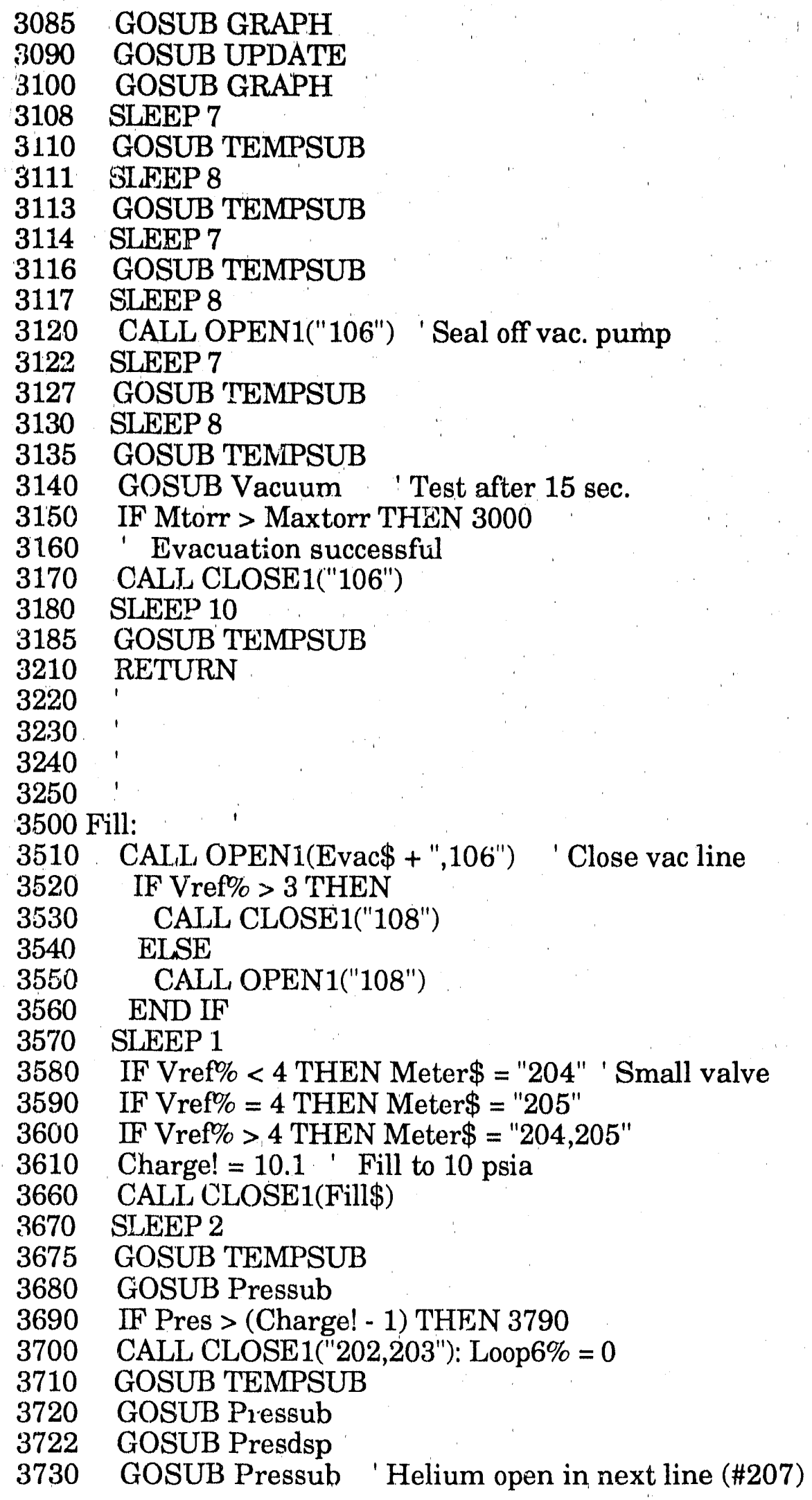


3735 IF (Loop6\% = 0) AND (Pres < Charge!) THEN CALL CLOSE1("207," + Meter\$)

3737 Loop6\% $=$ Loop6\% +1

3740 IF Pres < (Charge! - .1) THEN 3720

3750 CALL OPEN1("202,203,204,205,206,207") ' He \& Meter\$ closed

3760 SLEEP 2

3770 GOSUB Vacuum ' Update Mtorr value

3790 GOSUB UPDATE

3800 RETURN

3810

3820

3830

3840

3850

4300 Stable:

$4310 \quad$ Factor $=7$

4320 GOSUB Wait1 'Min X Factor

$4330 \quad \mathrm{P} 5=0: \mathrm{C} 4=0$

$4340 \quad$ FOR N\% $=0$ TO 4

4350 GOSUB Pres ab

$4360 \quad \mathrm{C}(\mathrm{N} \%)=\mathrm{Ctr} 1^{\prime} 5$ decimal Digit\% Counter value

4364 IF $\mathrm{C}(\mathrm{N} \%)>\mathrm{C} 4 \mathrm{THEN} \mathrm{C} 4=\mathrm{C}(\mathrm{N} \%)^{\prime} \max$ value

4365 IF N\% $=0$ THEN C5 = Ctr 1

4366 IF $\mathrm{C}(\mathrm{N} \%)<=\mathrm{C} 5$ THEN $\mathrm{C} 5=\mathrm{C}(\mathrm{N} \%)$ ' min. value

$4370 \quad$ P5 $=$ P5 + Pres

4380 GOSUB UPDATE

4390 NEXT N\%

4400 IF 'Timeflag\$ = "Short" THEN 4420

4410 Spread $\%=(\mathrm{C} 4-\mathrm{C} 5) * 10^{\wedge} 5$

4415 IF Spread\% > Spreadmax\% THEIN Spreadmax\% = Spread\%

$4420 \quad$ Pres $=$ P5 $/ 5$

4430 RETURN

4440

4450

4460

4470

4500 Expand:

4510 CALL CLOSE1(Evac\$)

4520 GOSUB UPDATE

4530 GOSUB UPDATE

4540 RETURN

4550

4560

4570

4580

5000 Wait1:

5010 Timefini $=$ INT $($ TIMER $)+$ Min $*$ Factor $* 60$

5020 GOSUB UPDATE

5040 SLEEP 4 


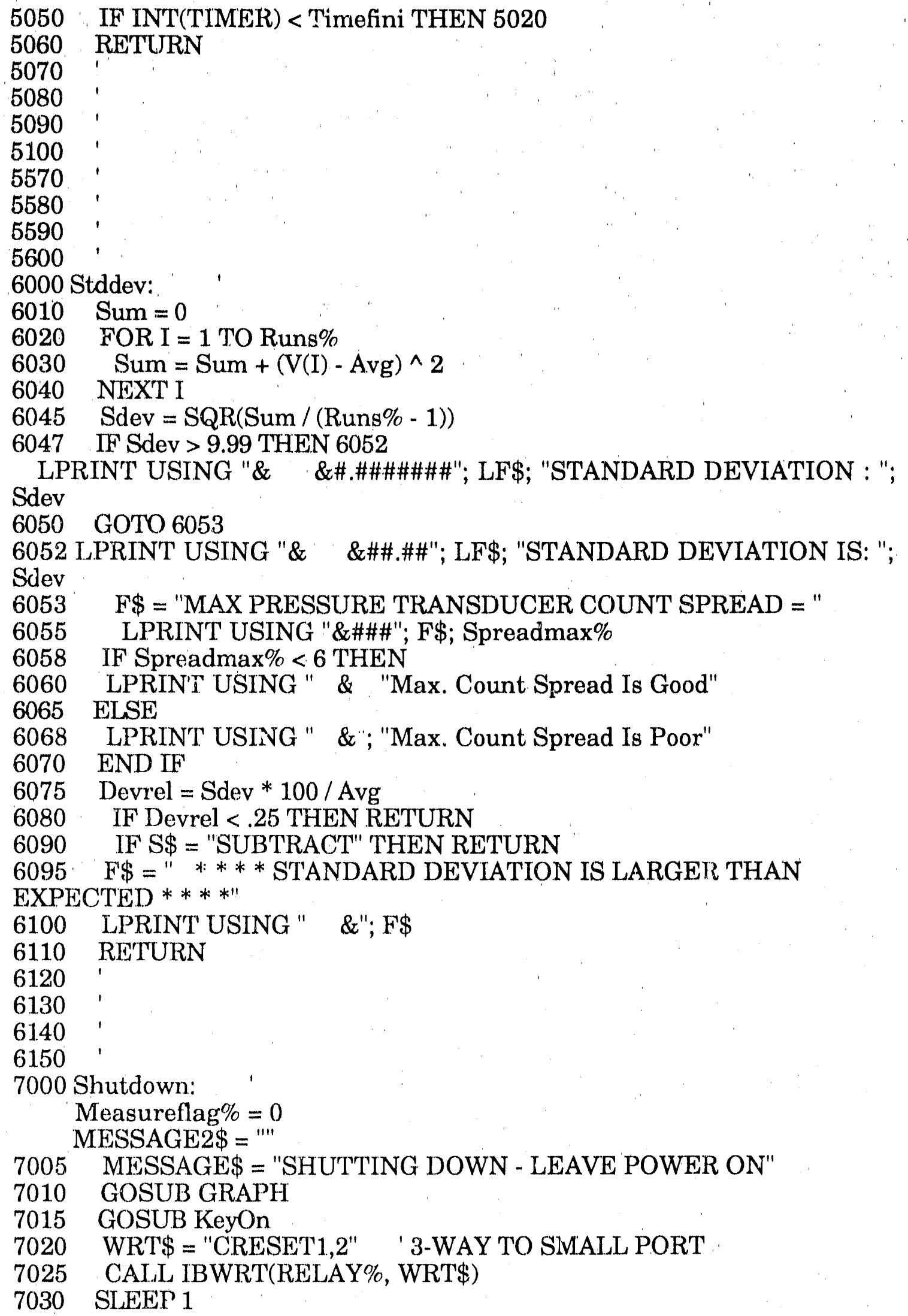


7040 CALL CLOSE1("105,106,108,109,200,201") ' 3-WAY TO LARGE PORT

7050 SLEEP 1

7060 GOSUB Pressub

7070 IF Pres $>14$ THEN 7120

7080 CALL CLOSE1("202,203,204,205,206,207") 'LARGE PORT FILLING

7090 GOSUB Pressub

7100 GOSUB Presdsp

7110 IF Pres < 14 THEN 7090

7120 CALL OPEN1("200,201,301") ' 109 STILL OPEN,PUMP OFF

7140 CALL CLOSE1("107") . 'Vac line open

7150 SLEEP 2

7160 CALL OPEN1("105")

7170 GOSUB Pressub

7180 GOSUB Presdsp

7190 IF Pres < 14 THEN 7170

7200 WRT $\$=$ "CRESET1,2"

7205 CALL IBWRT(RELAY\%, WRT\$) ' Open all relays,3-WAY TO

SMALL PORT

7210 IF Shutdown $\$=$ "PARTIAL" THEN MESSAGE $\$=$ "TEST

COMPLETED"

7220 IF Shutdown $\$=$ "PARTIAL" THEN GOSUB GRAPH

7225 GOSUB Presdsp

7229 IF Shutdown $\$=$ "PARTIAL" THEN RETURN

7232 MESSAGE $\$=$ " TURN OFF POWER KEY SWITCH"

7234 MESSAGE2 $\$="+1$

7240 GOSUB GRAPH

7250 BEEP

7270 SLEEP 3

7280 GOTO 7250 ' Program ended.

7290 RETURN ' Not used

7300

7310

7320

7330

9000 Refselect:

9010 ' Exercise cycle through 9240

9020 CALL OPEN1("109,201") ' Close 109 \& 201;106-108,202 are open

9030 FOR I = 1 TO 1 ' Exercise for just 1 loop

$9040 \quad$ Factor $=1$

$9050 \quad$ Min $=1$

9060 GOSUB Wait1 ' Vac exercise in process

9070 CALL OPEN1("107") ' Vac line closed

9080 SLEEP 1

9090 CALL CLOSE1("203,204,207") ' Helium on

9100 GOSUB Pressub

$9110 \quad$ GOSUB Presdsp

9130 GOSUB Vacuum

$9140 \quad$ IF Pres $<10.5$ THEN 9100

9150 CALL OPEN1("203,204,207") 


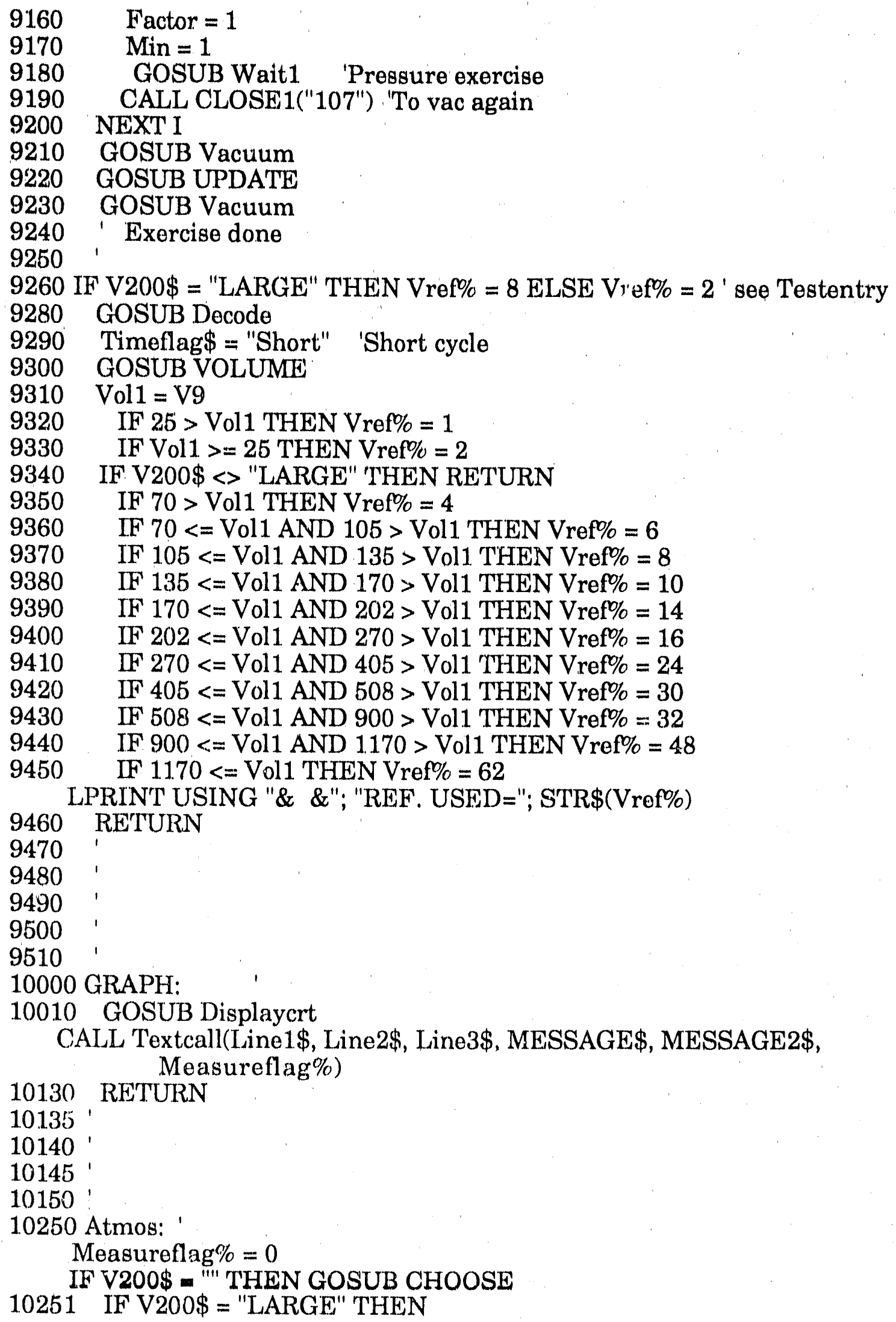




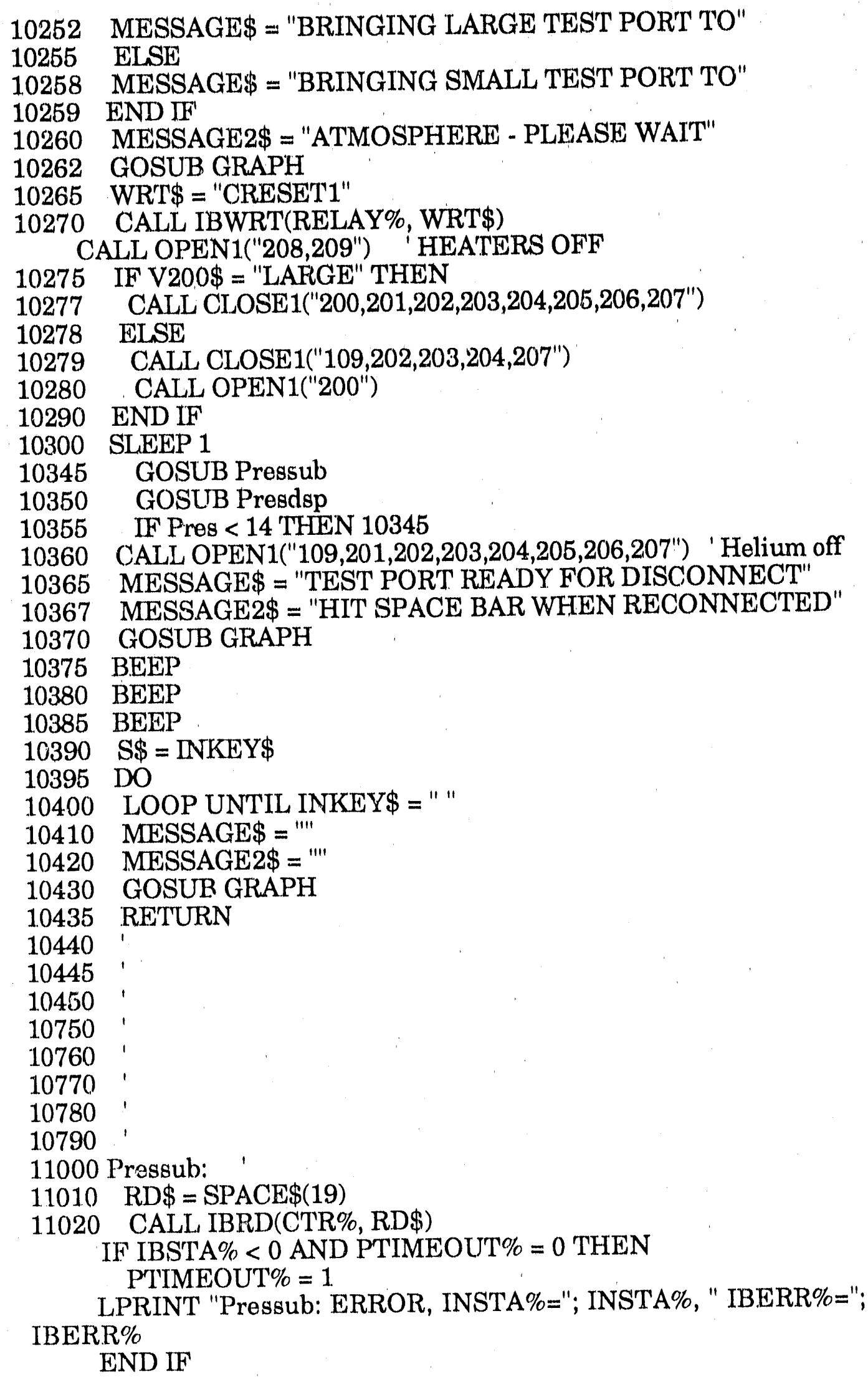




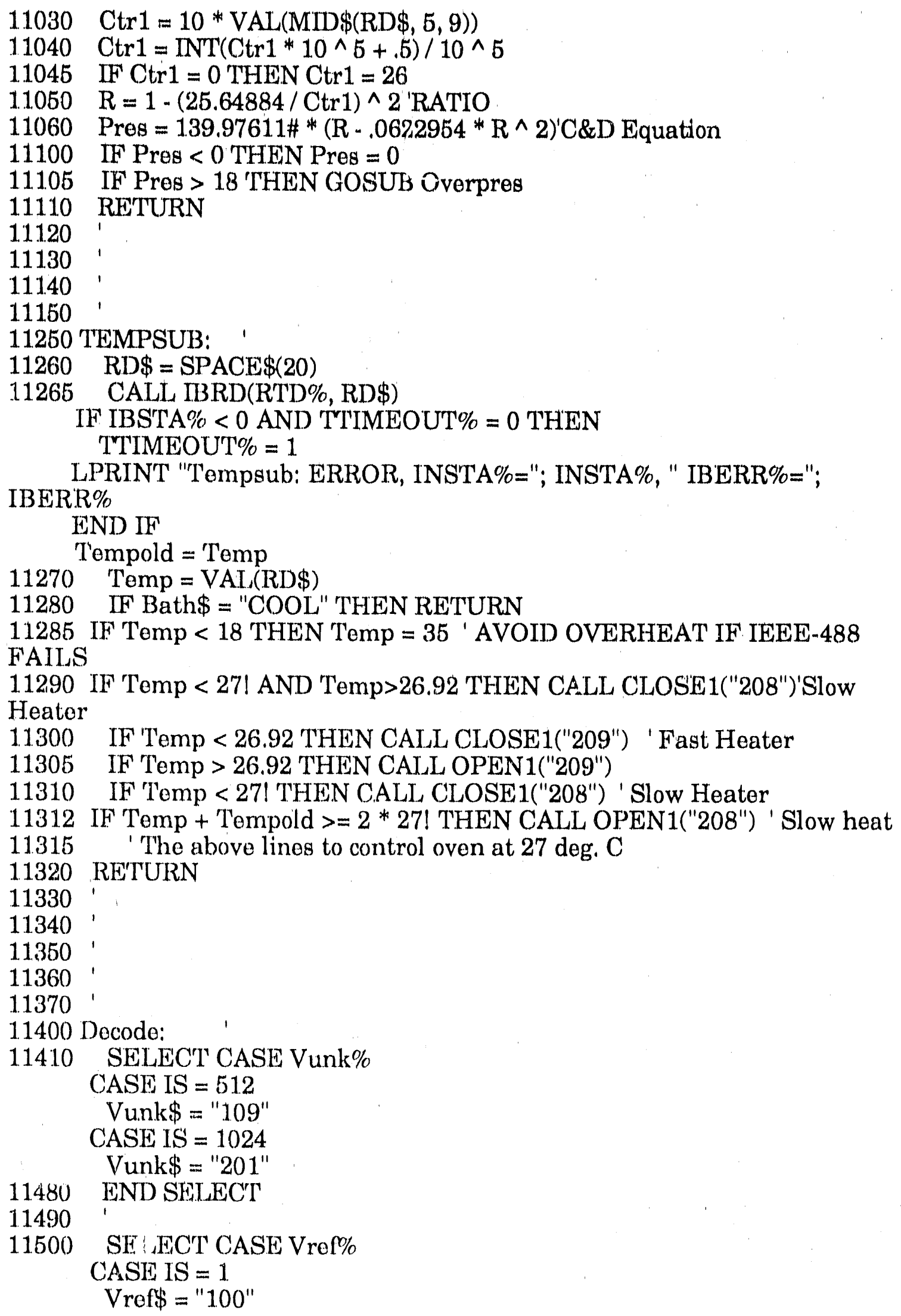




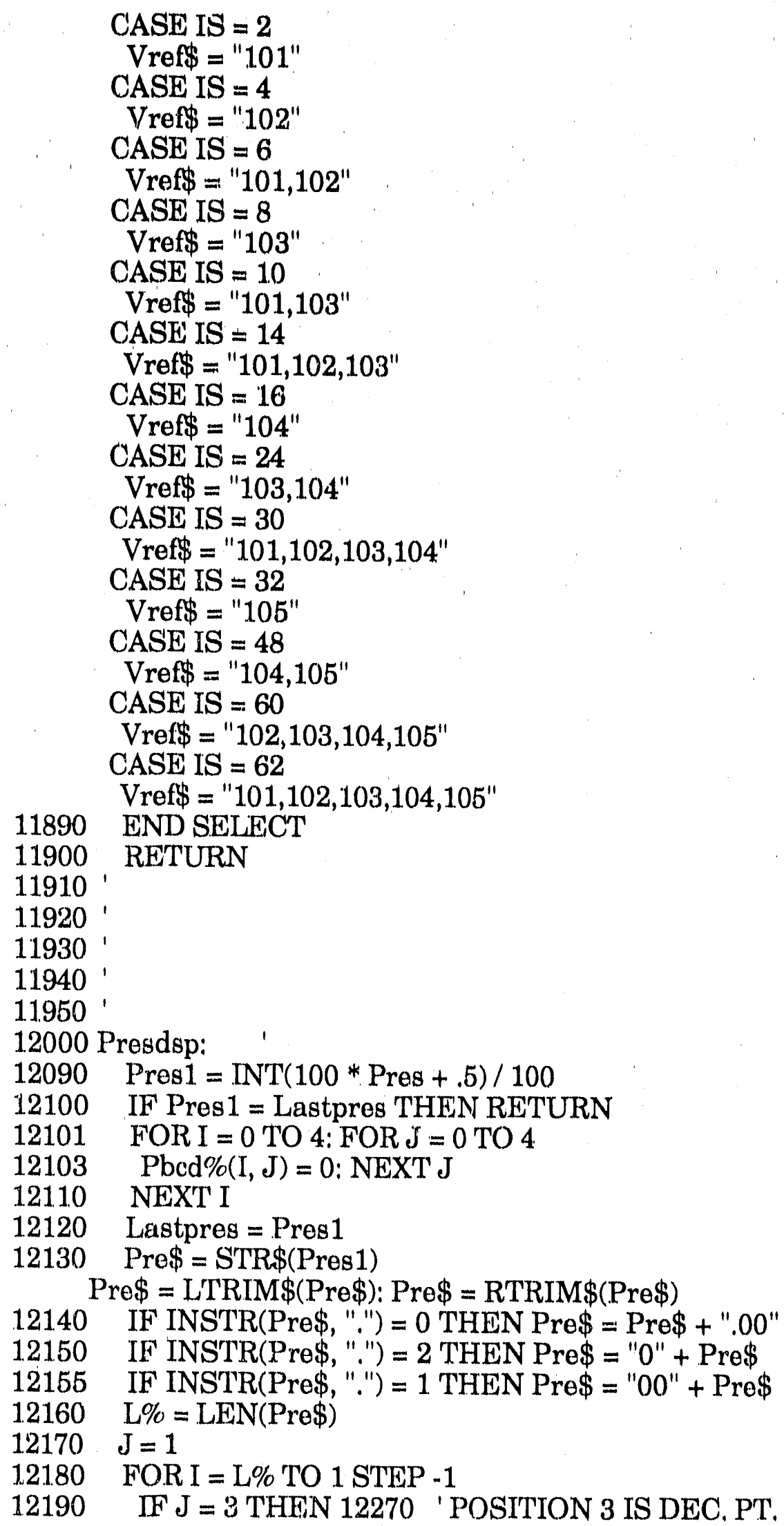




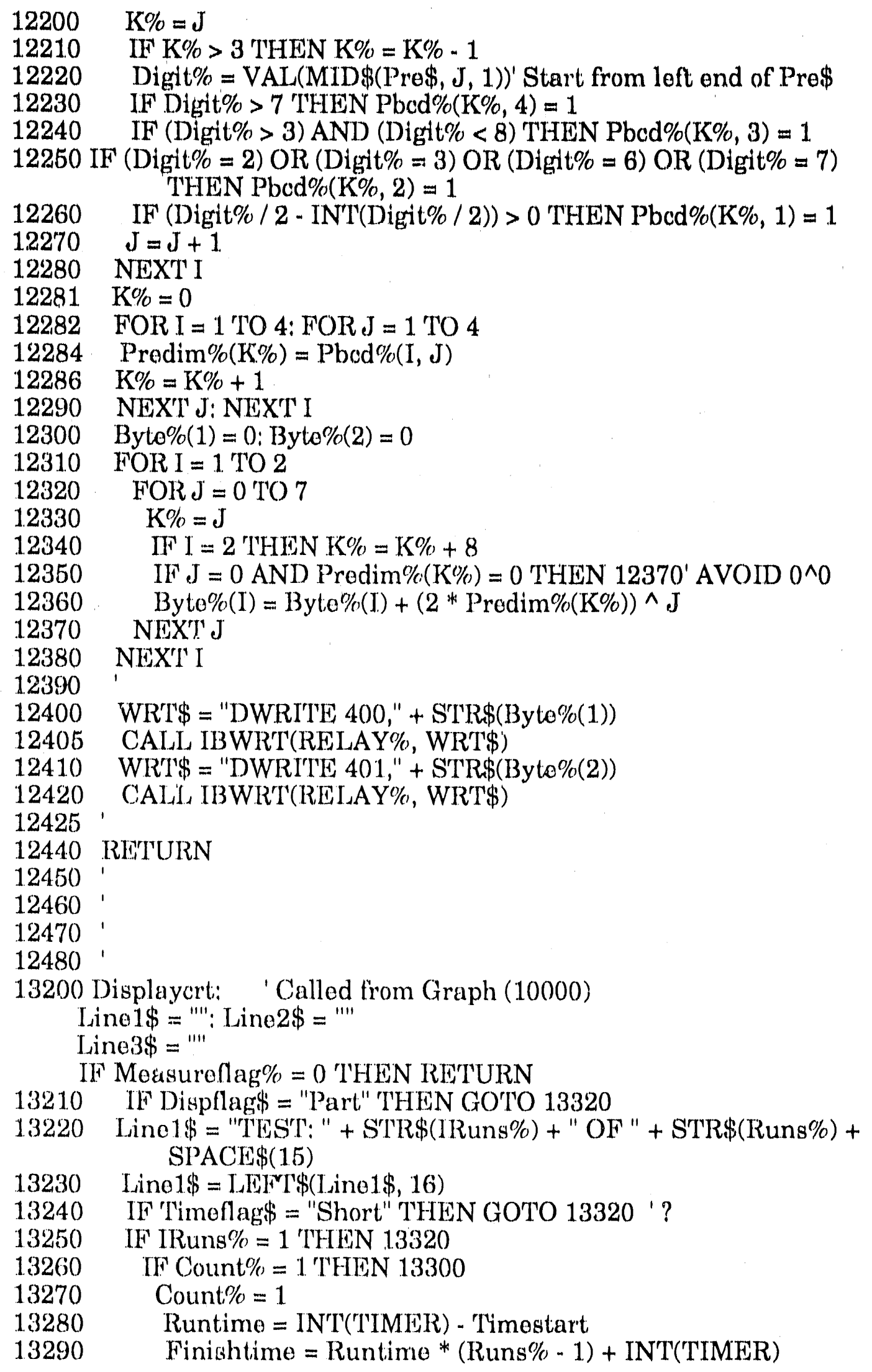




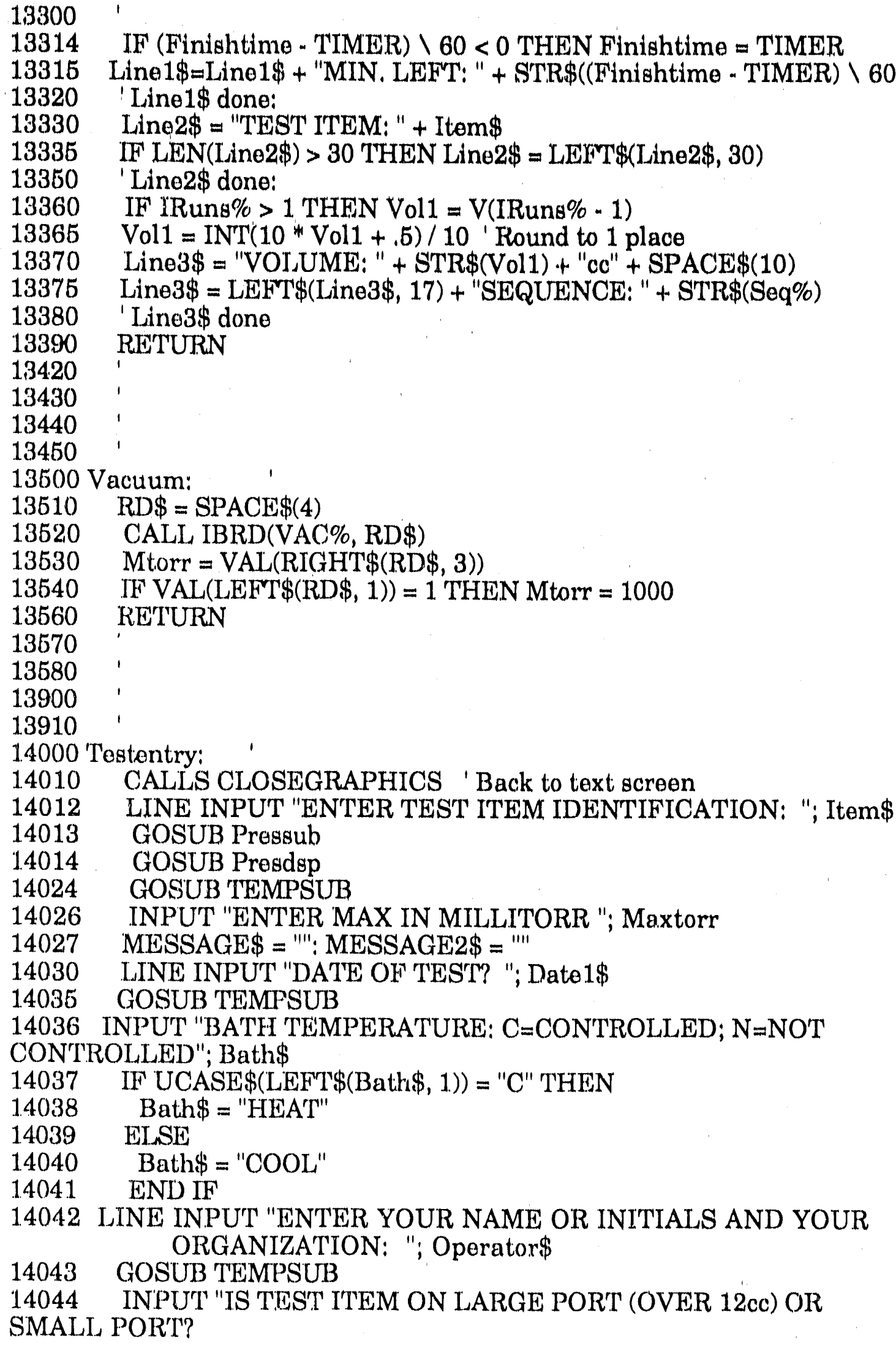




\begin{tabular}{|c|c|}
\hline & $\mathrm{L}=\mathrm{LARGE}, \mathbf{S}=\mathrm{SMALI} \quad " \mathrm{~V} 2$ \\
\hline 04 & IF UCASE $\$$ (LEFT T $(V 200 \$, 1))=$ "L" THEN \\
\hline & V200\$ = "LARGE": Vunk $\%=1024$ \\
\hline & CALLL CLOSE $1(" 200,201 ")$ ' Valve 200 default is OPEN=SMALL \\
\hline 048 & ELSE \\
\hline & V200\$ = "SMALL": Vunk\% = 512 \\
\hline & CALL OPEN1("200"): CALL CLOSE1("109") \\
\hline & END IF \\
\hline & GOSUB TEMPSUB \\
\hline & Runs $\%=3$ \\
\hline & INPUT "NUMBER OF RUNS? (DEFAULT $=3$, PRESS ENTER \\
\hline & "; Runs\% \\
\hline & IF' Runs $\%=0$ THEN Runs $\%=3$ \\
\hline & $\begin{array}{l}\text { GOSUB TEMPSU } \\
\text { CLS }\end{array}$ \\
\hline
\end{tabular}

F\$ = "THE 'TUBING RESULTS CAN BE SUB'TRAC'TED FROM THE TUBE + VESSELL

14120 PRIN'T USING "\&\&\&\&\&"; F\$; LF\$; SPC(28); "SPECIFYING A RESULTS BY"

SEQUENCE"; LF\$
14130 PRINT" $1=$ FIRST'RUN; $\quad 2=$ SECOND RUN; $0=$ NO SEQUENCE"; LF\$

14140 INPU'T' "SPECIFY SEQUENCE: "; Seq\%

$14141 \quad$ IF' Seq $\%=1$ 'TH'EN Saveruns $\%=$ Runs $\%$

14142 IF Seq $\%=2$ AND Saveruns $\%<>0$ THEN Runs $\%=$ Saveruns $\%$ 14150 CISS

14200

14210

14220

14230

14250

14260

14270

14280

14290

14300

14310

15000 Overpros:

15010 CALL., CL,OSE1("105,106,107,108")

15020 CALL, OPEN1("109,201,202,203,204,205,206,207")

15030 MESSAGE\$ = "EVACUA'TING SYS'TEM"

15035 GOSUB GRAPH

15040 GOSUB Pressub,

15050 IF Pres $>1$ THEN 15040

15060 WRT' = "CRESET' 1" ' CLOSE ALL 100 VALVES

15065 CALL IBWR'T(RELAY\%, WRT'\$)

15070 MESSAGE\$ = "'"

15075 GOSUB GRAPH

15080 GOTO Start 


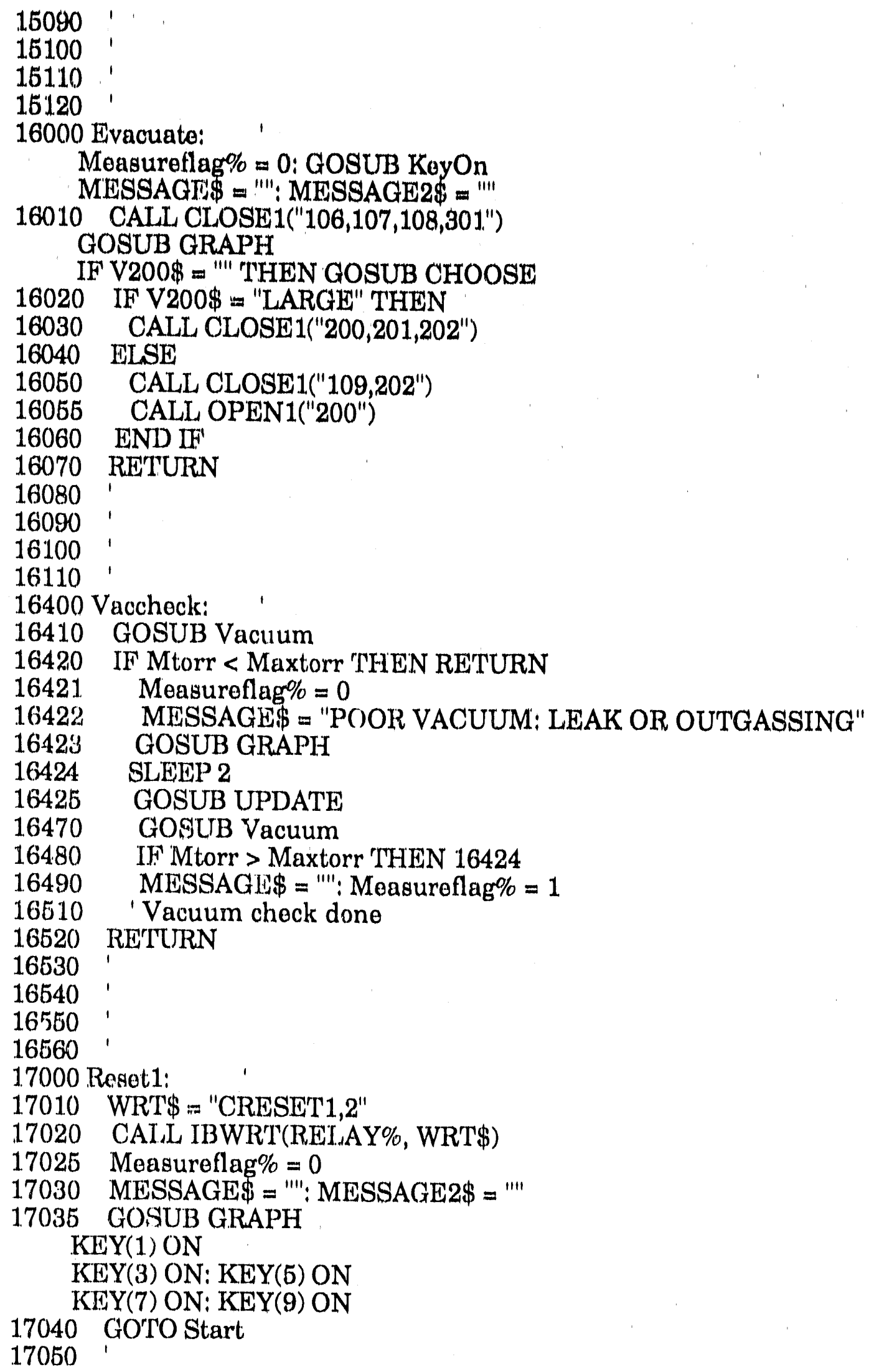




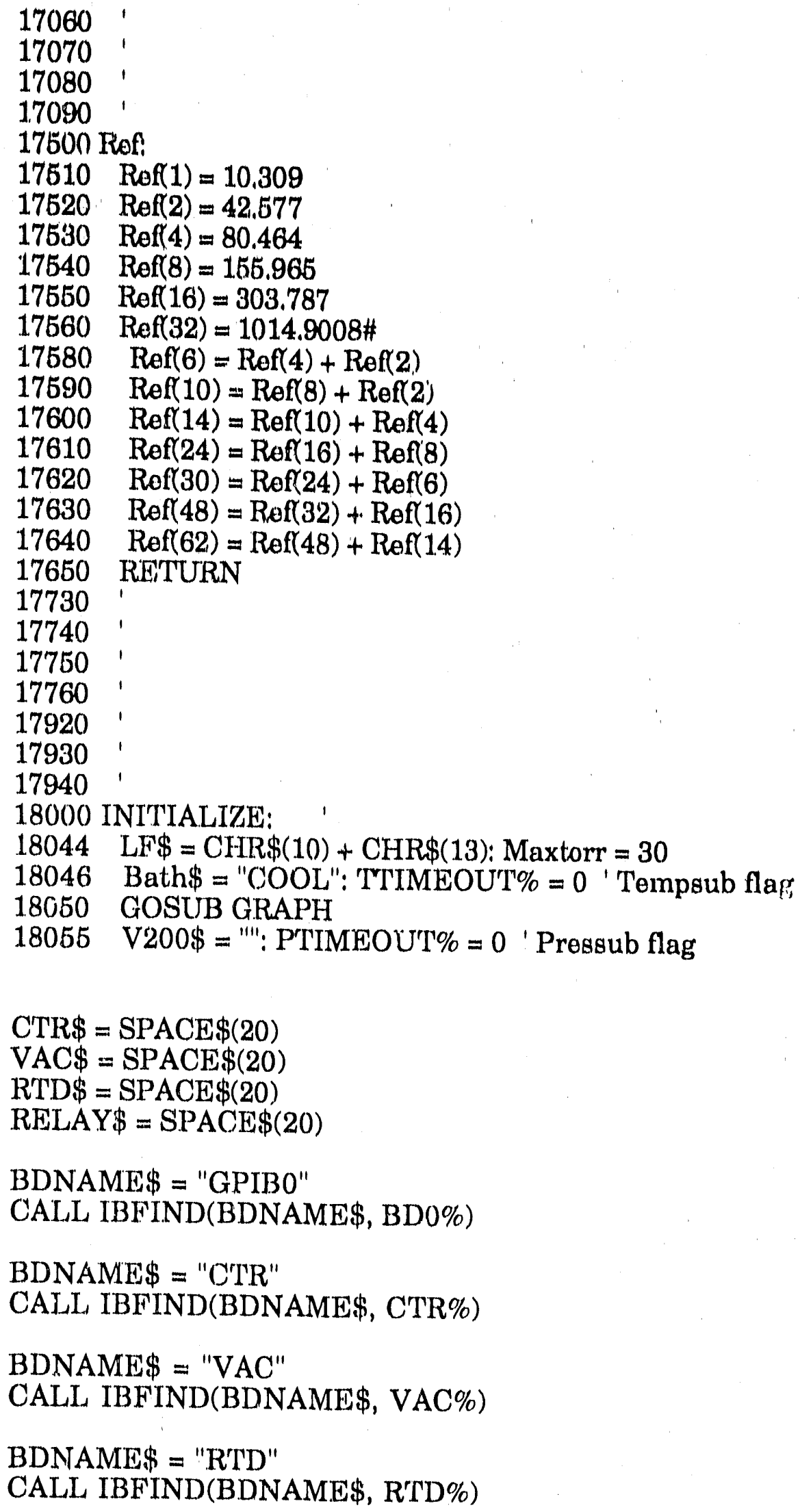

BDNAME $\$=$ "CTR"

CALL IBFIND(BDNAME\$, CTR\%)

BDNAME $\$=$ "VAC"

CALL IBFIND(BDNAME\$, VAC\%)

BDNAME $=$ = $\mathrm{RTD} "$

CALL IBFIND(BDNAME\$, RTD\%) 
BDNAME\$ = "RELAY"

CALL IBFIND(BDNAME\$, RELAY\%)

CALL IIBSIC(BD0\%)

CALL IBCLR(CTR\%)

CALL IBCLR(VAC\%)

CALL IBCLR(RTD\%)

WRT\$ = "IN,FU2,FI1,GA2"

CALI, IBWRT(CTR\%, WRT\$)

$\mathrm{SEC} \%=\& \mathrm{H} 60 \quad$ ' HEX 96

CALL IBSAD(VAC\%, SEC\%) ' SECONDARY ADDRESS

WIRT = "N4,TB0,TP1,TH0,I1,O1,A0,B0"

CALL IBWRT(VAC\%, WRT\$)

$\mathrm{SEC} \%=0$

CALL IBSAD(VAC\%, SEC\%)

WRT\$ = "O1 Y3 L0 M1"

CALL IBWRT(RTD\%, WRT\$)

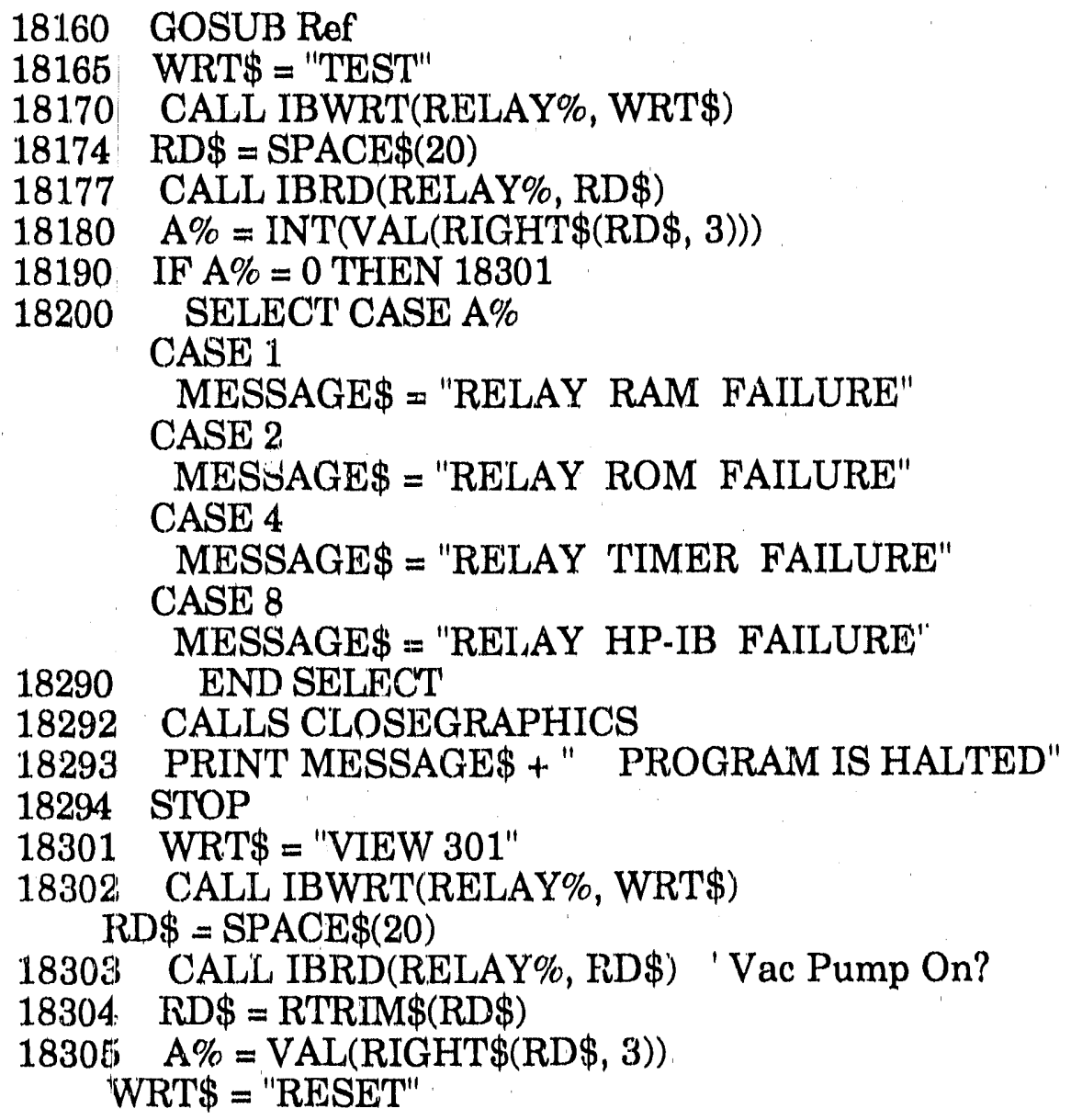




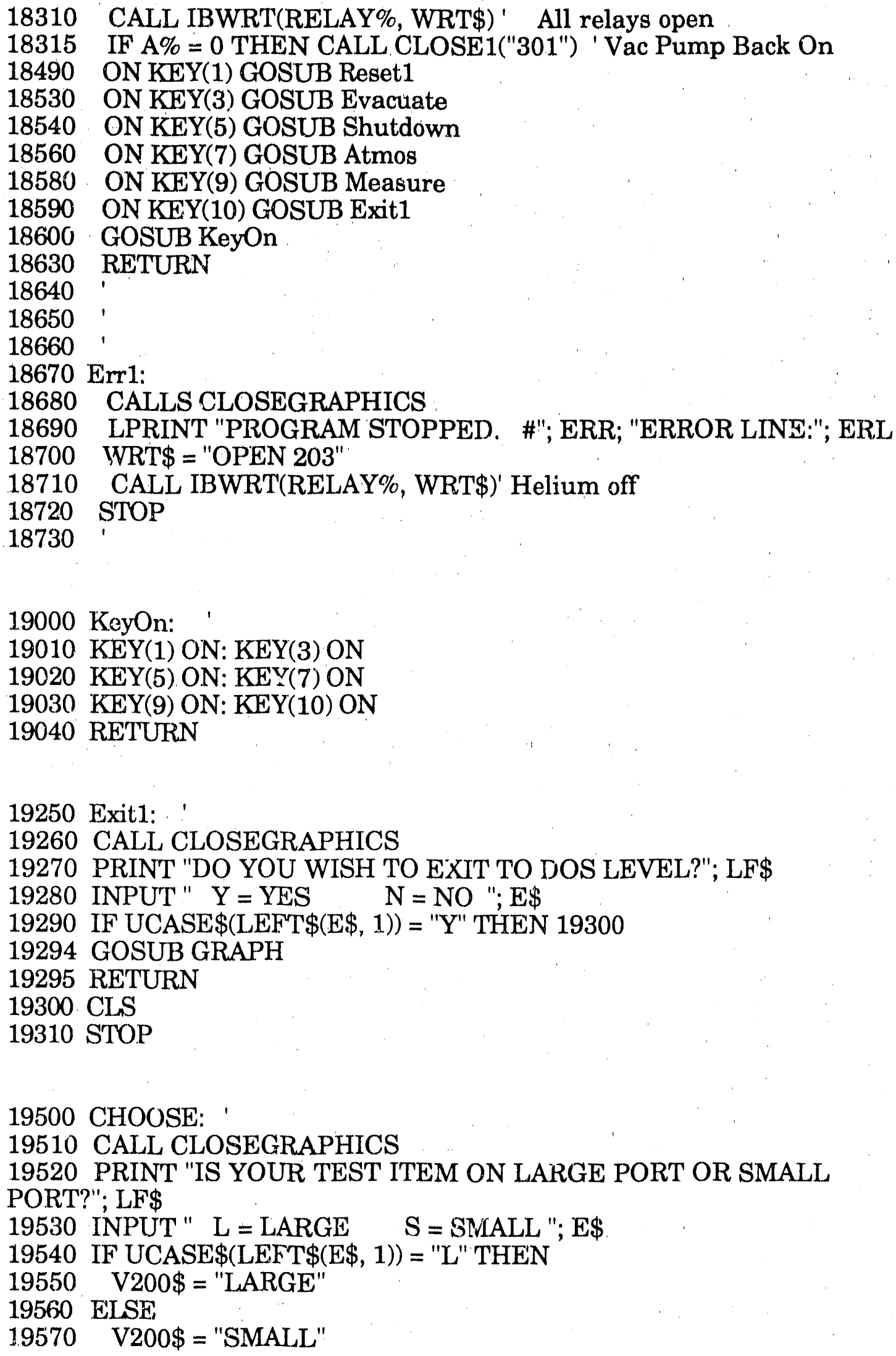


19580 END IF

19590 GOSUB GRAPH

19600 RETURN

SUB CLOSE1 (Vc\$)

WRT $\$=$ "CLOSE " + Vc\$

CALL IBWRT(RELAY\%, WRT\$)

END SUB

SUB OPEN1 (Vo\$)

WRT $\$=$ "OPEN" + Vo\$

CALL IBWRT(RELAY\%, WRT\$)

END SUB

SUB Textcall (L1\$, L2\$, L3\$, M\$, M2\$, F\%)

' PROGRAM "TITLE" TO

' DRAW TITLE BOX

$\mathrm{X} !=0$

$\mathrm{Y} !=1000$

$\mathrm{X} \%=0$

DEVICES\$ = "haloibmg.dev"

CALLS SETDEV(DEVICES\$)

$\mathrm{X} 2 \%=0$ ' MODE $=0$ (16 COLORS)

CALLS INITGRAPHICS(X2\%)

$\mathrm{X} 1 !=.01: \mathrm{Y} 1 !=.01$

$\mathrm{X} 2 !=.99: \mathrm{Y} 2 !=.4$

$\mathrm{Y} \%=2$

CALLS SETVIEWPORT(X1!, Y1!, X2!, Y2!, Y\%, Y\%)

CALLS SETWORLD(X!, X!, Y!, Y!)

ASP! $=.875$

$\mathrm{X} 2 \%=1: \mathrm{X} \%=1$ MAGENTA ON BLUE

CALLS SETIPAL(X\%, X2\%)

CALLS SETASP(ASP!)

FONT $\$$ = "HALO103.FNT"

CALLS SETFONT(FONT $\$$ )

$\mathrm{X} 1 !=285$

$\mathrm{Y} 1 !=.75$

$\mathrm{Z} \%=0$

CALLS SETSTEXT(X1!, Y1!, Z\%)

$\mathrm{X} 1 !=200$

$\mathrm{Y} 1 !=580$

CALLS MOVTCURABS(X1!, Y1!)

TEXT\$ = "VOLUME" 
CALLS STEXT(TEXT\$)

$\mathrm{X} 1 !=40: \mathrm{Y} 1 !=100$

CALLS MOVTCURABS(X1!, Y1!)

$\mathrm{X} 1 !=255$

$\mathrm{Y} 1 !=.65$

$\mathrm{Z} \%=0$

CALLS SETSTEXT(X1!, Y1!, Z\%)

TEXT\$ = "MEASUREMENT"

CALLS STEXT(TEXT\$)

$\mathrm{X} 1 !=.01^{\prime} \mathrm{X} 2 !=.99$

$\mathrm{Y} 1 !=.37^{\prime} \mathrm{Y} 2 !=.4$

'CALLS BAR(X1!, Y1!, X2!, Y2!)

$\mathrm{X} 1 !=.01: \mathrm{Y} 1 !=.41$

$\mathrm{X} 2 !=.99: \mathrm{Y} 2 !=.99$

$\mathrm{X} \%=0: \mathrm{Y} \%=0$

CALLS SETVIEWPORT(X1!, Y1!, X2!, Y2!, X\%, Y\%)

$\mathrm{X} 1 !=120$

$\mathrm{Y} 1 !=.6$

$\mathrm{Z} \%=0$

CALLS SETSTEXT(X1!, Y1!, Z\%)

TEXT\$ = "'"

FOR I $\%=800$ TO 400 STEP -200

$\mathrm{X} 1 !=2$

$\mathrm{Y} 1 !=\mathrm{I} \%$

CALLS MOVTCURABS(X1!, Y1!)

SELECT CASE I\%

CASE 800

TEXT $\$=\mathrm{L} 1 \$$

CASE 600

TEXT $\$=\mathrm{L} 2 \$$

CASE 400

TEXT $\$=\mathrm{L} 3 \$$

END SELECT

CALLS STEXT(TEXT\$)

NEXT I\%

$\mathrm{X} 1 !=0: \mathrm{Y} 1 !=200$

IF F\% $=0$ THEN Y $1 !=600$

CALLS MOVTCURABS(X1!, Y1!)

$\mathrm{X} 1 !=120$

$\mathrm{Y} 1 !=.575$

$\mathrm{Z} \%=0$

CALLSS SETSTEXT(X1!, Y1!, Z\%)

CALLS STEXT(M\$)

IF M2\$ <> "' THEN

$\mathrm{X} 1 !=0$

$\mathrm{Y} 1 !=100$

IF F\% $=0$ THEN Y $1 !=300$

CALLS MOVTCURABS(X1!, Y1!)

CALLS STEXT(M2\$) 


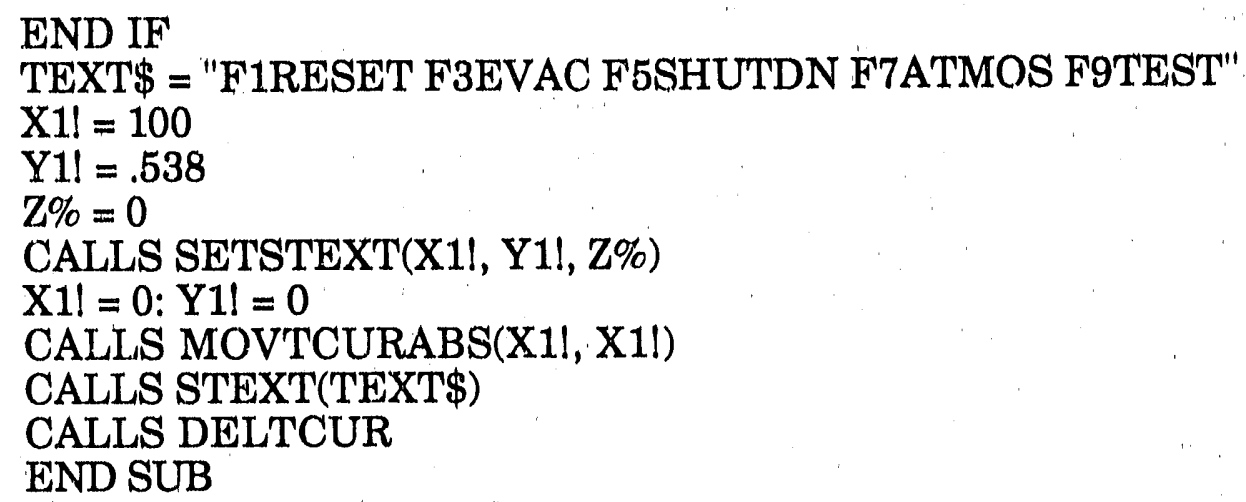


APPENDIX B

PVMS DRAWINGS

$\mathrm{B} 1$ / B2 


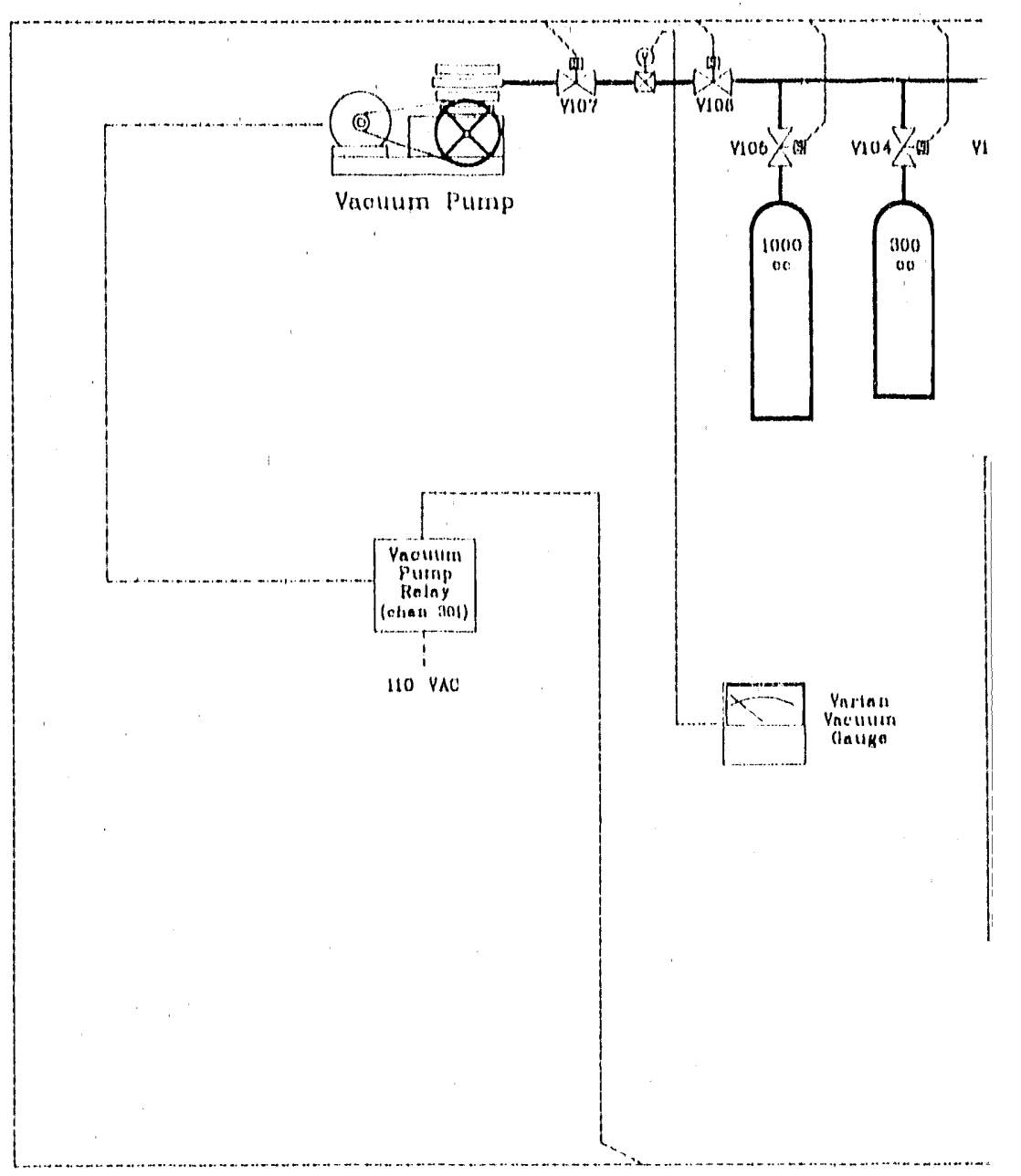




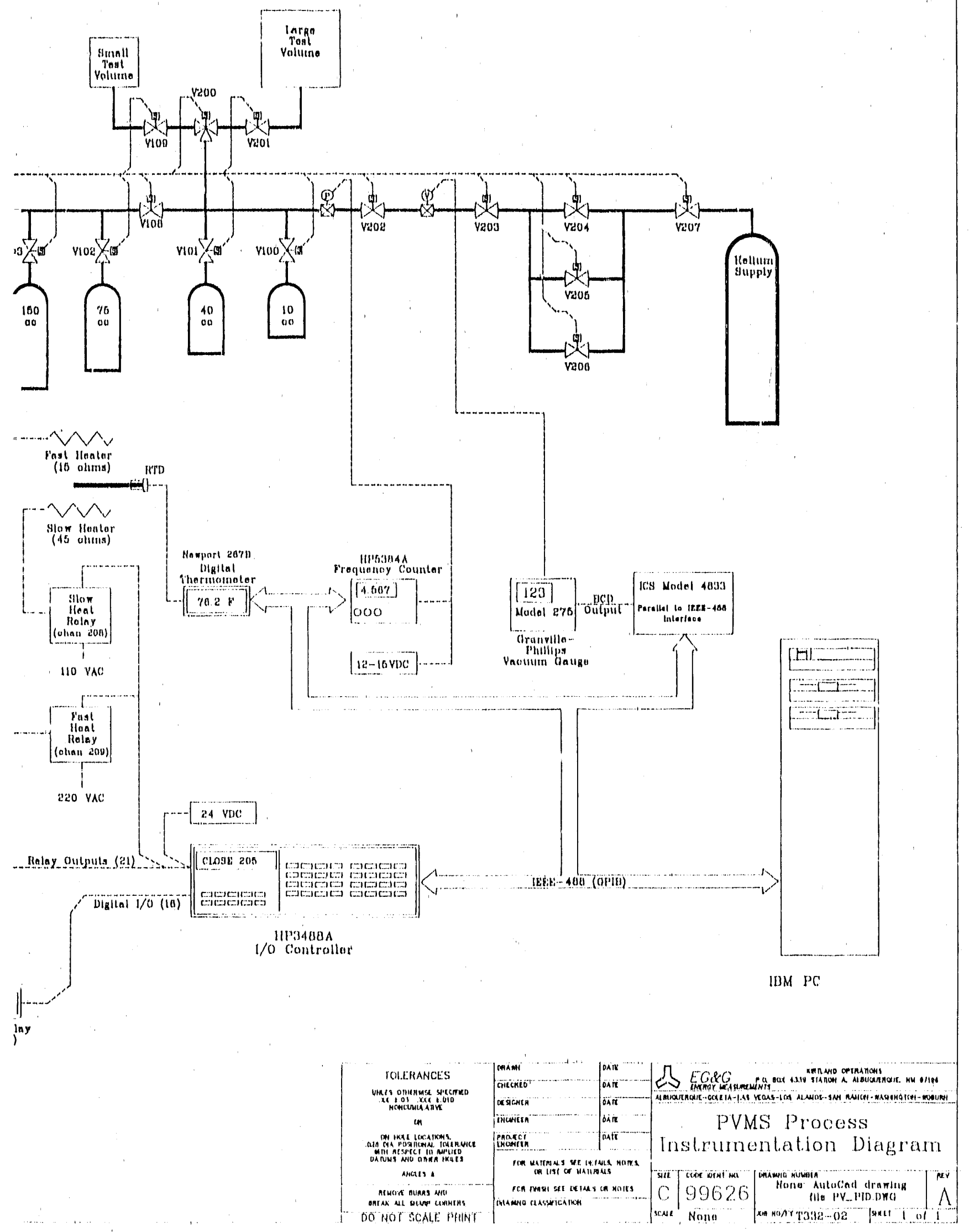




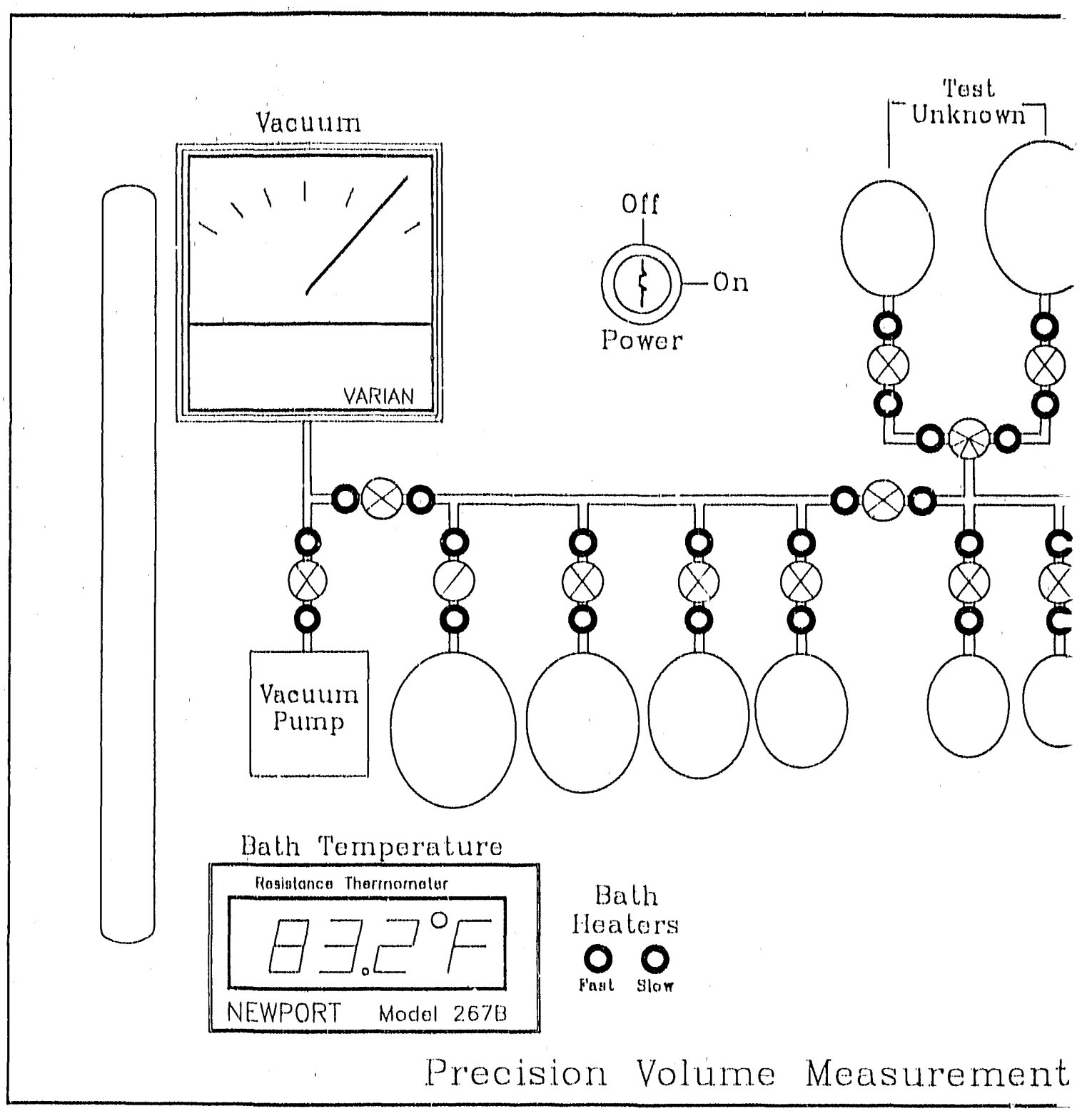


$j$

Prassure (PSIA)

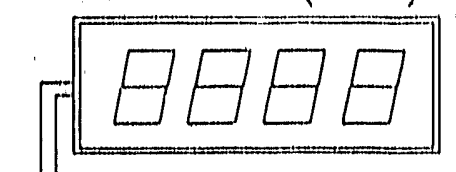

Hellum

Supply
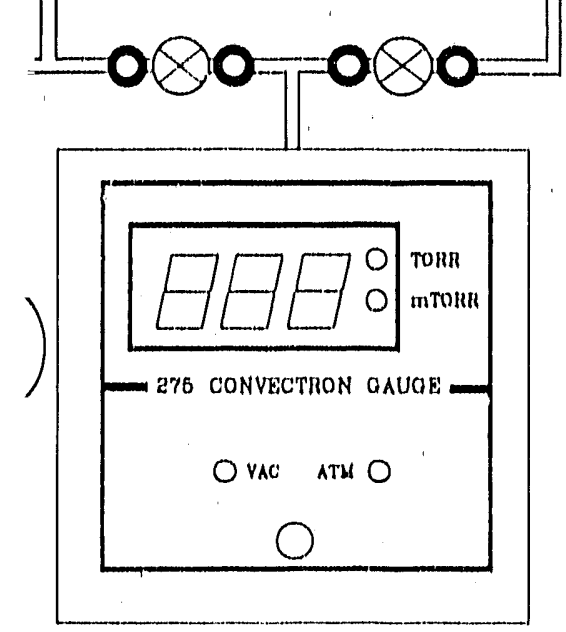

Vacuum

System

'

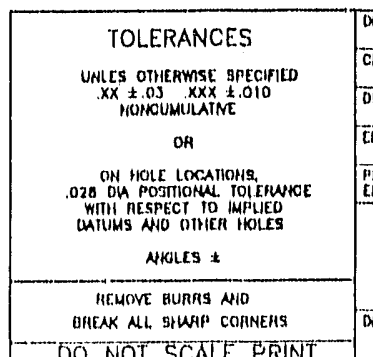

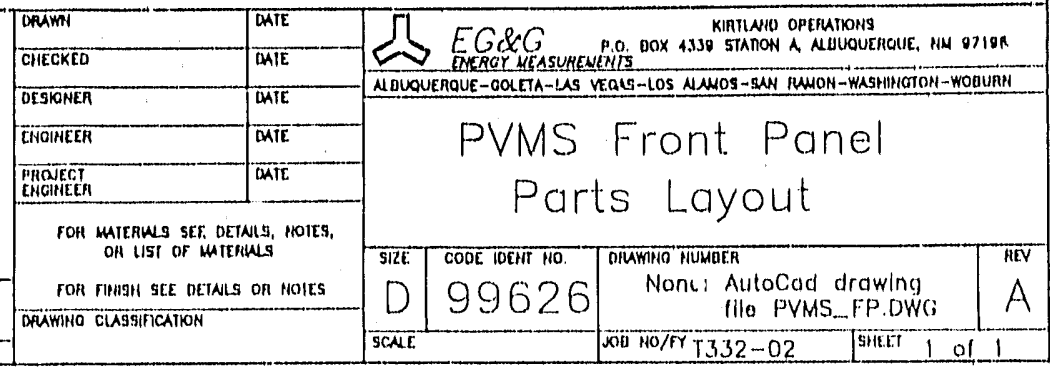




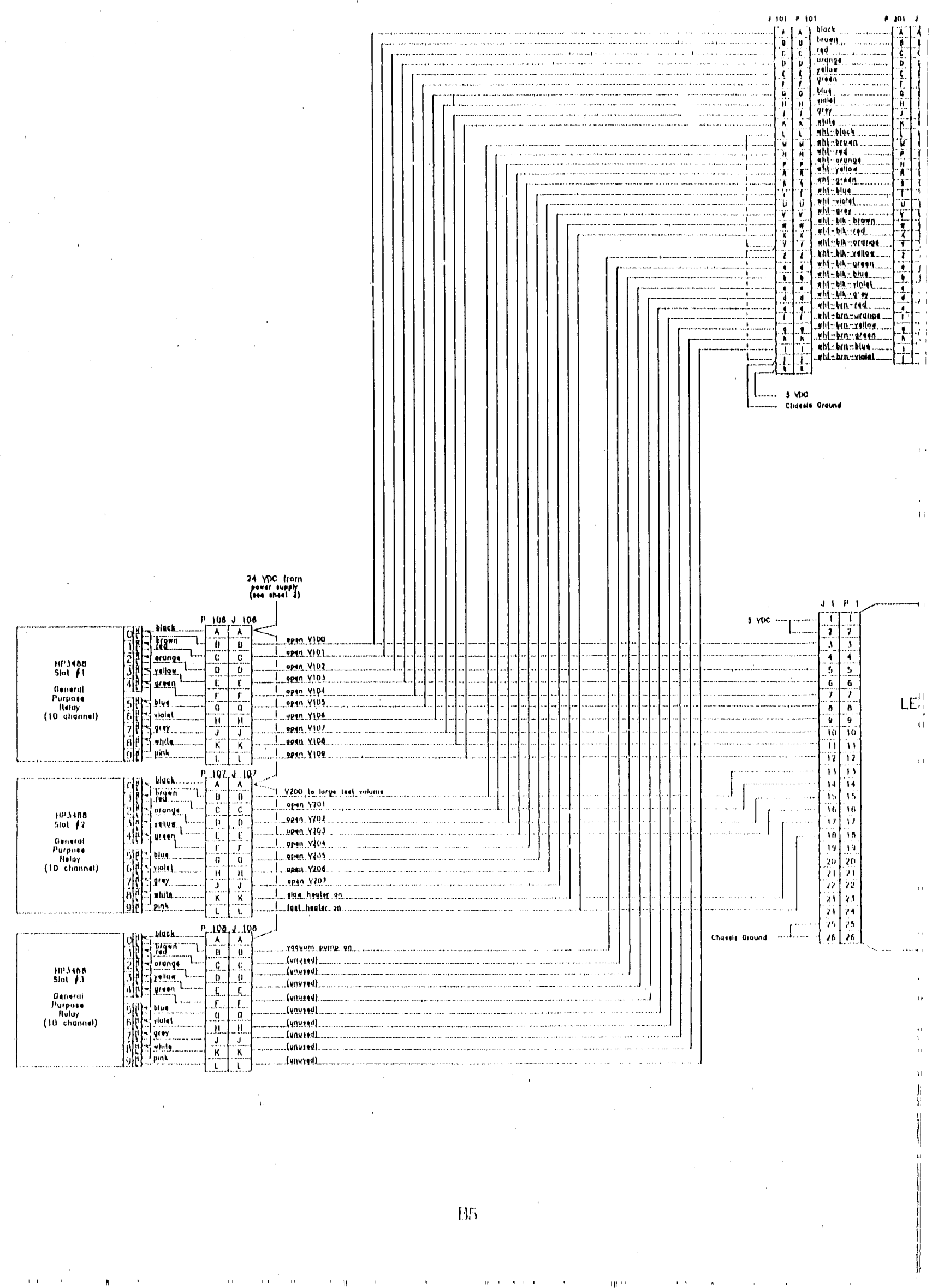



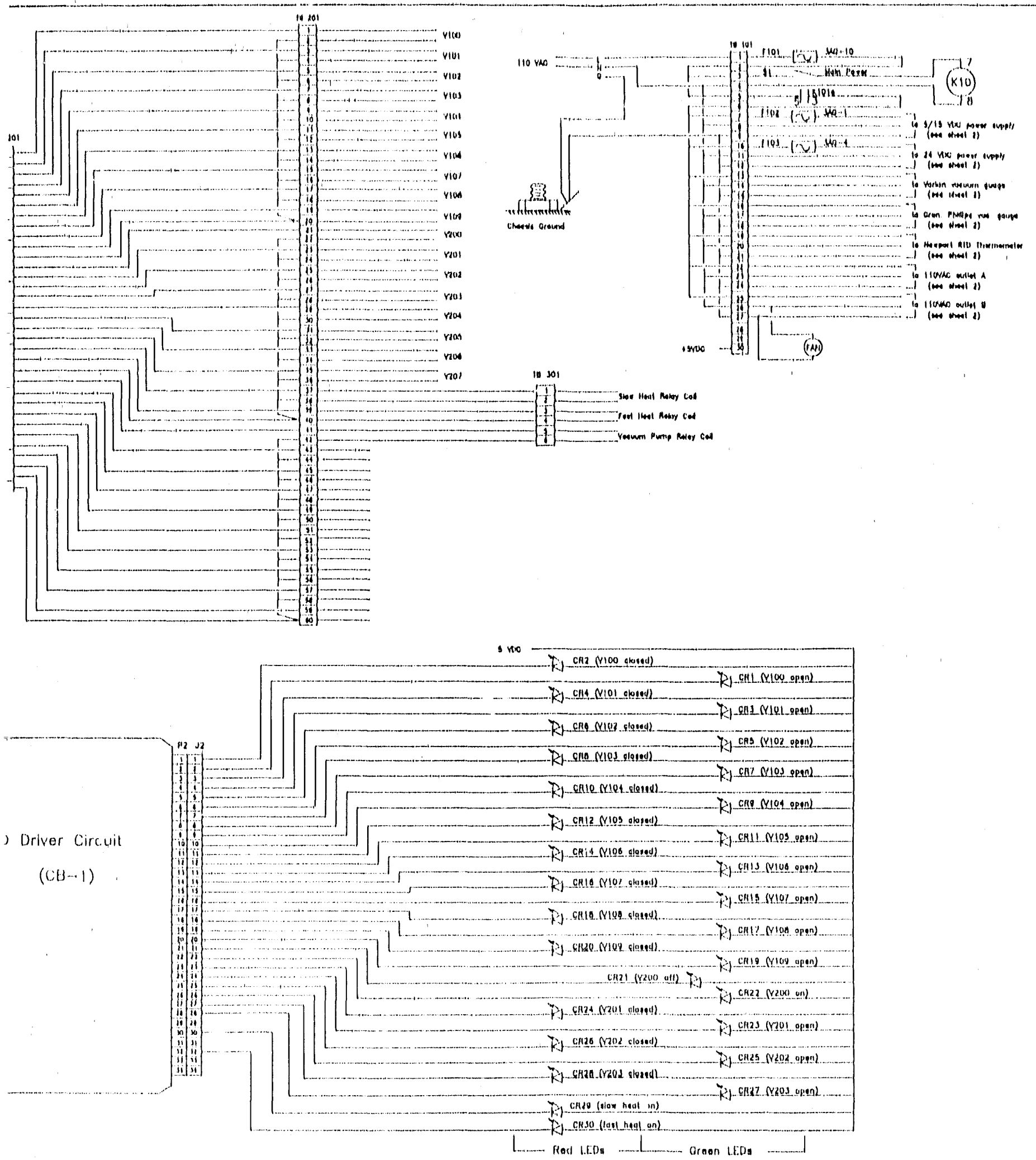

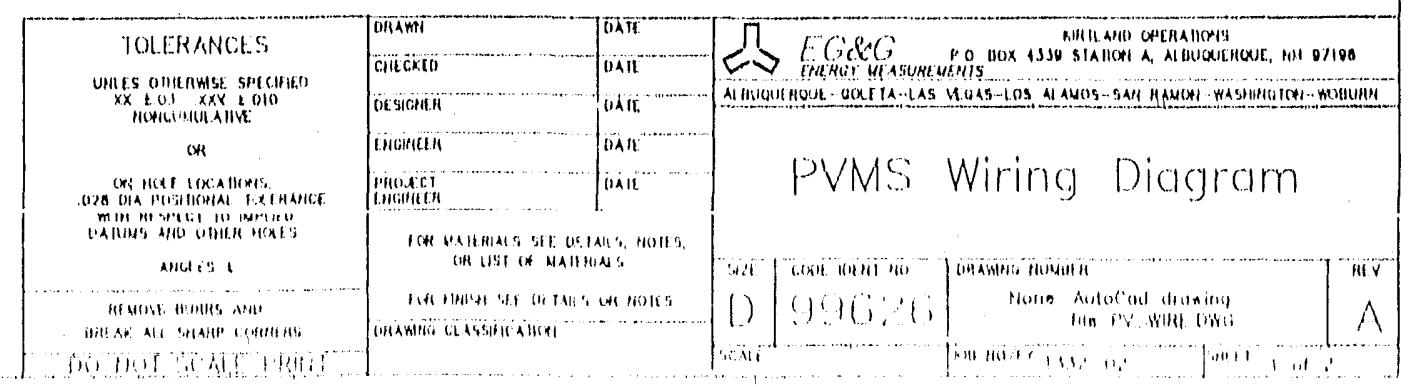



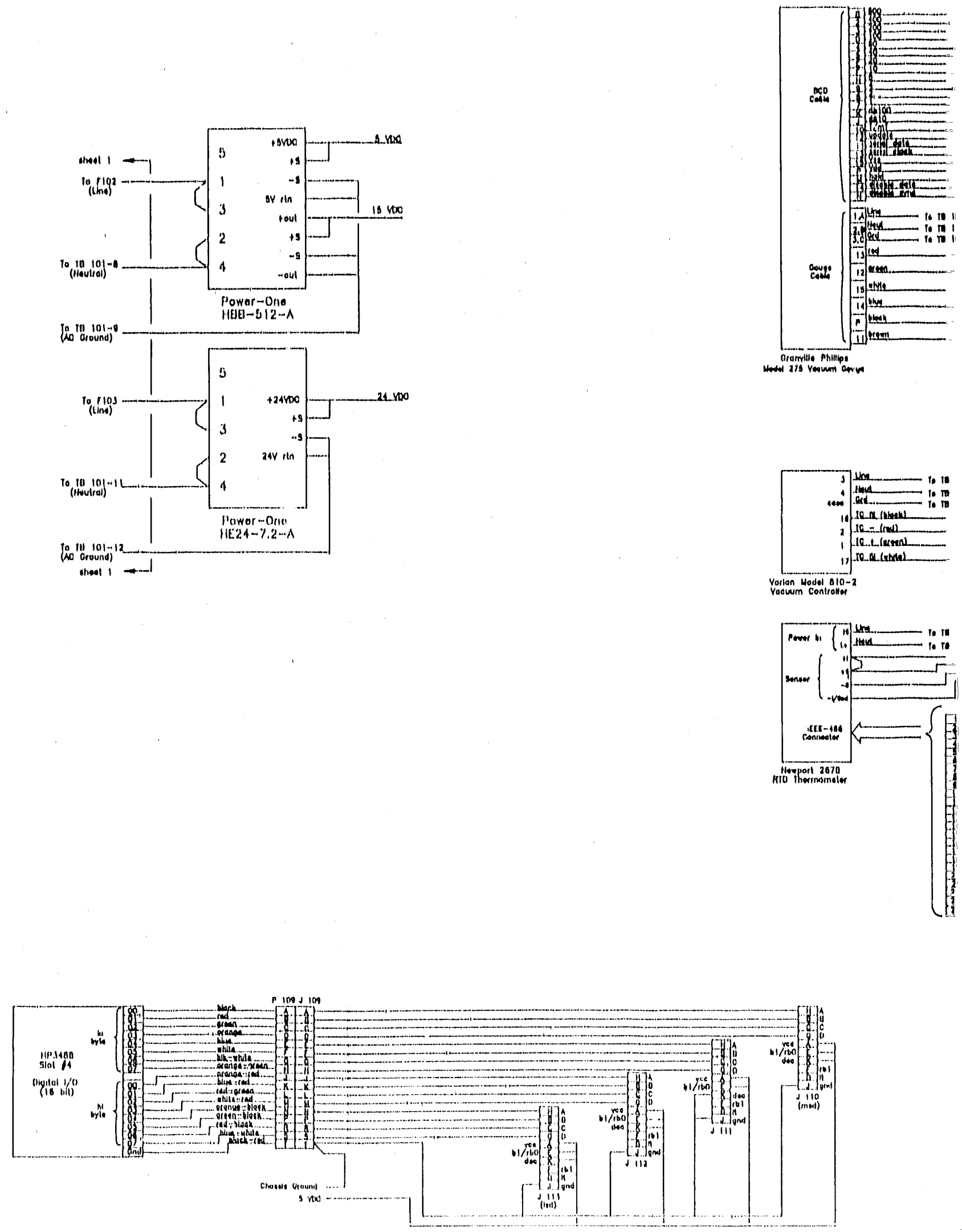


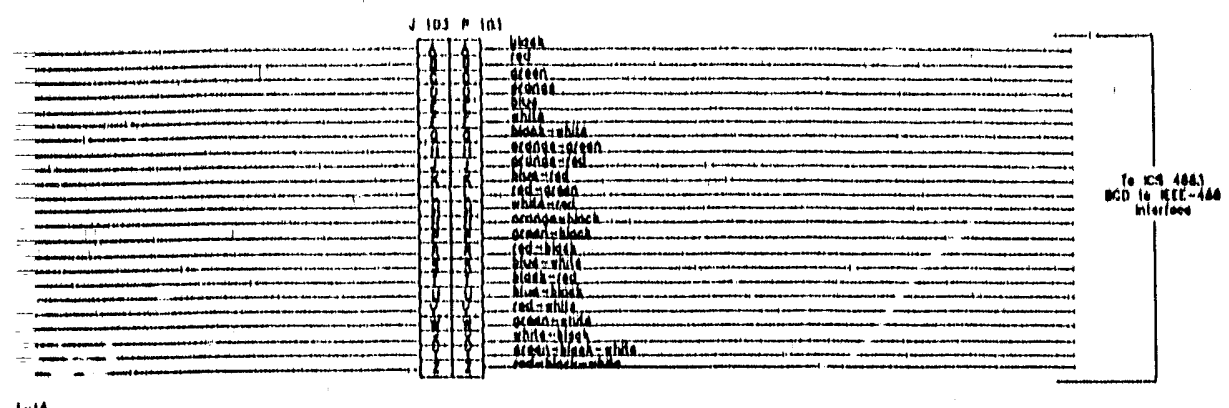

1011
$1+11$

|nith
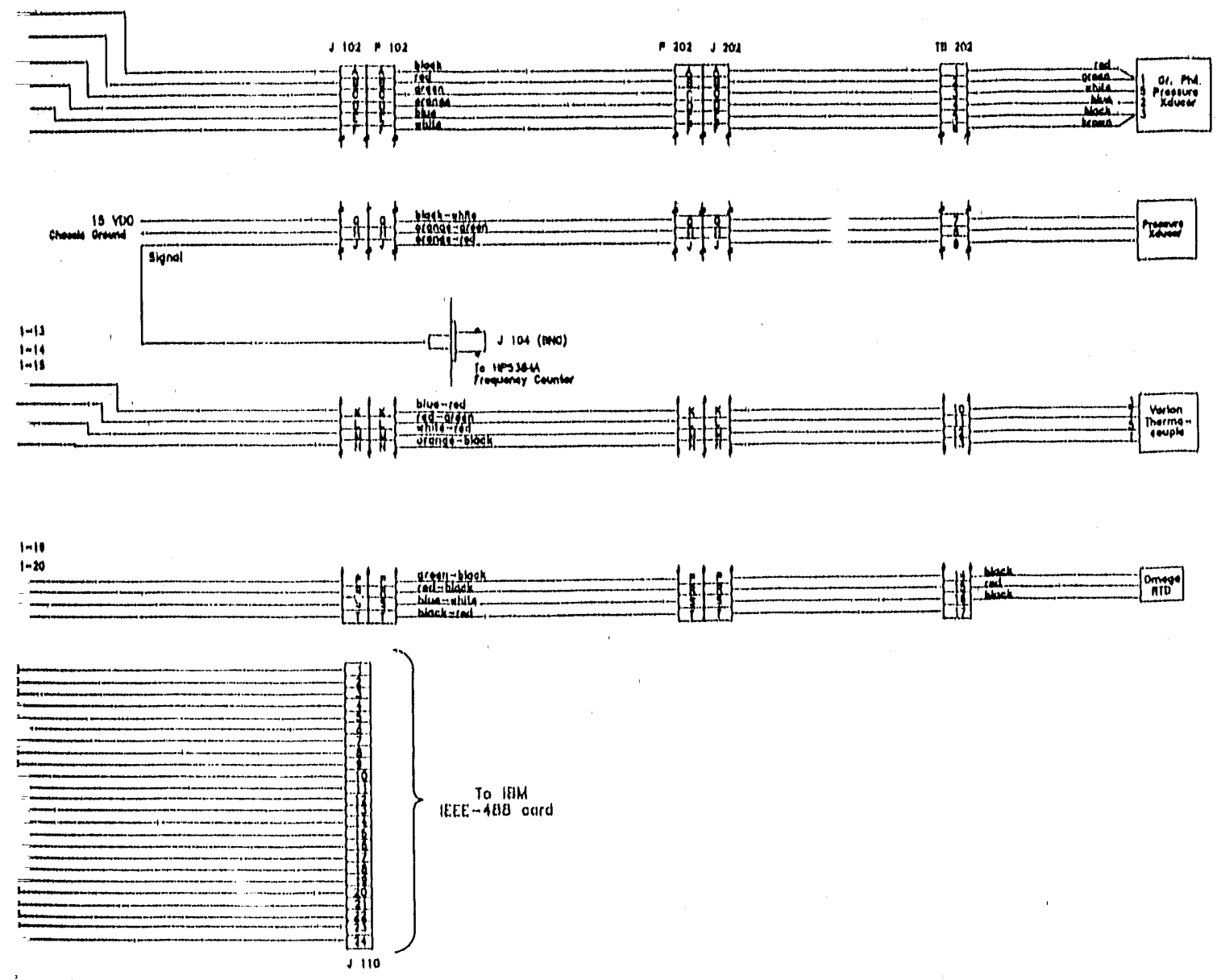

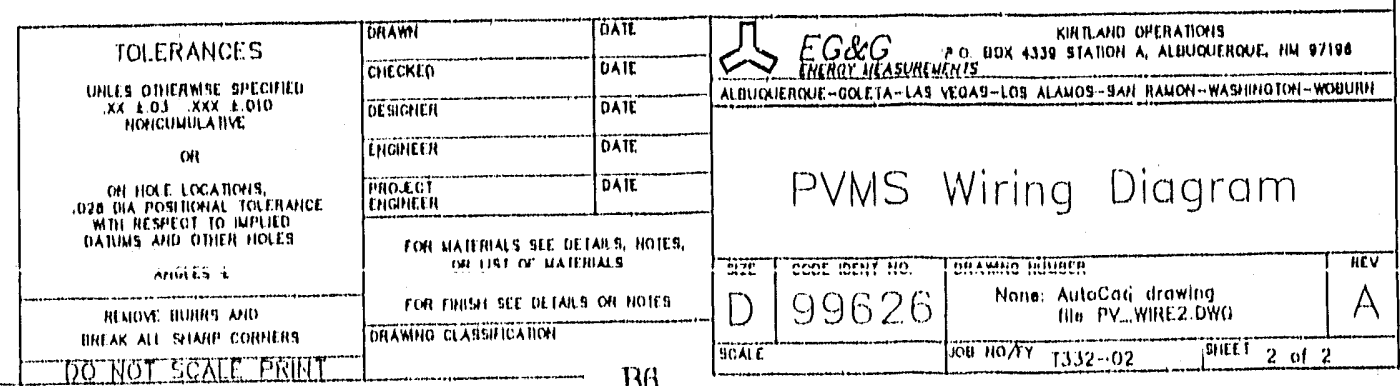




\begin{tabular}{|c|c|c|c|c|c|}
\hline \multicolumn{2}{|c|}{ Hoter From } & $x$ & $Y^{\prime}$ & divom. & dinn $\theta$ \\
\hline$A$ & $X, Y$ & 4420 & 1.250 & 0,1000 & 0.455 \\
\hline . & $\begin{array}{l}x y \\
X Y \\
X Y\end{array}$ & $\begin{array}{l}5.980 \\
7.650\end{array}$ & $\begin{array}{r}1.250 \\
1250\end{array}$ & $\begin{array}{l}0.5600 \\
0.300\end{array}$ & $\begin{array}{l}0.453 \\
0.455\end{array}$ \\
\hline D & $X, Y$ & 1.390 & $4.230^{\circ}$ & 1.350 & \\
\hline & $x, y$ & 0.815 & 4805 & 0,125 & \\
\hline 02 & $x, y$ & 1,905 & 4.805 & 0,125 & \\
\hline .93 & $x_{1}$, & 0,815 & 3.665 & 0.125 & \\
\hline 94 & $X, Y$ & 1.903 & 3.695 & 0.123 & - \\
\hline & $x, y$ & 3.195 & 4230 & 1,350 & \\
\hline E. 1 & $X, Y$ & 2.620 & 4.805 & 0.125 & \\
\hline$E_{2}$ & $x, y$ & 3.770 & 4.805 & 0.125 & \\
\hline & $X Y$ & 2020 & 3.665 & 0.125 & \\
\hline EI & $x, y$ & 3.770 & 3,655 & 0.125 & \\
\hline & $X Y$ & 5.030 & 4.230 & 1.100 & $=$ \\
\hline$P 1$ & $X, Y$ & 4.345 & 4.725 & 0.125 & $=$ \\
\hline 92 & $X, Y$ & 5,515 & 4,725 & 0.125 & \\
\hline & & 4.545 & & & \\
\hline H4 & $X, Y$ & 5.515 & 3.740 & 0.125 & \\
\hline & $X, Y$ & 6.860 & 4.230 & 0.375 & 0.340 \\
\hline & $X, Y$ & 10.460 & 9.230 & 0.975 & \\
\hline 11 & $X, Y$ & 10.010 & 4.680 & 0.125 & - \\
\hline & $\overline{X Y Y}$ & 10.910 & 4.680 & 0.126 & -1 \\
\hline & $X, Y$ & & 3180 & & \\
\hline 14 & $x_{y}$ & 10.910 & 3780 & 0.125 & \\
\hline 7 & $X, Y$ & 12.255 & 4.230 & 0.975 & - \\
\hline [II & $X, Y$ & 11.805 & 4.680 & 0.125 & \\
\hline$\sqrt{2}$ & $X, Y$ & 12.705 & $4,8 \in 0$ & 0.125 & $=$ \\
\hline$\sqrt{3}$ & $X, Y$ & 11805 & 3.780 & 0.125 & - \\
\hline[]$_{4}$ & $X, Y$ & 12.705 & 3,780 & 0.125 & - \\
\hline & & 14,055 & 4.230 & 0.975 & - \\
\hline $\mathrm{HI}$ & $X, Y$ & 13.605 & 4680 & 0.125 & \\
\hline $\mathrm{k}_{2}^{2}$ & $\bar{X}, Y$ & 14.505 & 4.680 & 0.125 & $=$ \\
\hline $\mathrm{HJ}$ & $X, Y$ & $13.605 !$ & 3.780 & 0.125 & - \\
\hline$k !$ & $x, y$ & 14.505 & 3,780 & 0.125 & \\
\hline & $X, Y$ & 15.820 & 4.230 & 1.380 & 1.335 \\
\hline $\mathrm{M}$ & $X, Y$ & 13585 & 8,920 & 4530 & \\
\hline$N \mid$ & $X, Y$ & 11.525 & $10.97 !$ & 0.166 & $z$ \\
\hline & $X, Y$ & 15,650 & 10.975 & 0.166 & - \\
\hline$M$ & $X, Y$ & 11.540 & 0.050 & 0.186 & \\
\hline $\mid N i \frac{14}{1}$ & $\begin{array}{l}X, Y \\
X Y Y\end{array}$ & $\begin{array}{r}-15,650 \\
-3\end{array}$ & -6.850 & 0.106 & $\ddot{ت}$ \\
\hline$A^{2}$ & $X$ & 2,970 & 1,250 & 0125 & $=$ \\
\hline & $\bar{X}, \bar{Y}$ & 8750 & 1250 & 0.186 & $=$ \\
\hline $\mathrm{C}^{2}$ & $X, Y$ & 10.600 & 1.250 & 0.166 & $\ldots$ \\
\hline FI & $X, Y$ & 11.620 & 1.250 & 0.125 & \\
\hline$A^{2}$ & $X Y$ & 13180 & 1250 & 0.125 & \\
\hline G1 & $x, y$ & -13949 & 1250 & 0.125 & $=$ \\
\hline 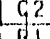 & $\begin{array}{l}X, Y \\
Y, Y\end{array}$ & $\frac{15500}{-15}$ & $\begin{array}{r}1250 \\
-5.50\end{array}$ & 0.125 & \\
\hline 12 & $X, Y$ & 2250 & & & - \\
\hline 183 & $\overline{X, Y}$ & 4.125 & 10,560 & 0.157 & - \\
\hline$\sqrt{14}$ & $X, Y$ & 4125 & 10.260 & 0.157 & \\
\hline & $X, Y$ & 2.250 & 9010 & 0.157 & \\
\hline & $X, Y$ & 225 & 8. 7 & 01 & \\
\hline & $X, Y$ & 4.125 & 0.010 & 0.15 & \\
\hline & $X, Y$ & 4.125 & 8.710 & 0.157 & \\
\hline in & $X, Y$ & 2.250 & 7480 & 0,157 & $\because$ \\
\hline & $X, Y$ & 2.250 & 7.160 & 0.157 & - \\
\hline & $X Y$ & 4.125 & 7,460 & $0.15 \%$ & \\
\hline 14 & $X . Y$ & 4.125 & 7.160 & 0.157 & \\
\hline & $X, Y$ & 00 & 3292 & Q.1ㄴ.1ㄴ. & \\
\hline & & & & & \\
\hline
\end{tabular}

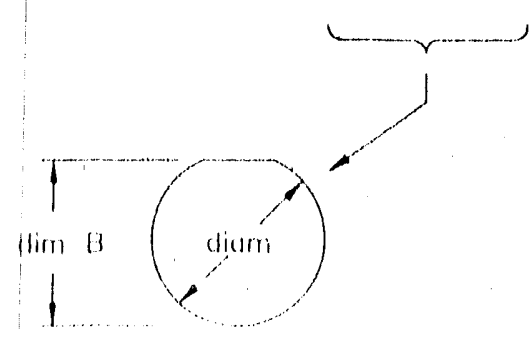

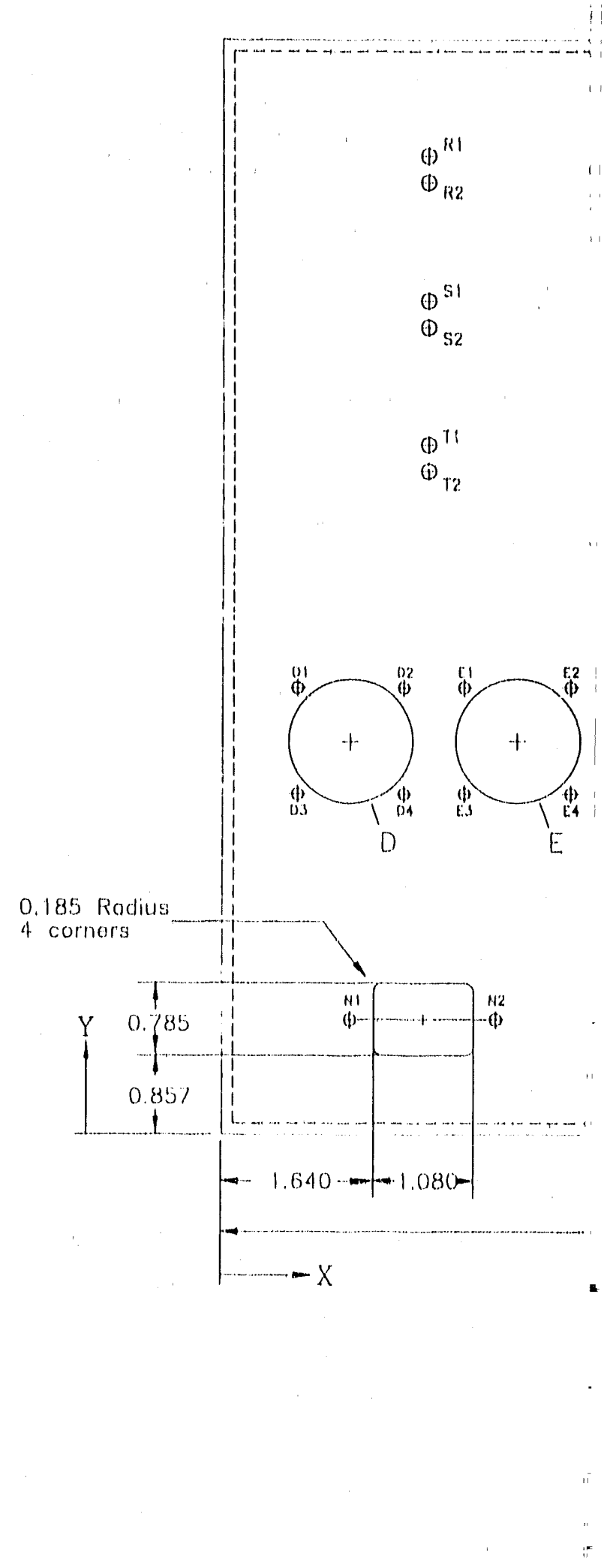




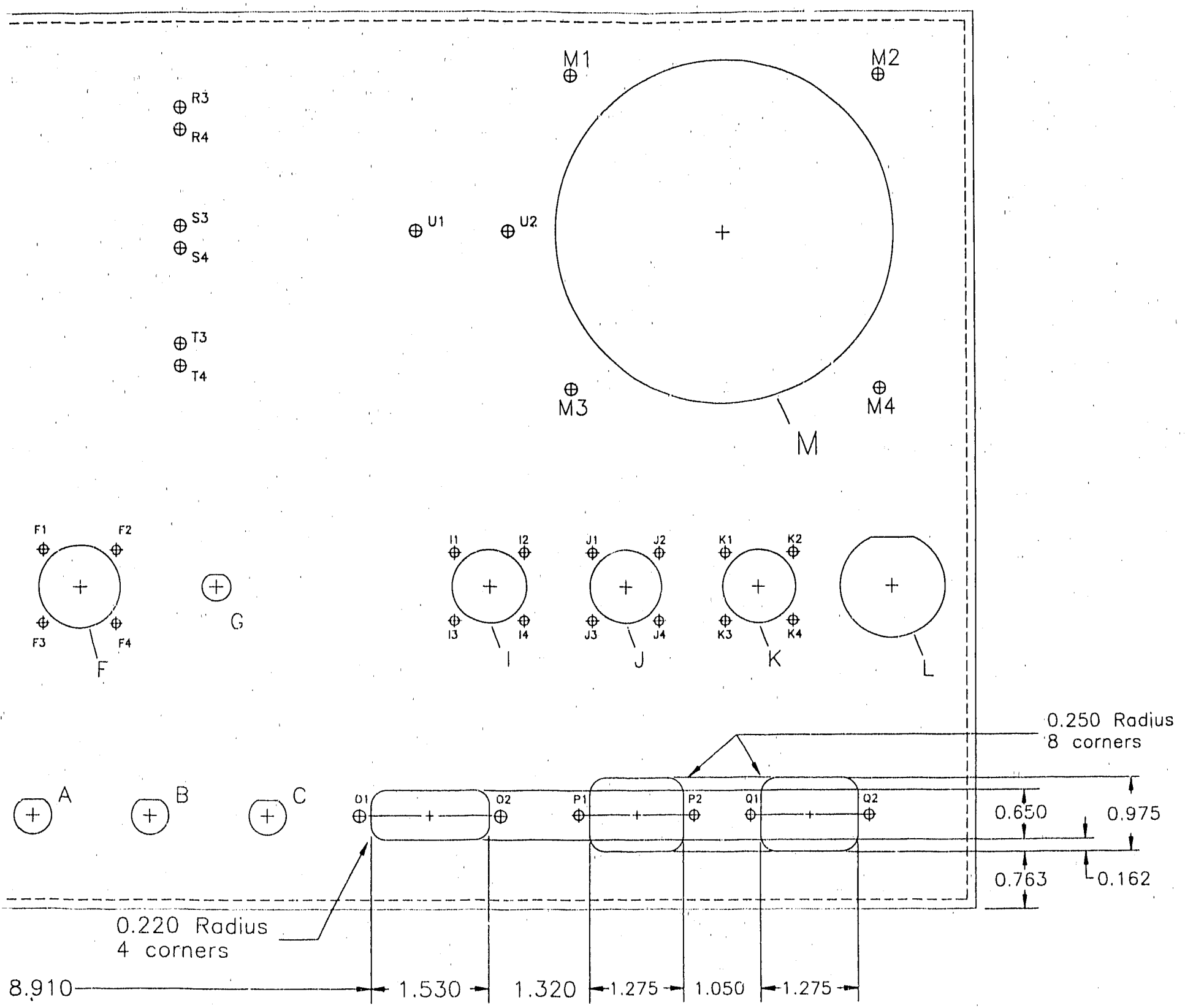

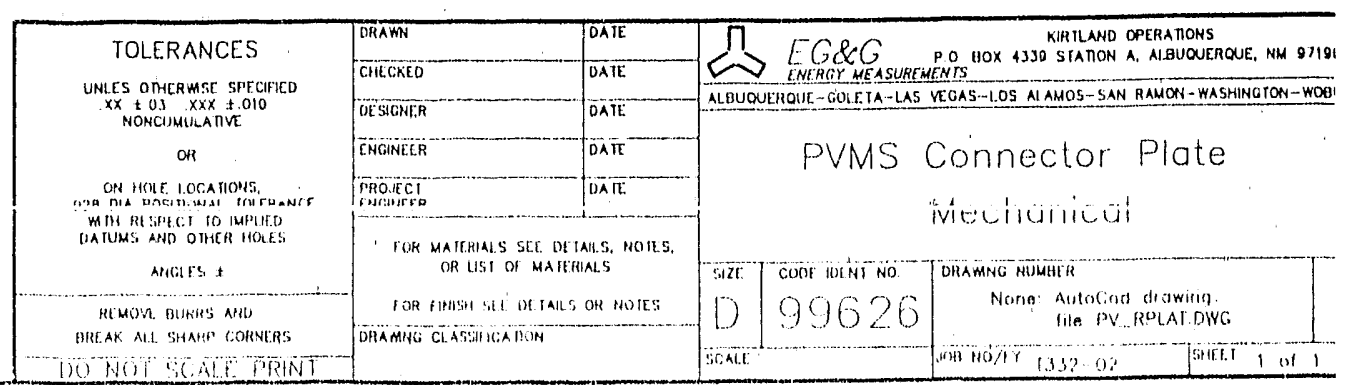



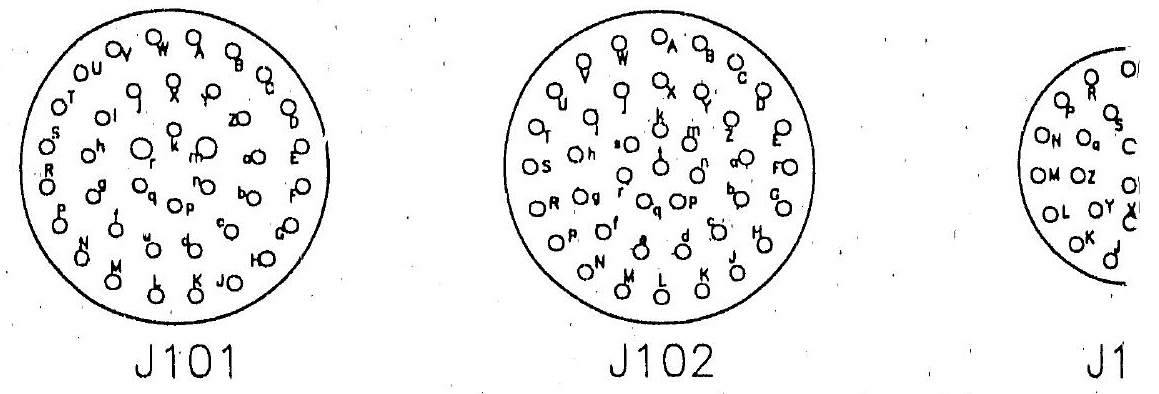

J1
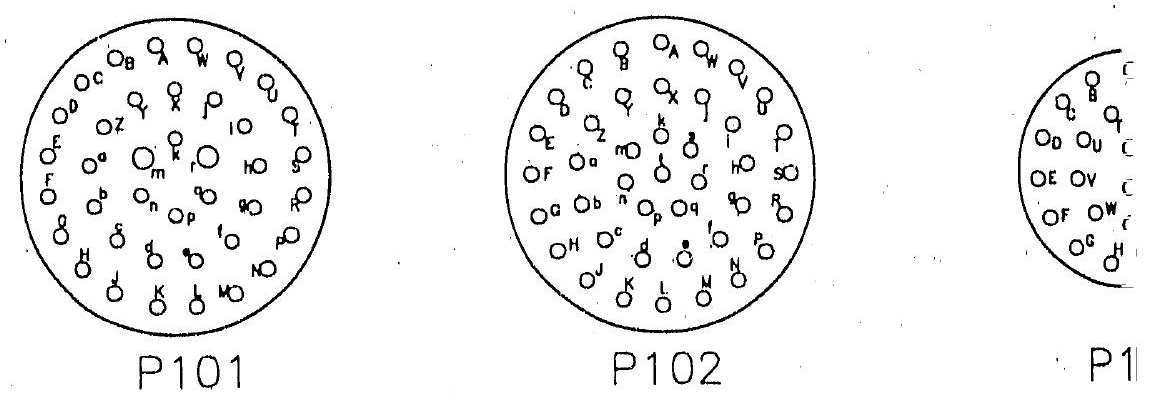

P1
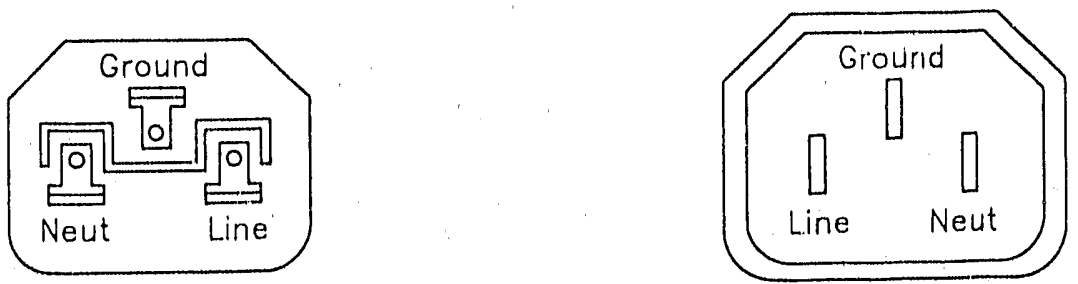

Power Input

Switched 110VAC Outlet (2 ea)

Note: All connectors viewed from the SOLDER side 


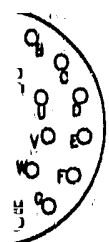

33
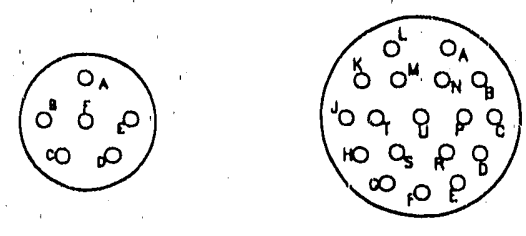

J105

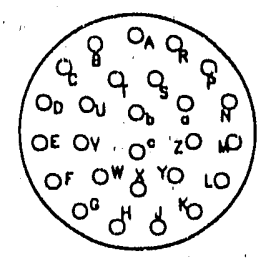

J109

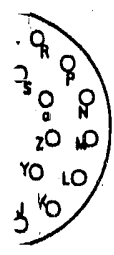

03

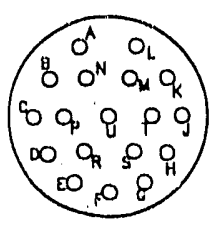

P106,P107,P108

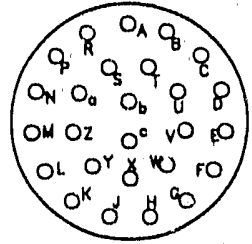

P109

\section{$2400000000000^{13}$ \\ ${ }_{12}^{000000000000_{1}}$}

$J 110$ 


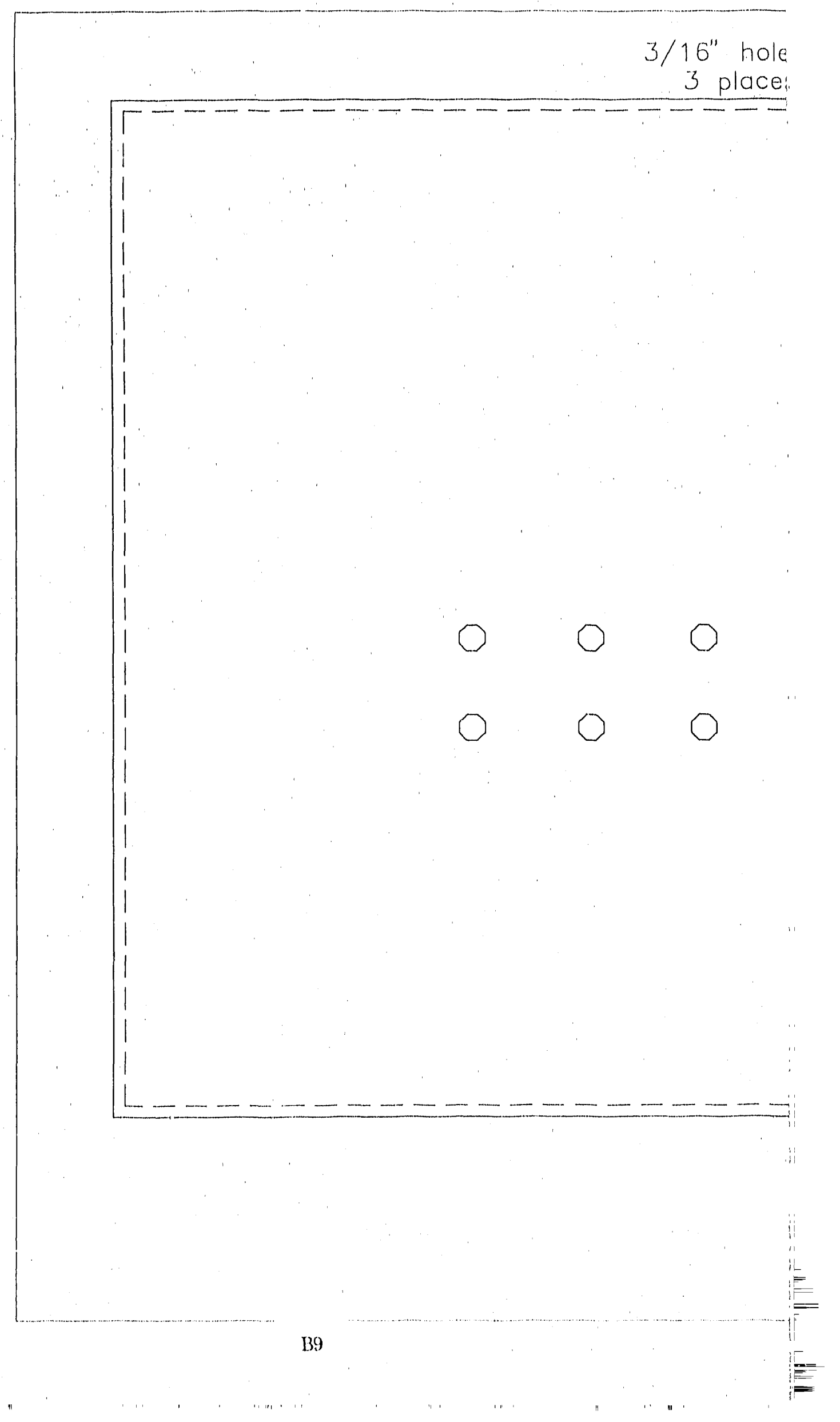



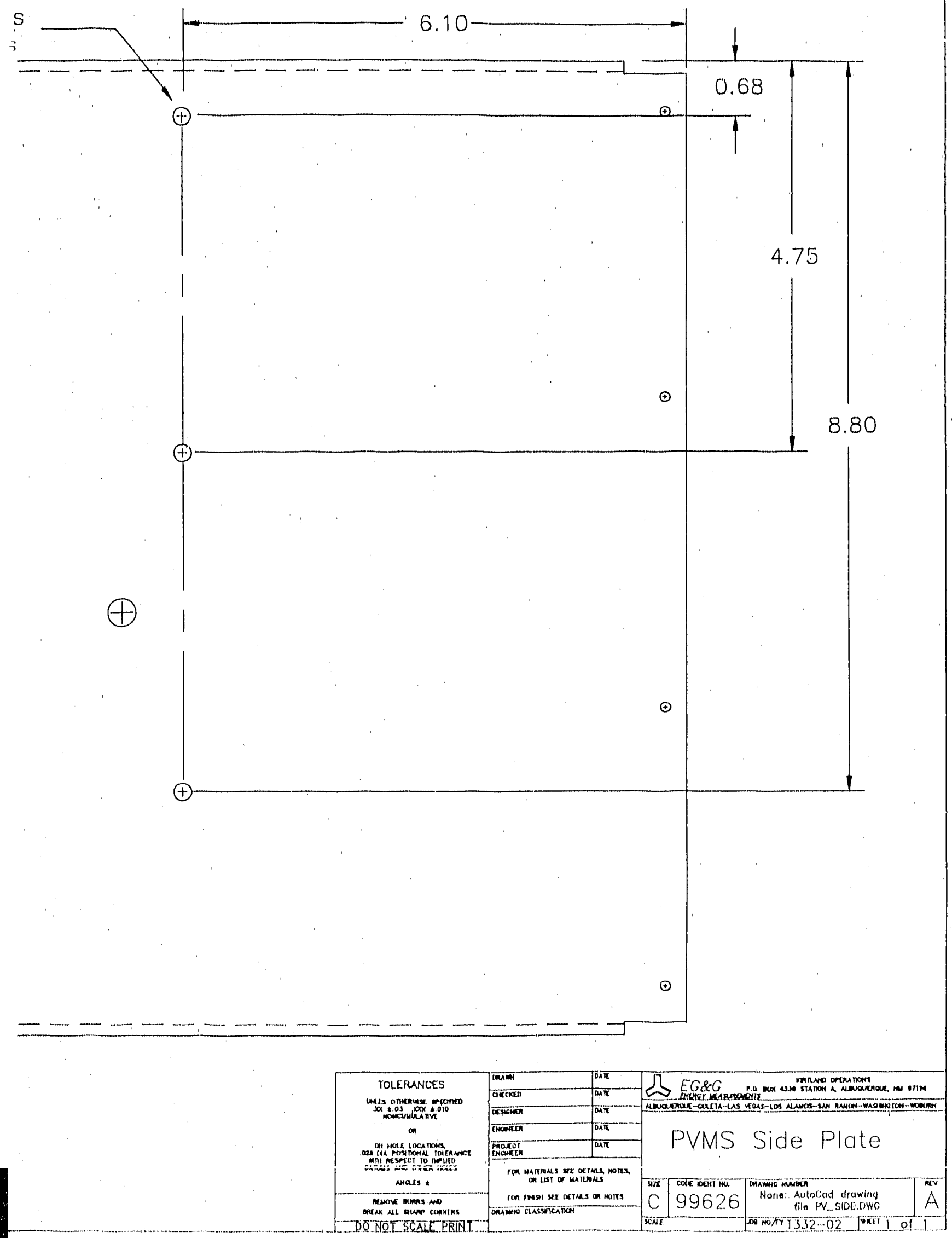


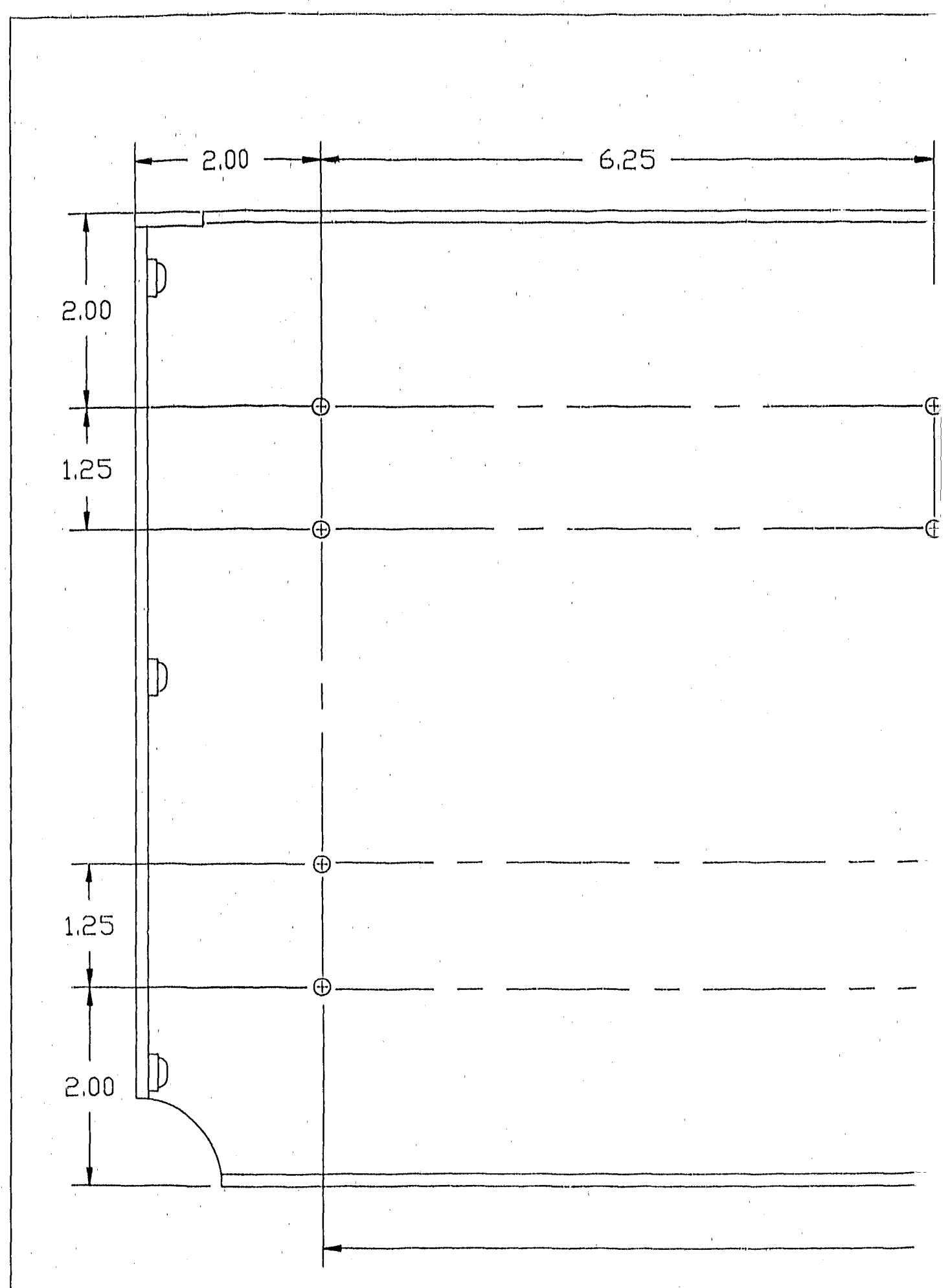



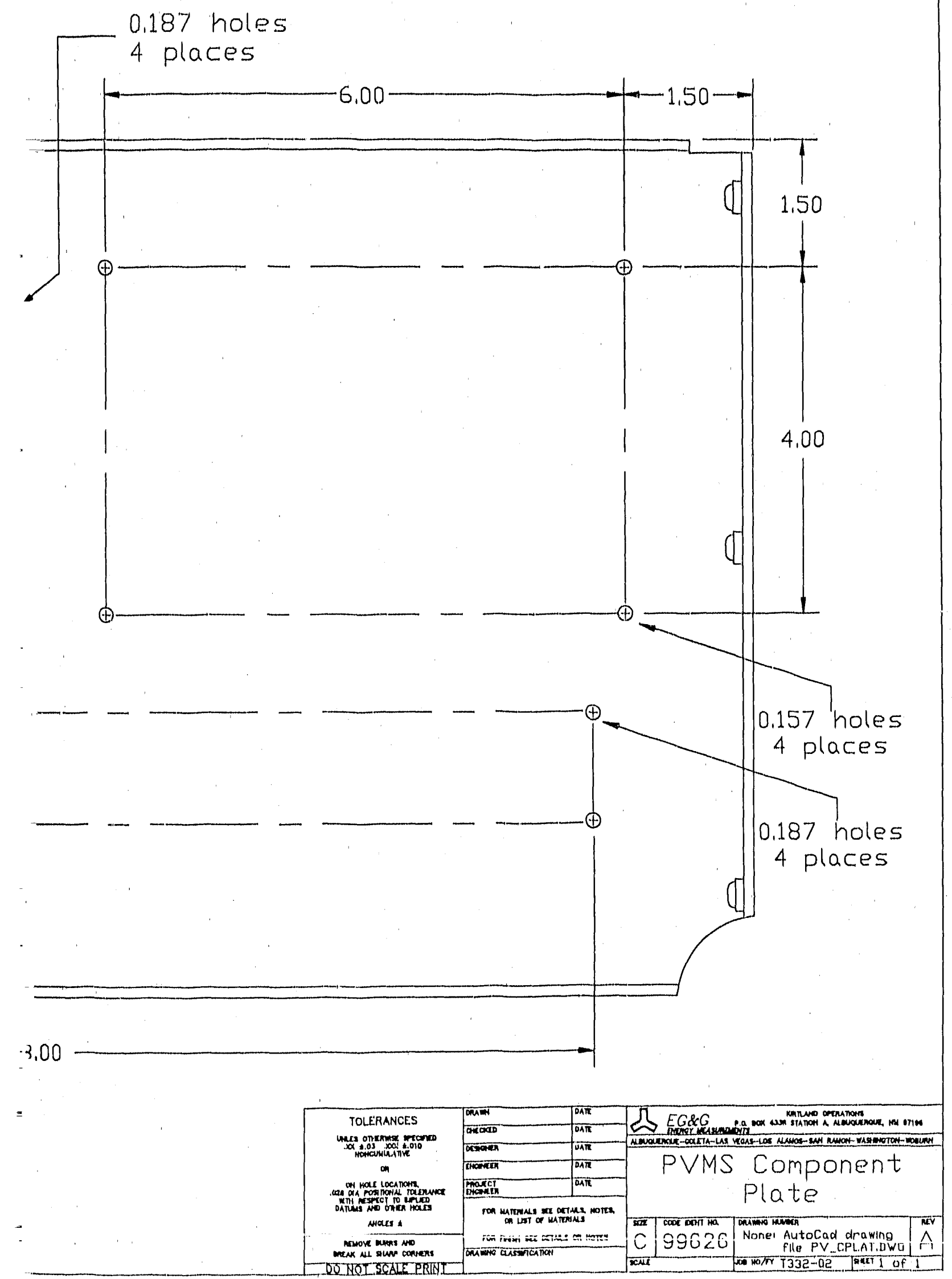


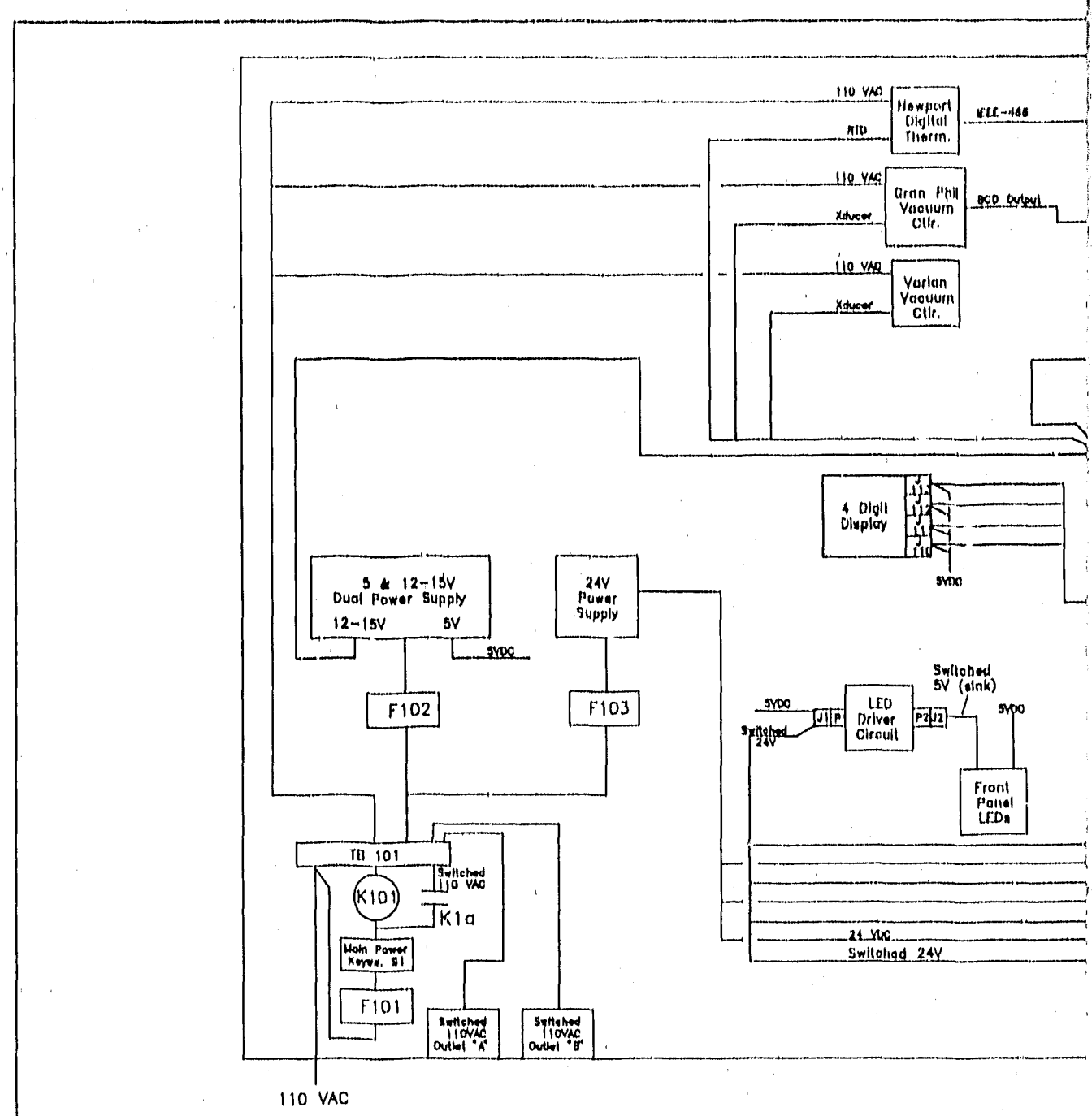


- iivinio

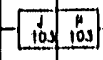

ICS Modal 4883

BCD to IEEE - 488

Interfisea

IQM PC

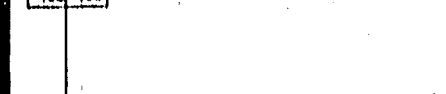

-1.0.104

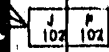

HP5384A

Frequency

Counter

(Pressure)

IEEE-488

(GPIB)

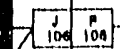

io. : io

Sion

- in

-
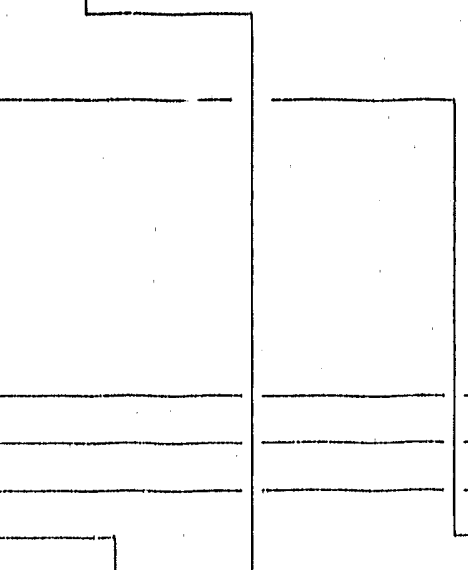

HP3488 Switch CU

IEEE -488

Inturtaces

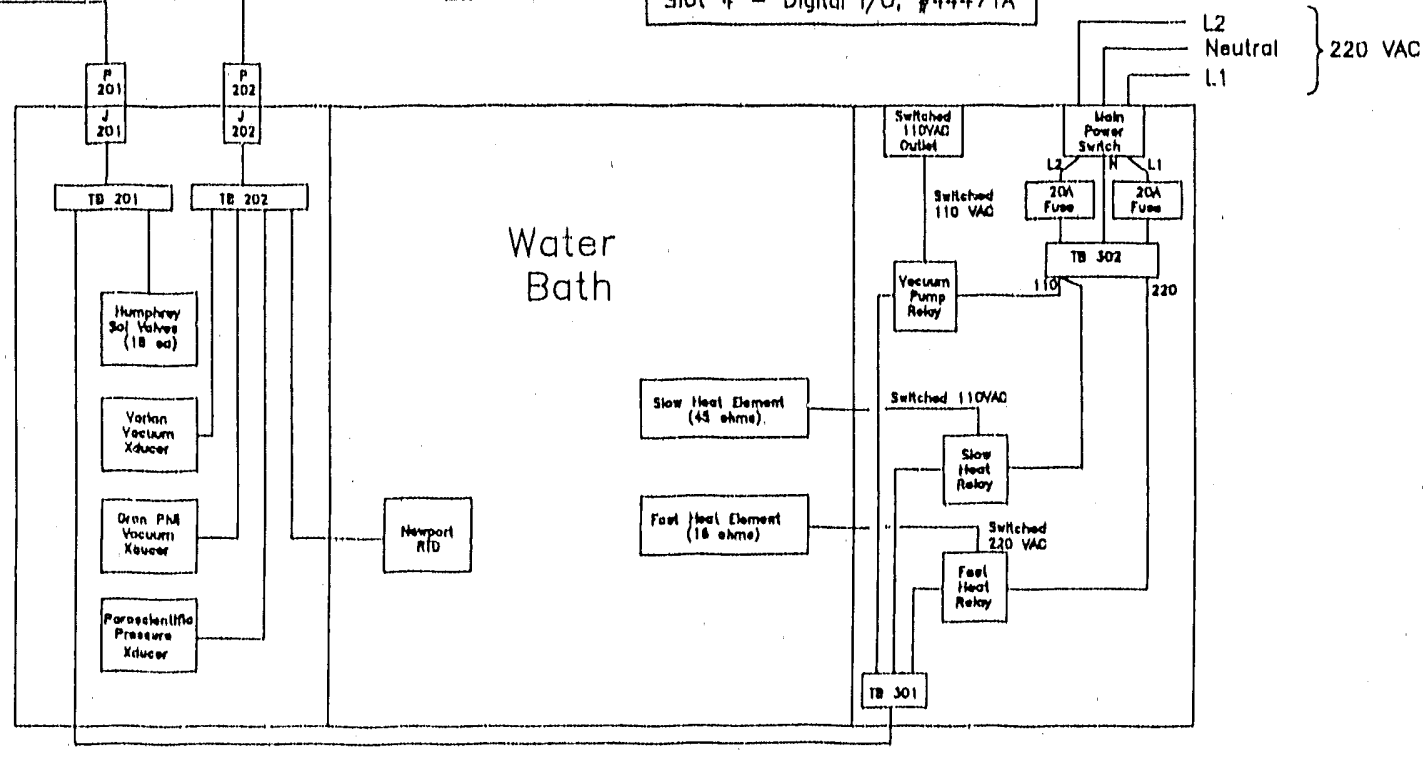

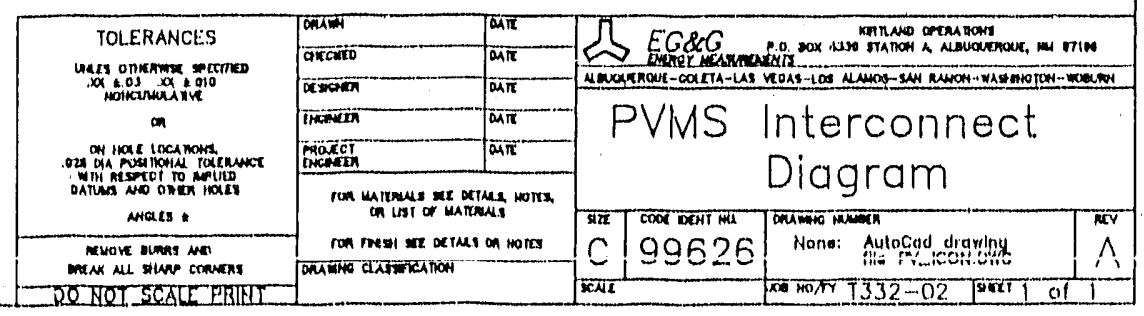




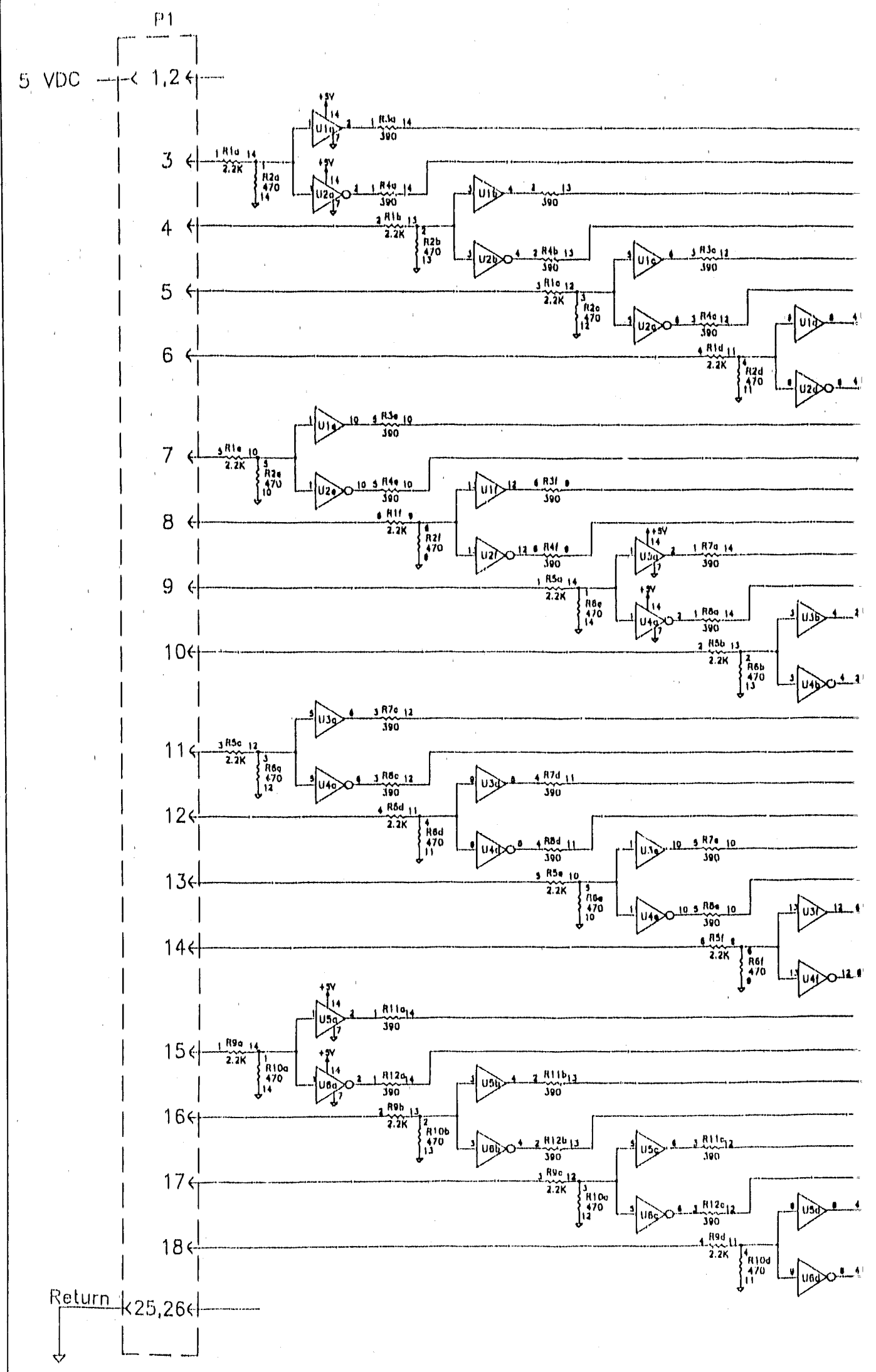



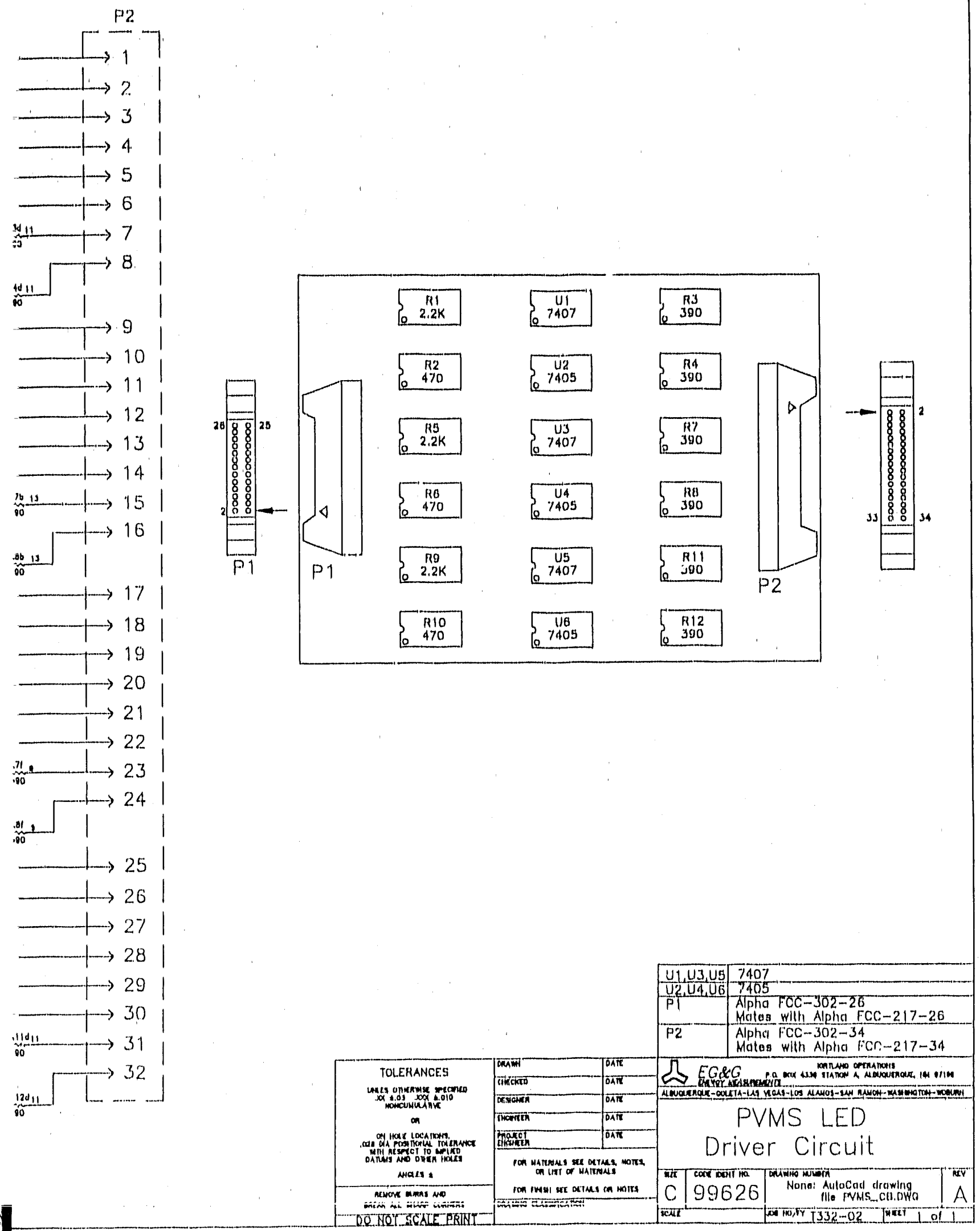


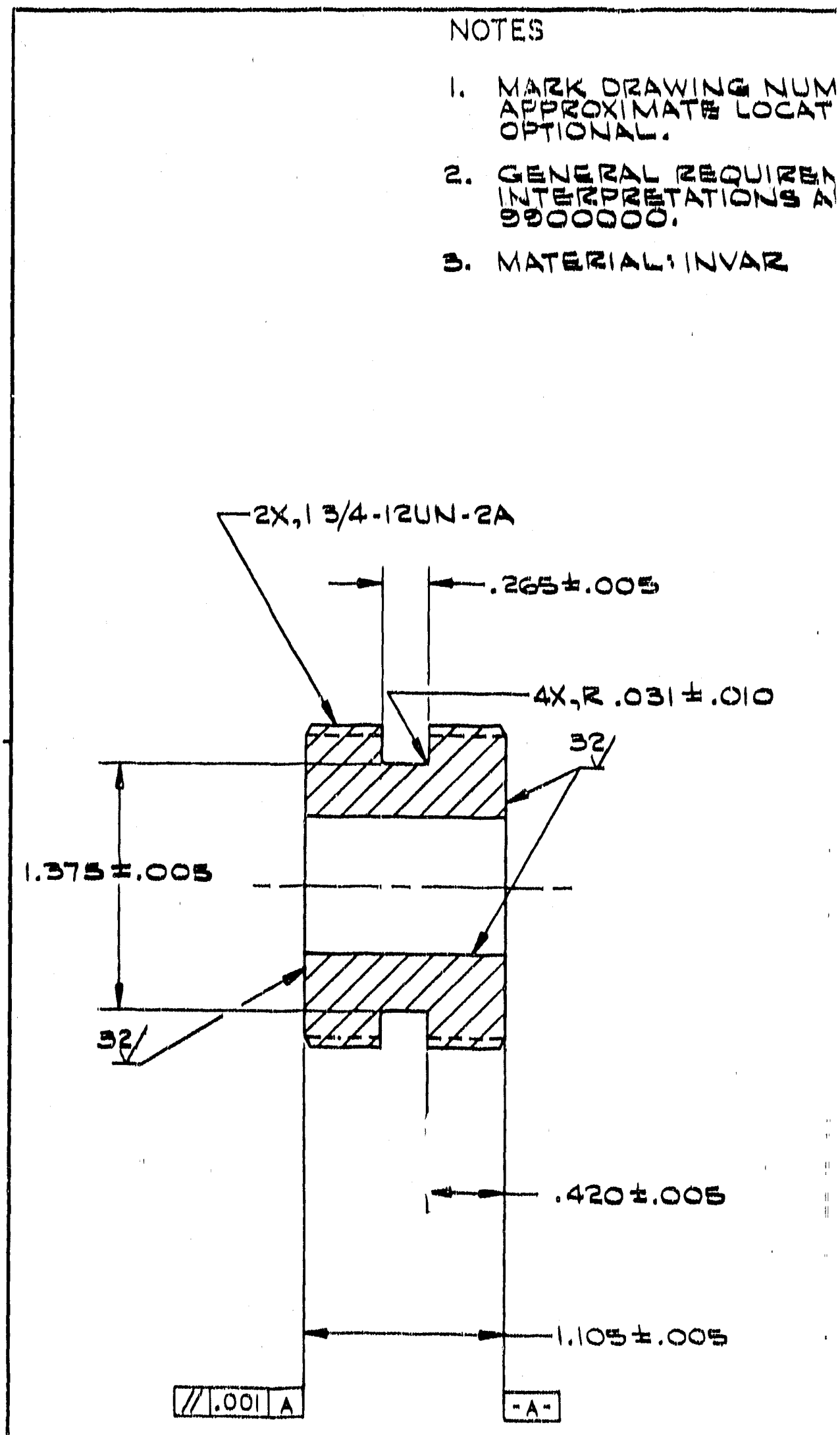



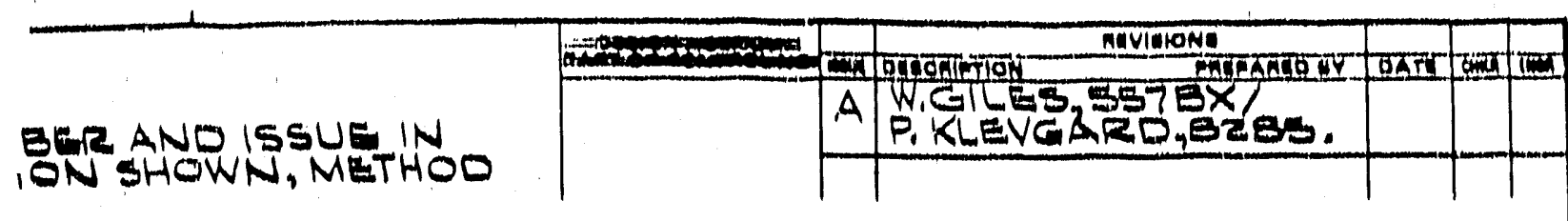

1WNTS AND DRAWING IE DEFINED IN

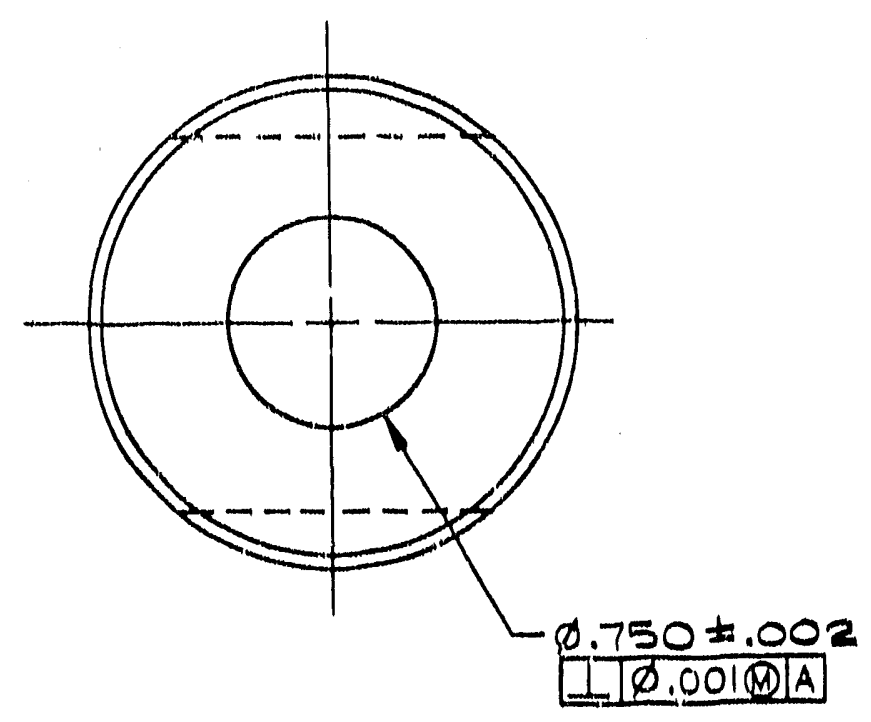

PRECISION

CYLINDER $B$

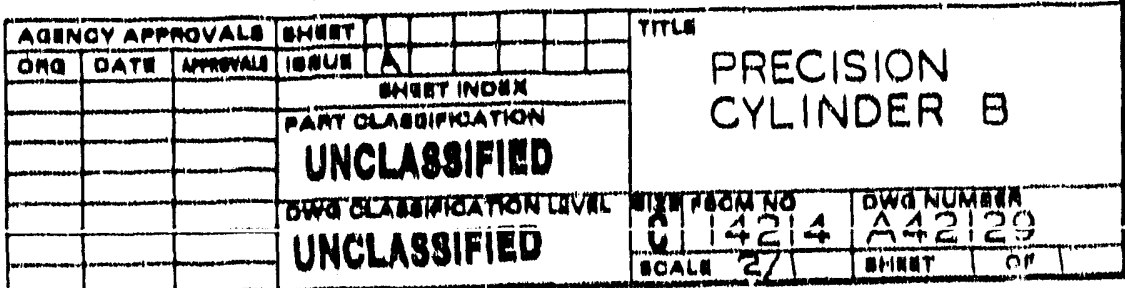




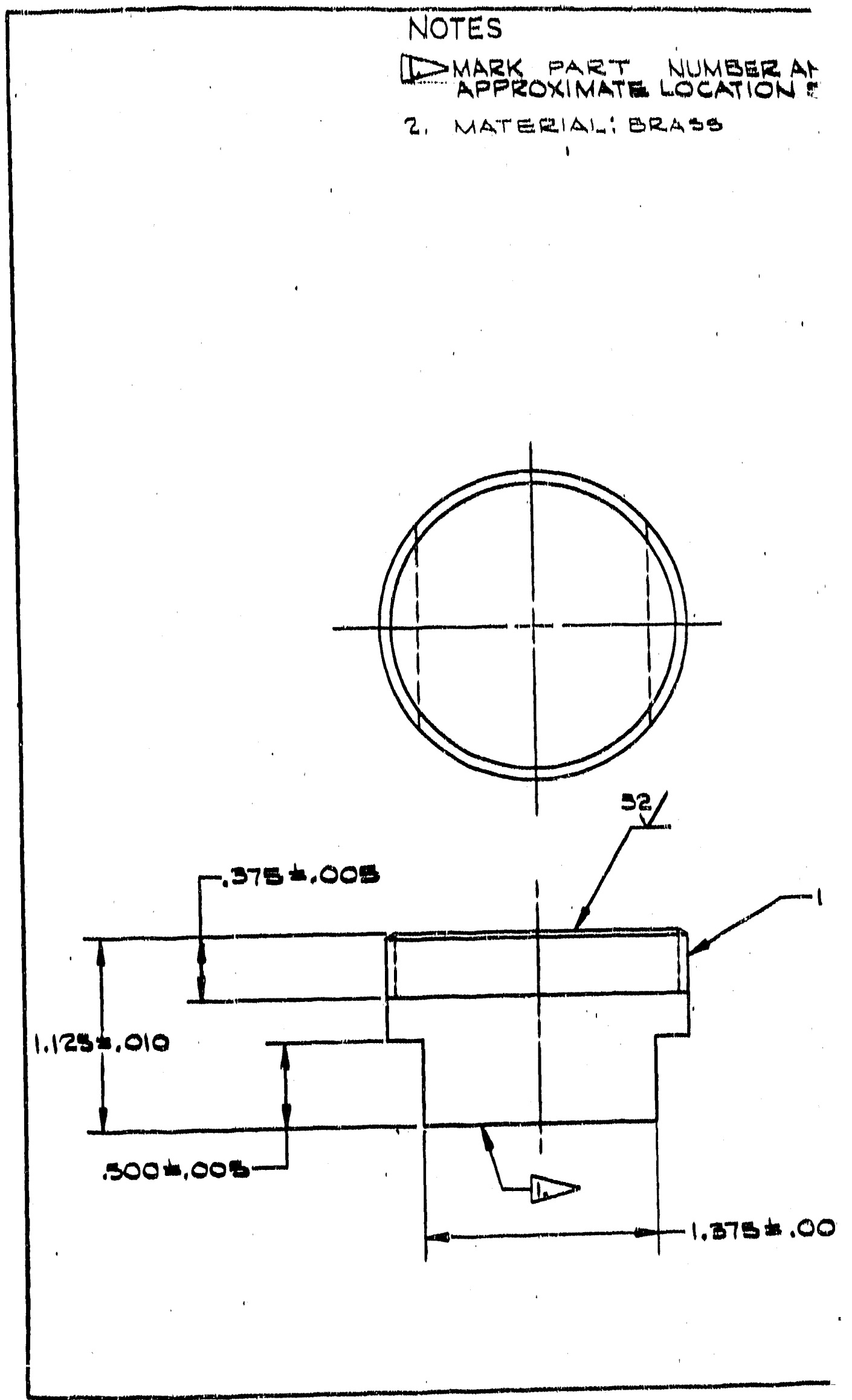


D SUFFIX IN

HOWN.

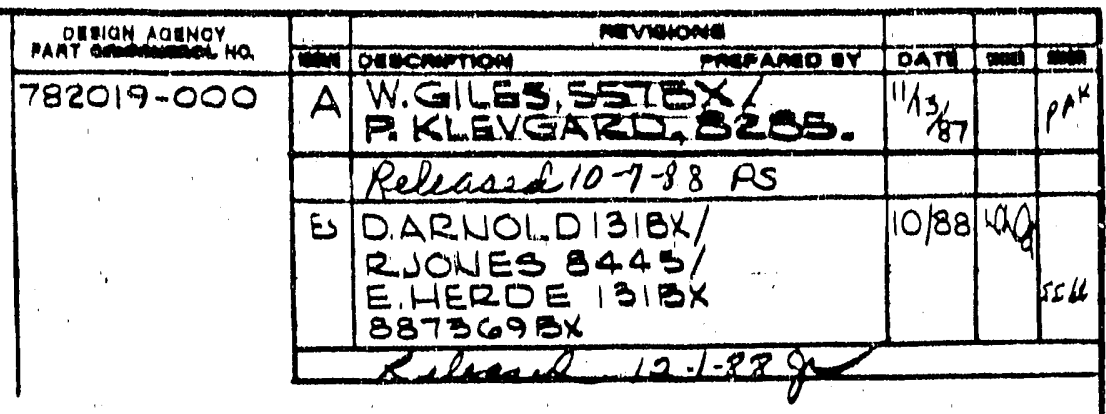

$-/ 4-12 \cup N-2 A$

DRC. $2 T$

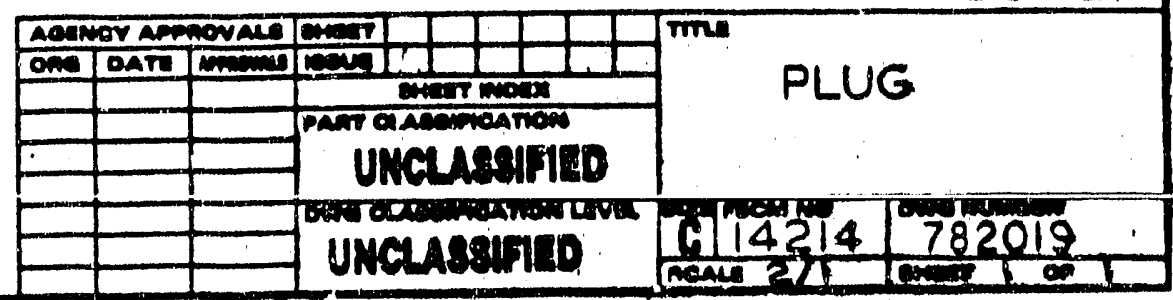




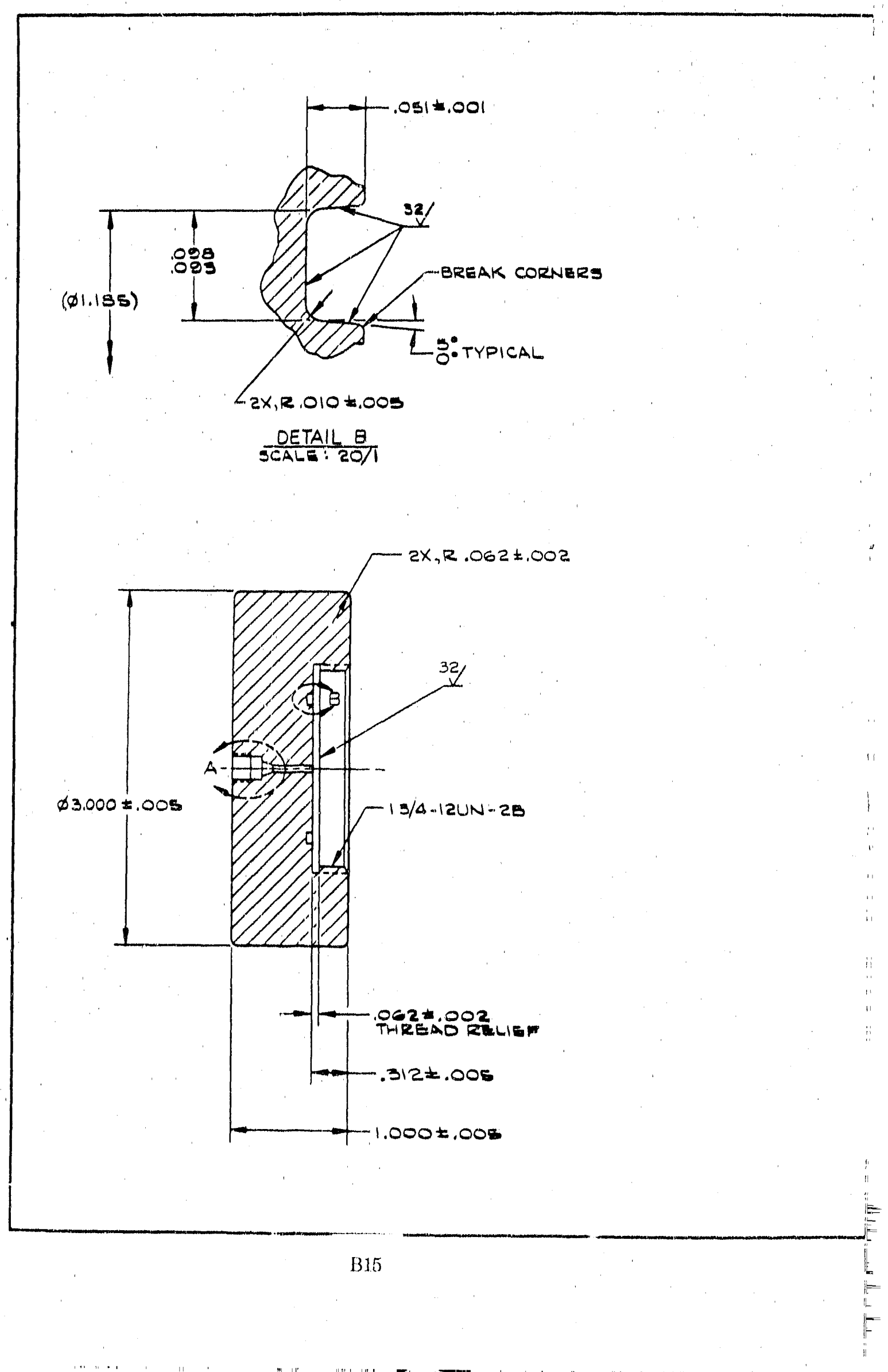


NOTES

1. MALK DRAWING NUMEER AND ISEUE IN APPROXIMATE LOCATION SHOWN, METHOD OPTIONALL.

2. GENERAL REOUIREMENTS AND DRAWING INTERPRETATIONS ARE DEFINEO IN 9900000.

5. MATERIAL: STAINLESS STEEL \$IG.

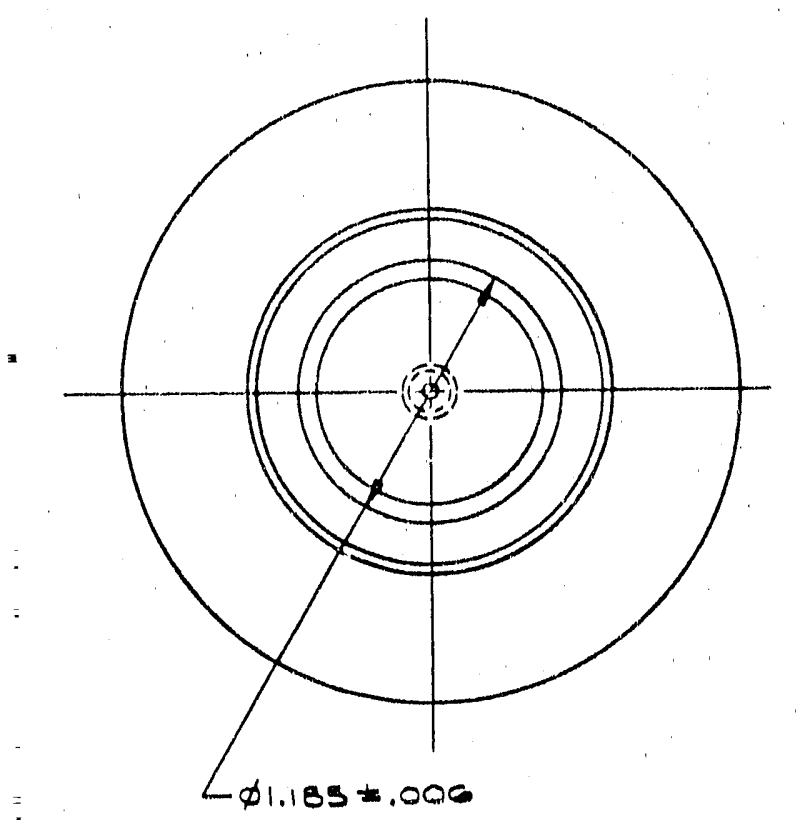

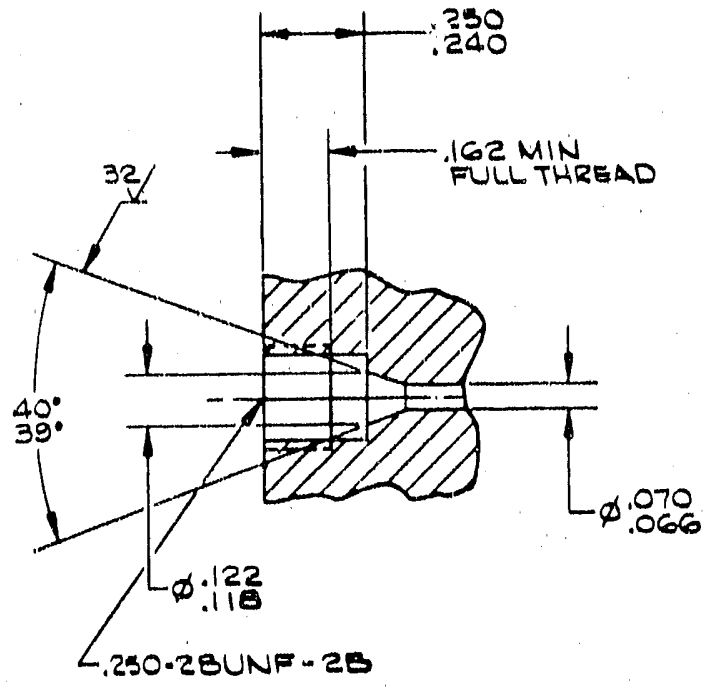

$\frac{\text { DETA.ILA }}{\text { SCALEI }}$

\begin{tabular}{|c|c|c|c|c|}
\hline \multicolumn{3}{|c|}{ 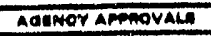 } & अa्ग I & \multirow{3}{*}{ END CAP, PORT } \\
\hline ore & DAT & mimens & IEman $\mid \mathrm{A}$ I 1 & \\
\hline & & & \multirow{2}{*}{ 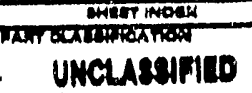 } & \\
\hline & & & & \\
\hline & & & \multirow{2}{*}{$\begin{array}{l}\text { UNCLABSIFIID } \\
\text { Und }\end{array}$} & 3 \\
\hline & & & & 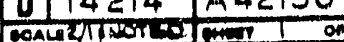 \\
\hline
\end{tabular}




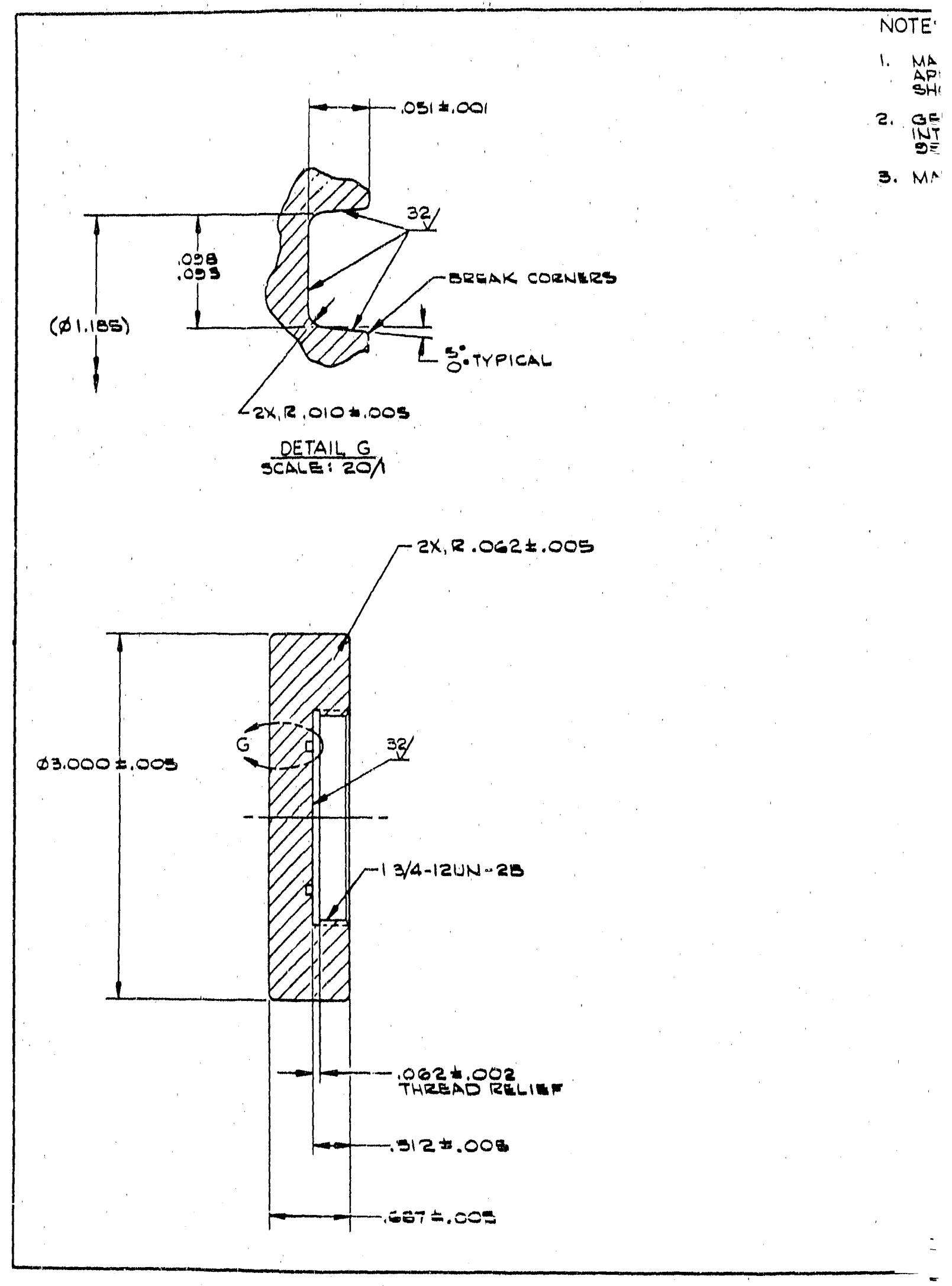




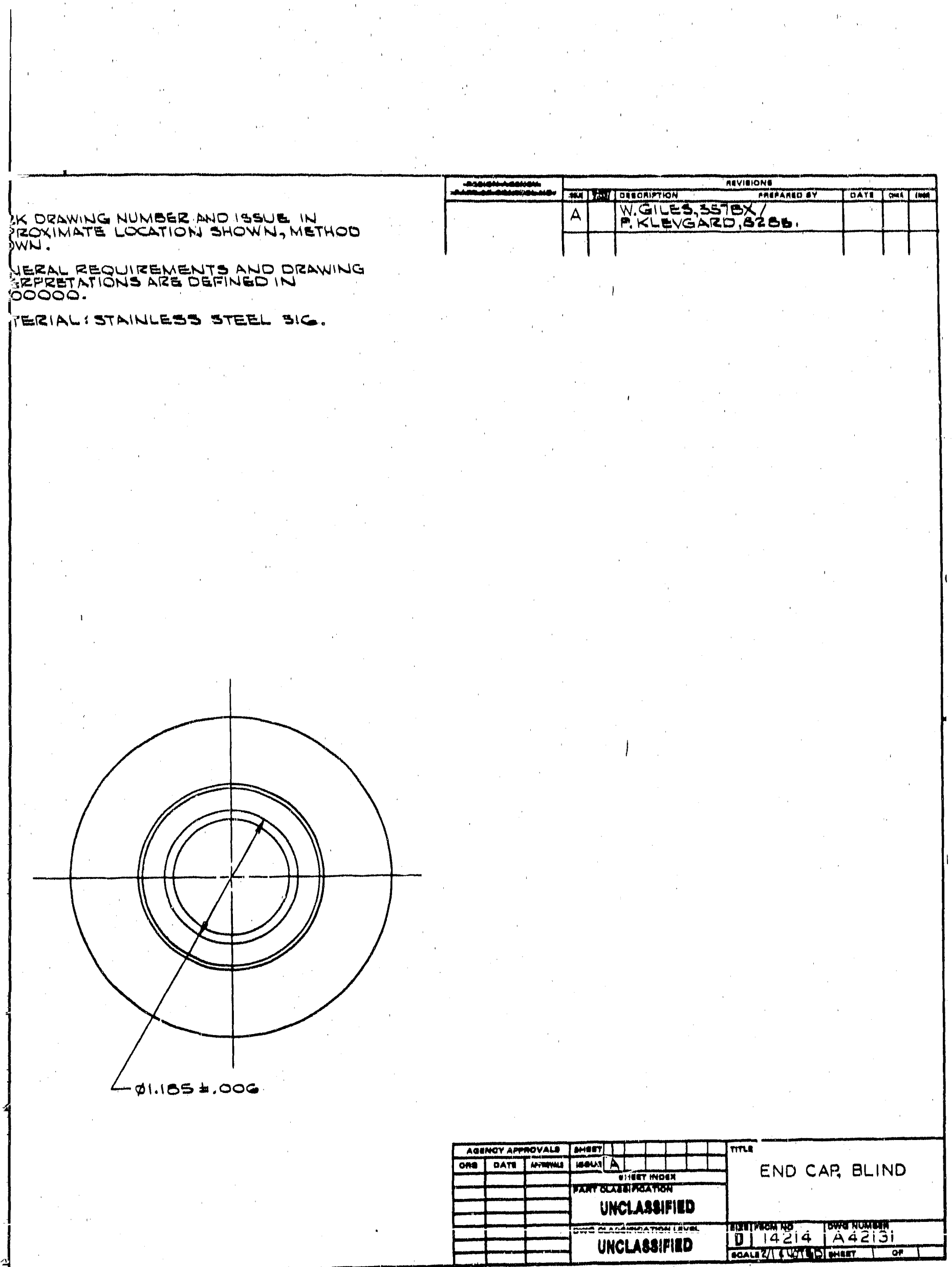

KK DRAWING NUMBER AND ISSUE IN IZOXIMATE LOCATIONJ SHOWN, METHOO

HERAL REOUIREMENTS AND DRAWING OOOOO.

ERIAL: STAINLESS STEEL BIG. 


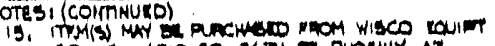

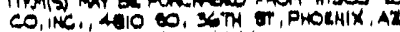

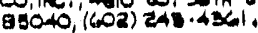

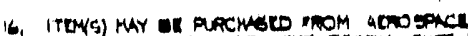

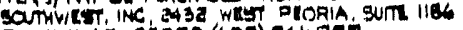

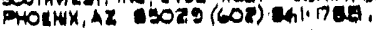

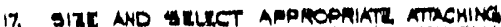

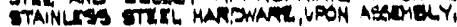

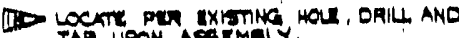
TAP UPON AESEMALY,

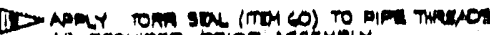
As ALOUIACO, PRION AssimeLY,

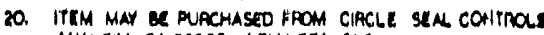
ANAKCM, CA 92803, 17141774 - 6110

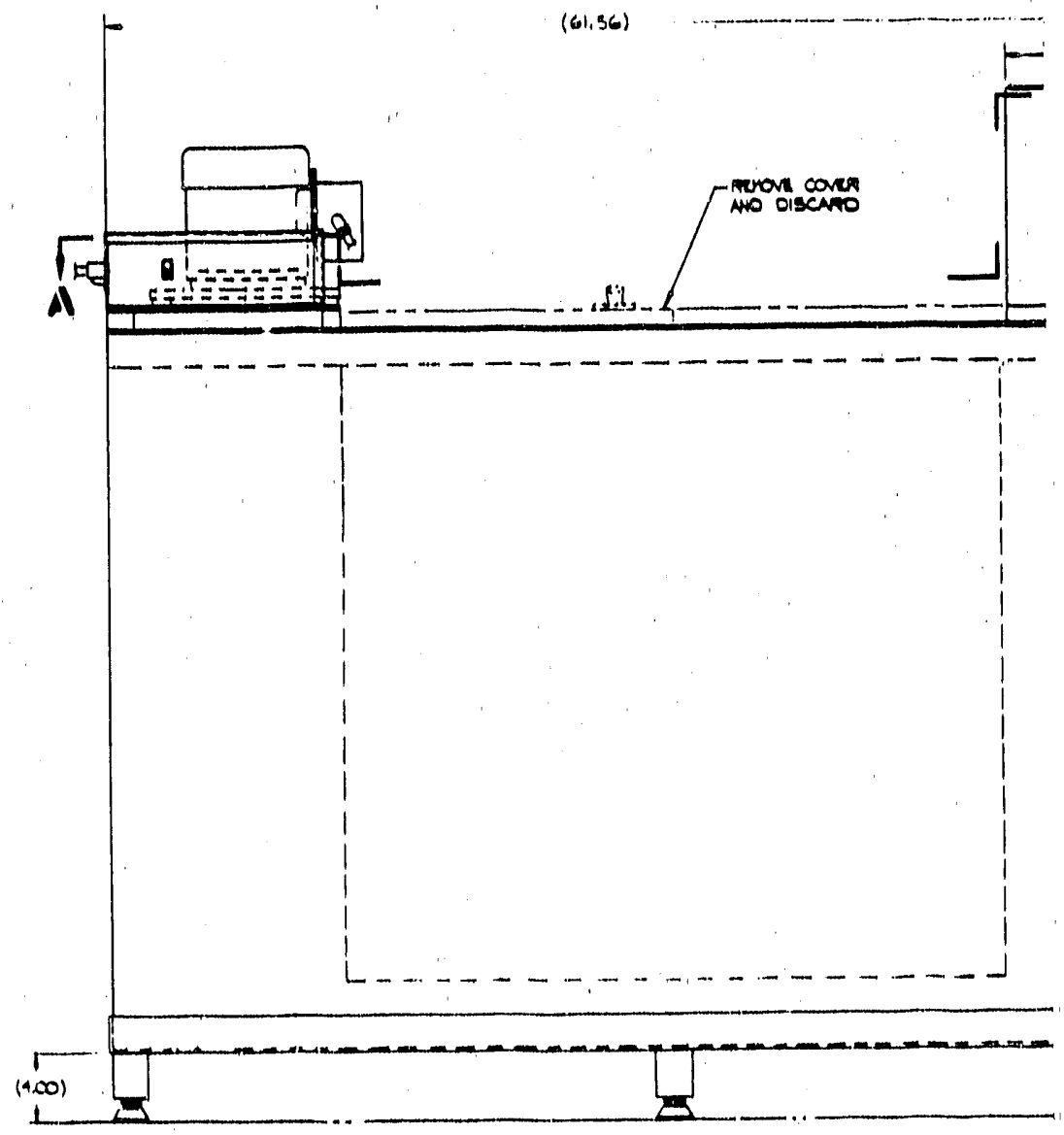




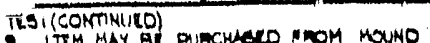
LADOAATORY, JAYTON, OHDO.

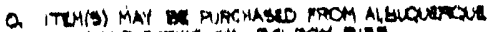

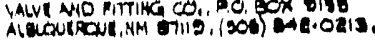

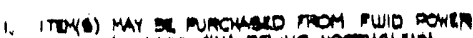

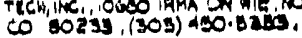

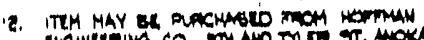

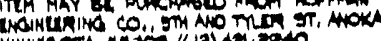

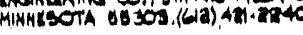

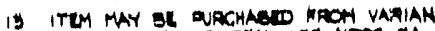

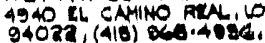

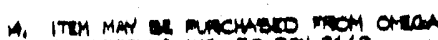

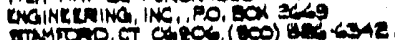

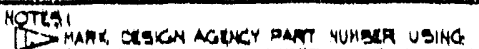

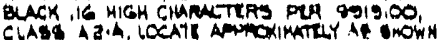

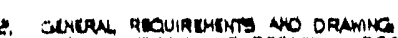
strits

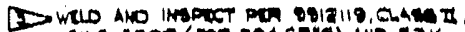

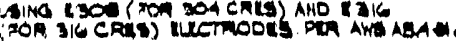

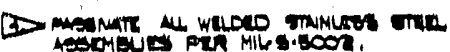

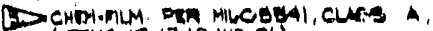
ITHMS 13,17,19 AND EI).

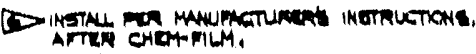

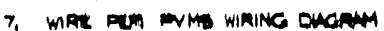

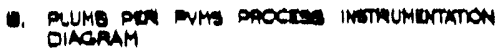

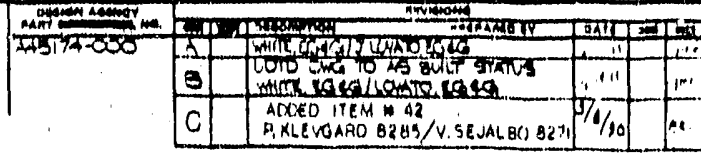

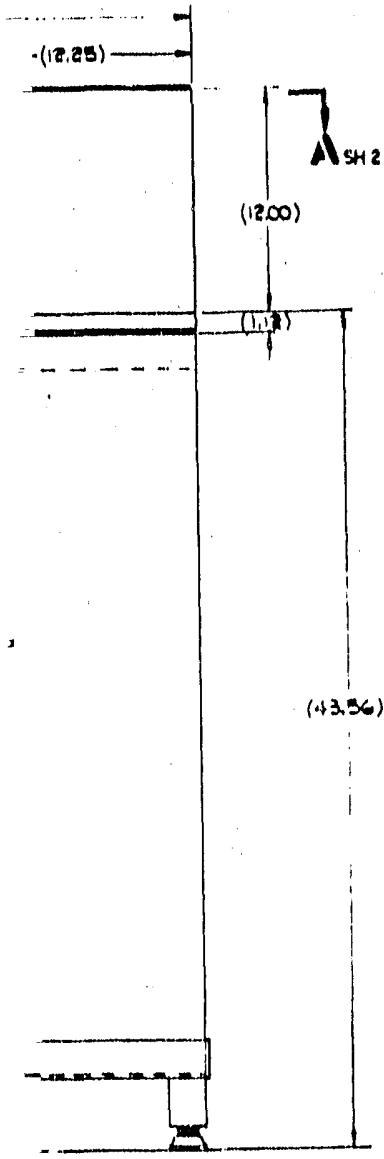

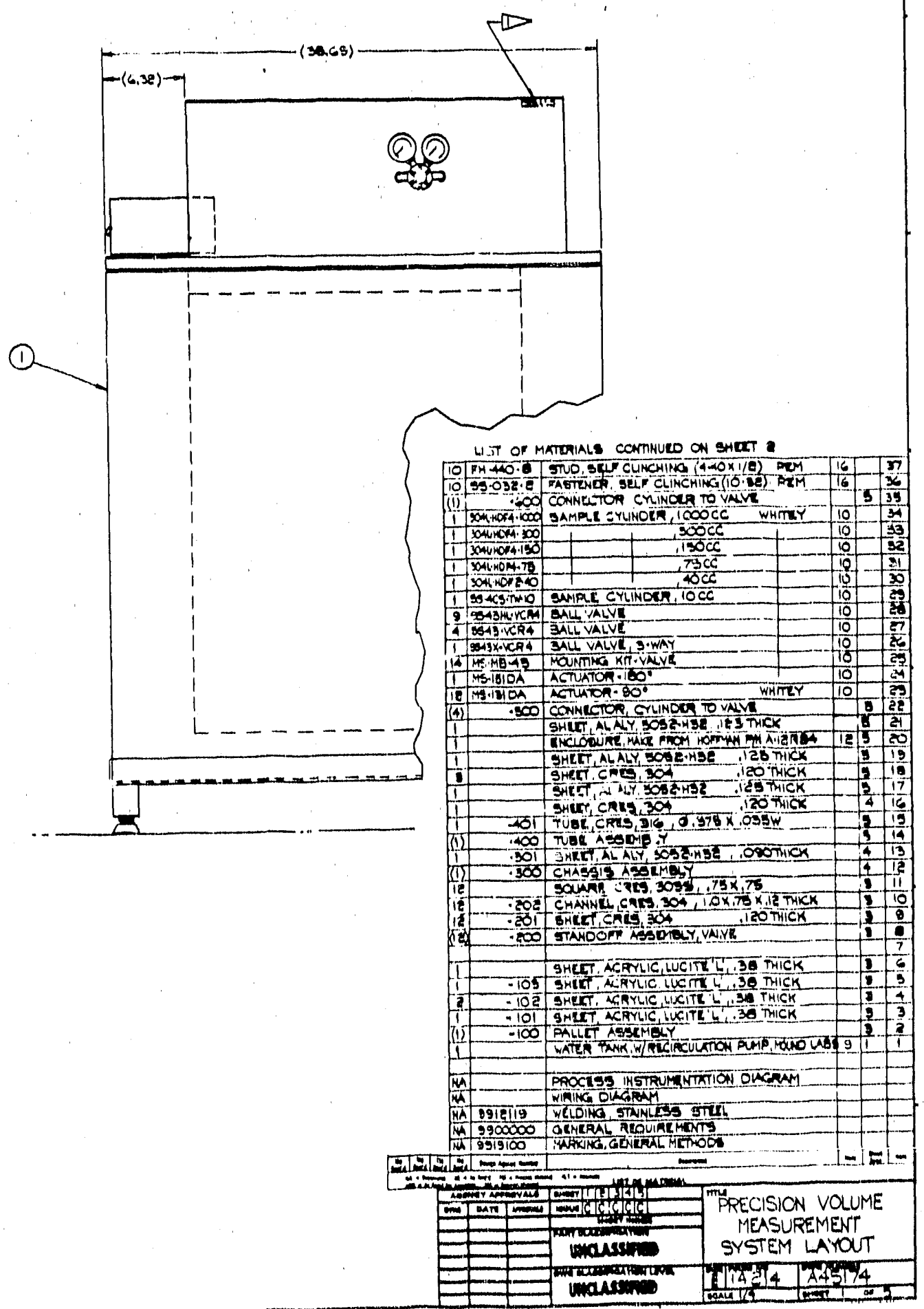




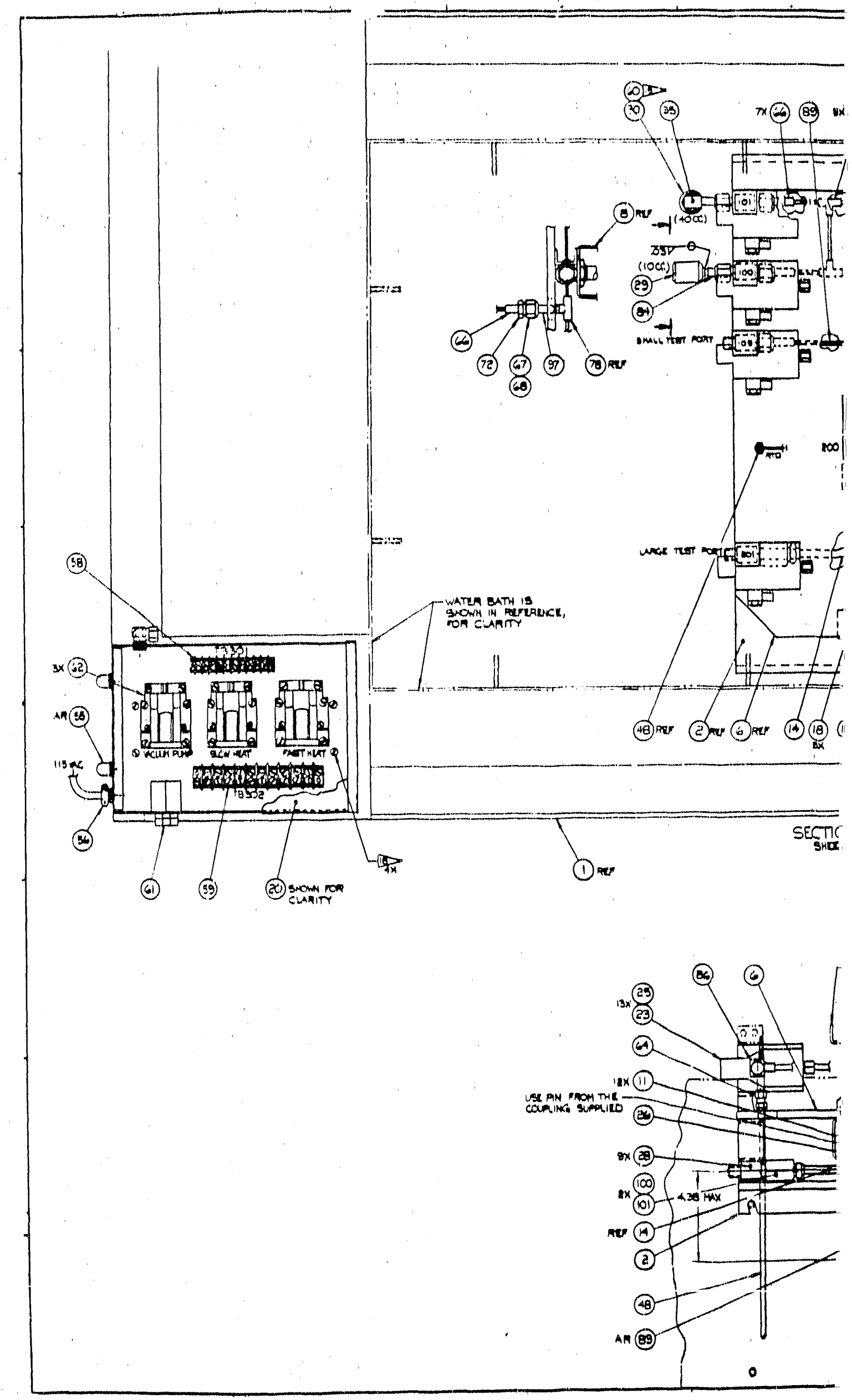




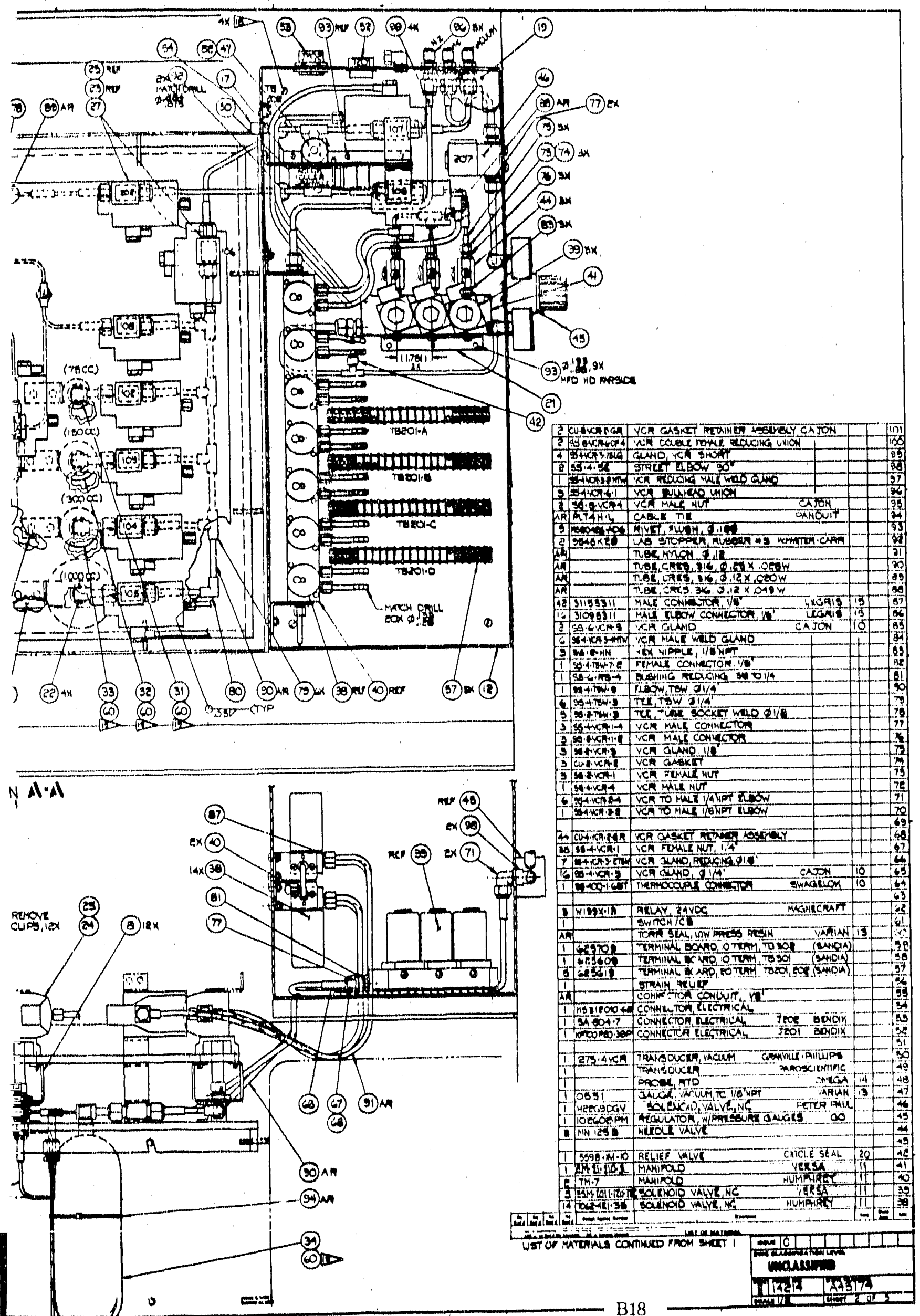



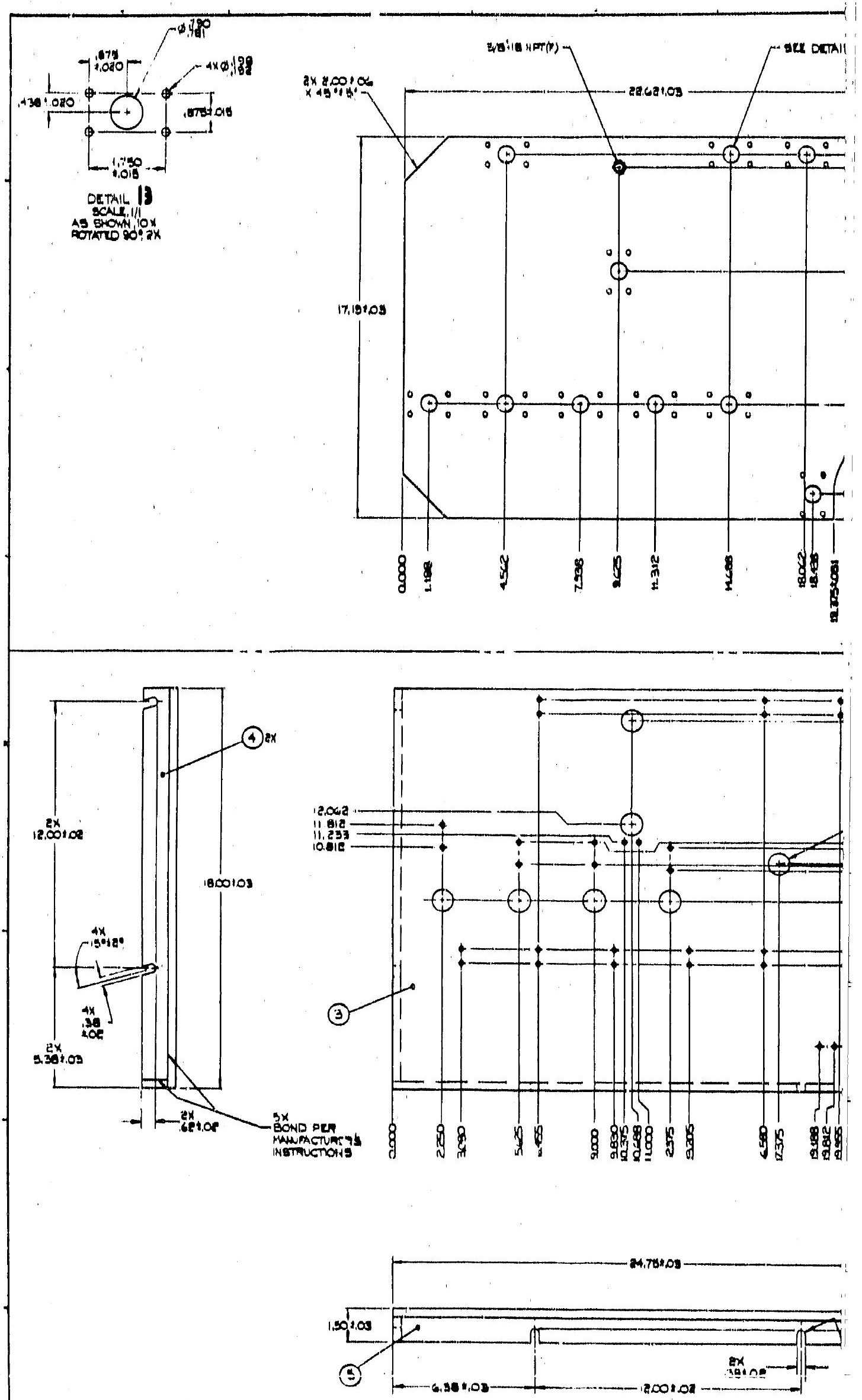
13
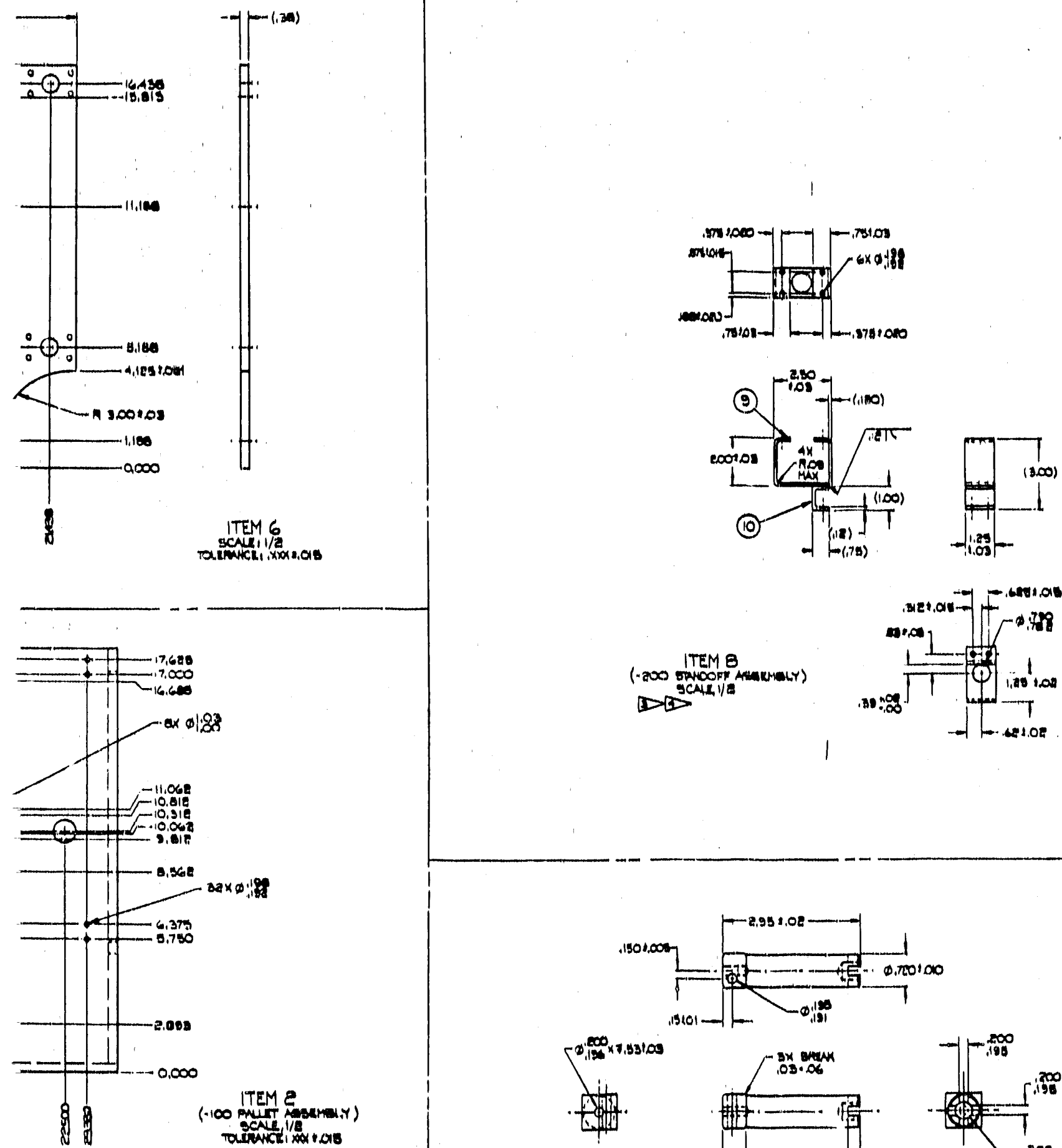

ITEM 8

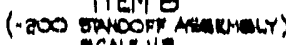
(1)
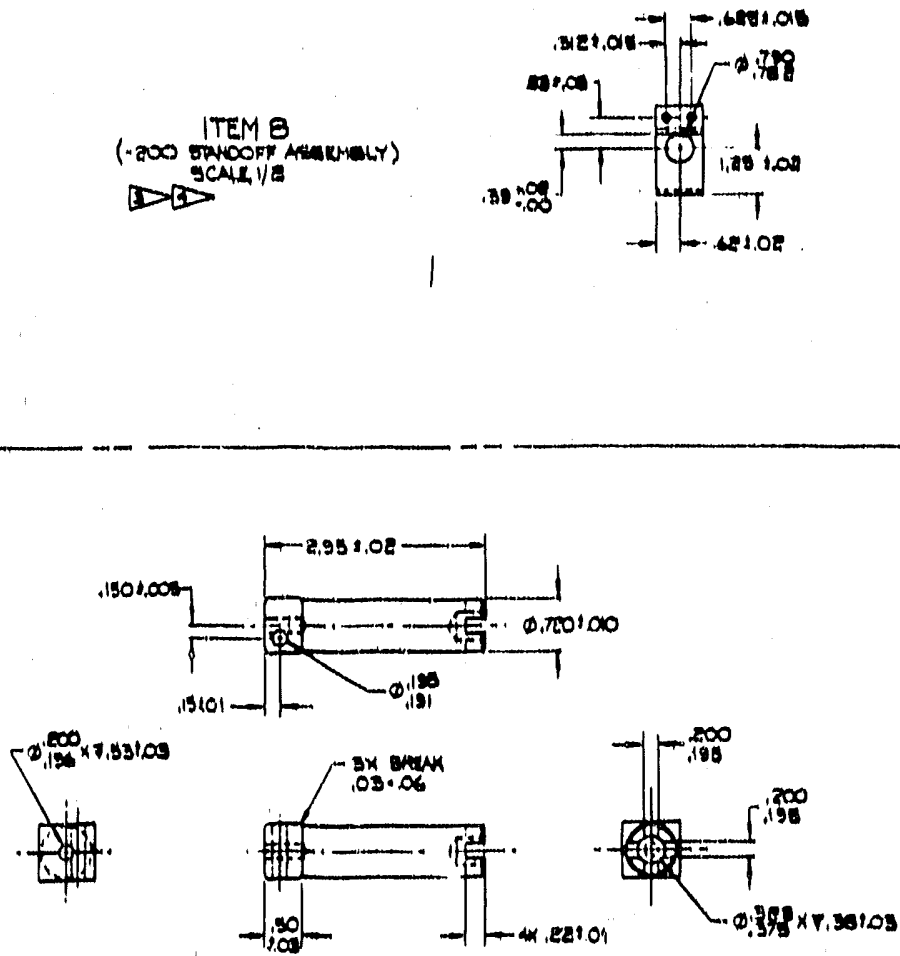

ITEMII

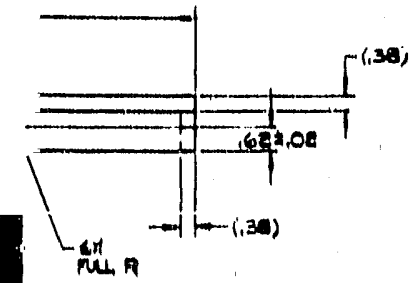




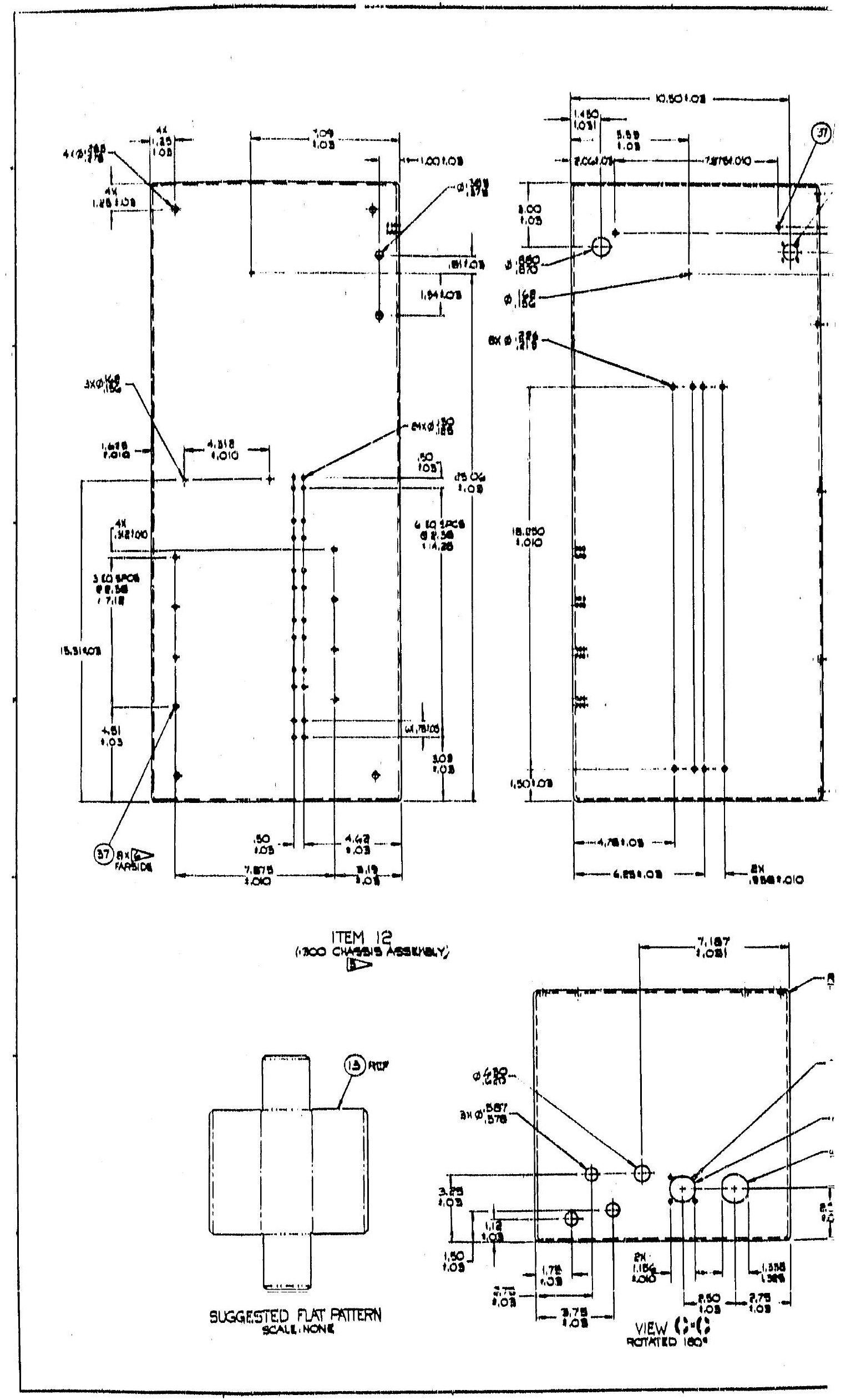




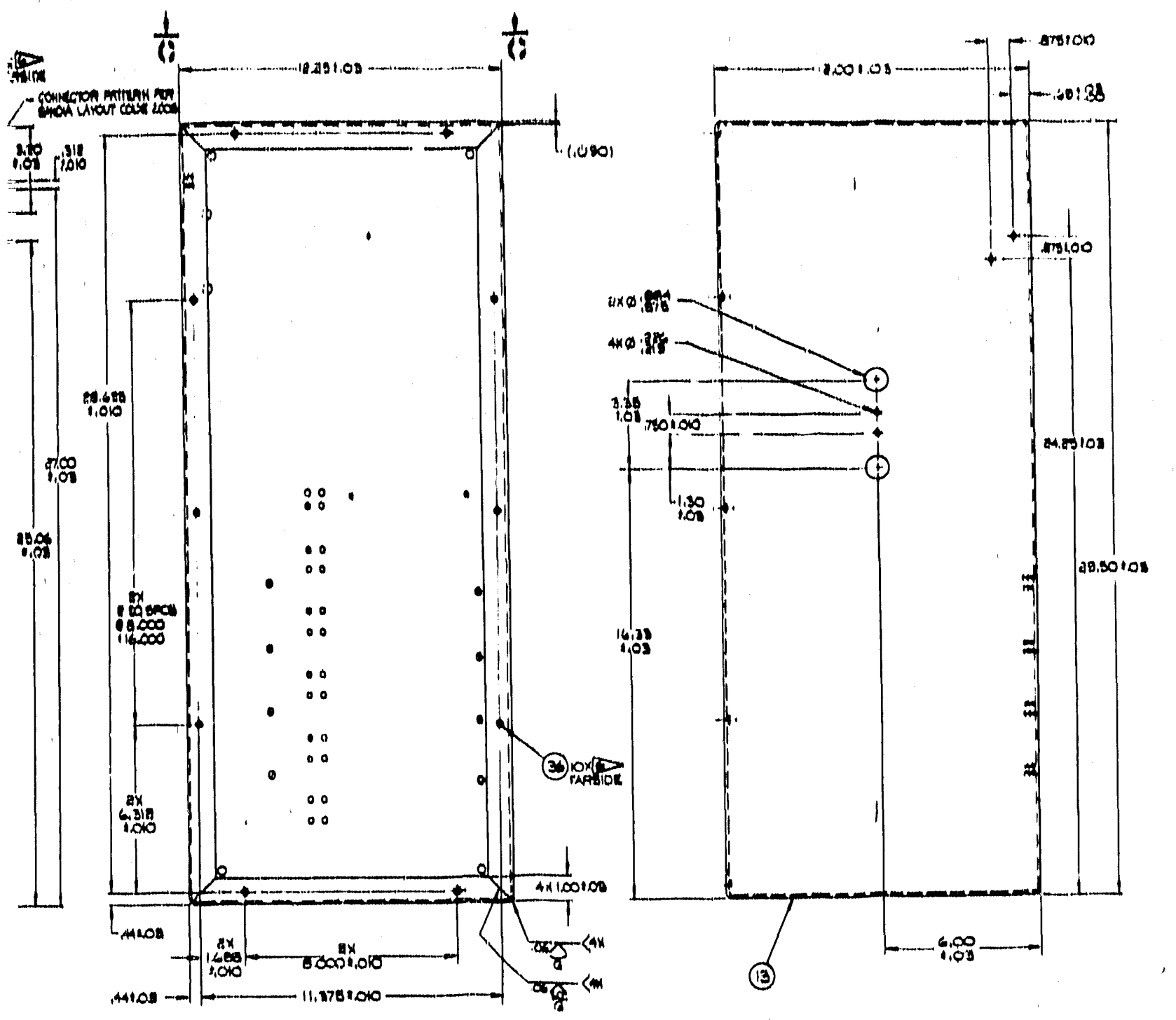

nute
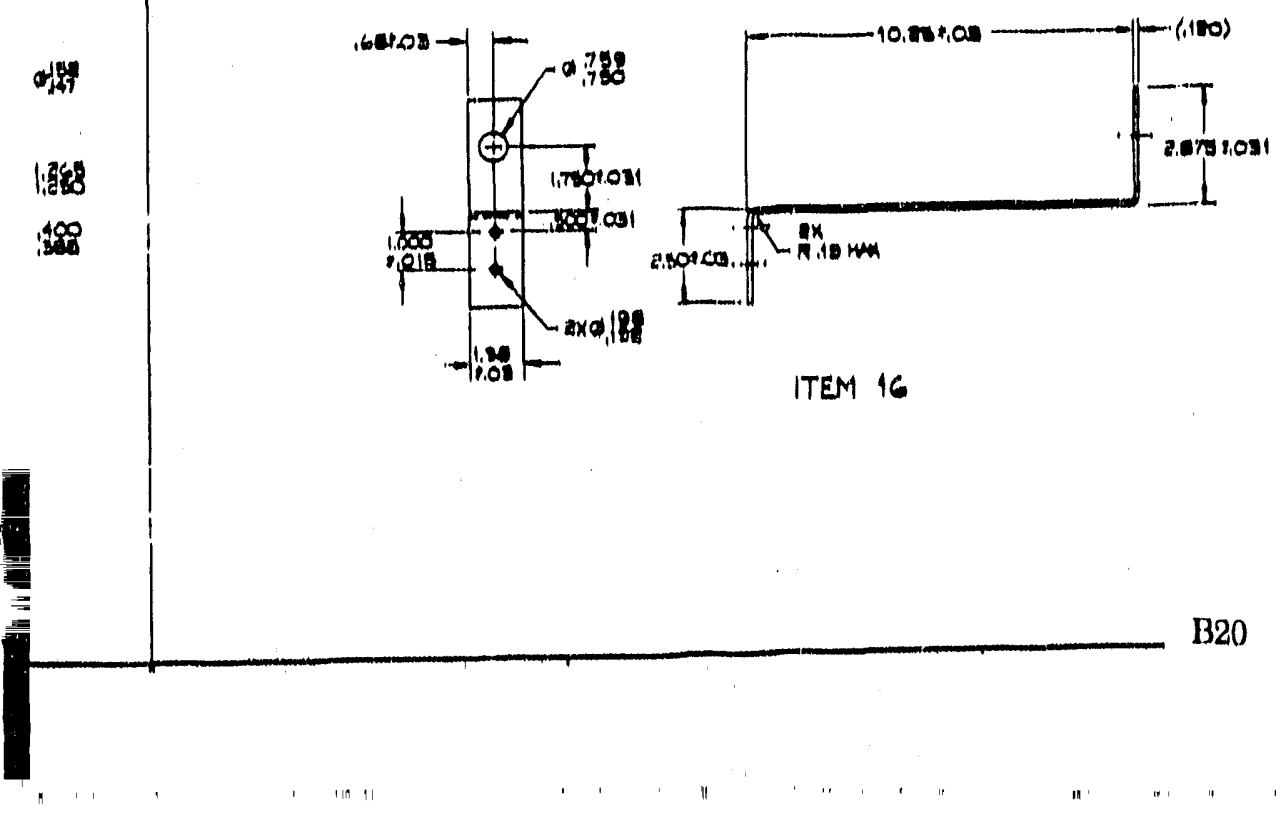


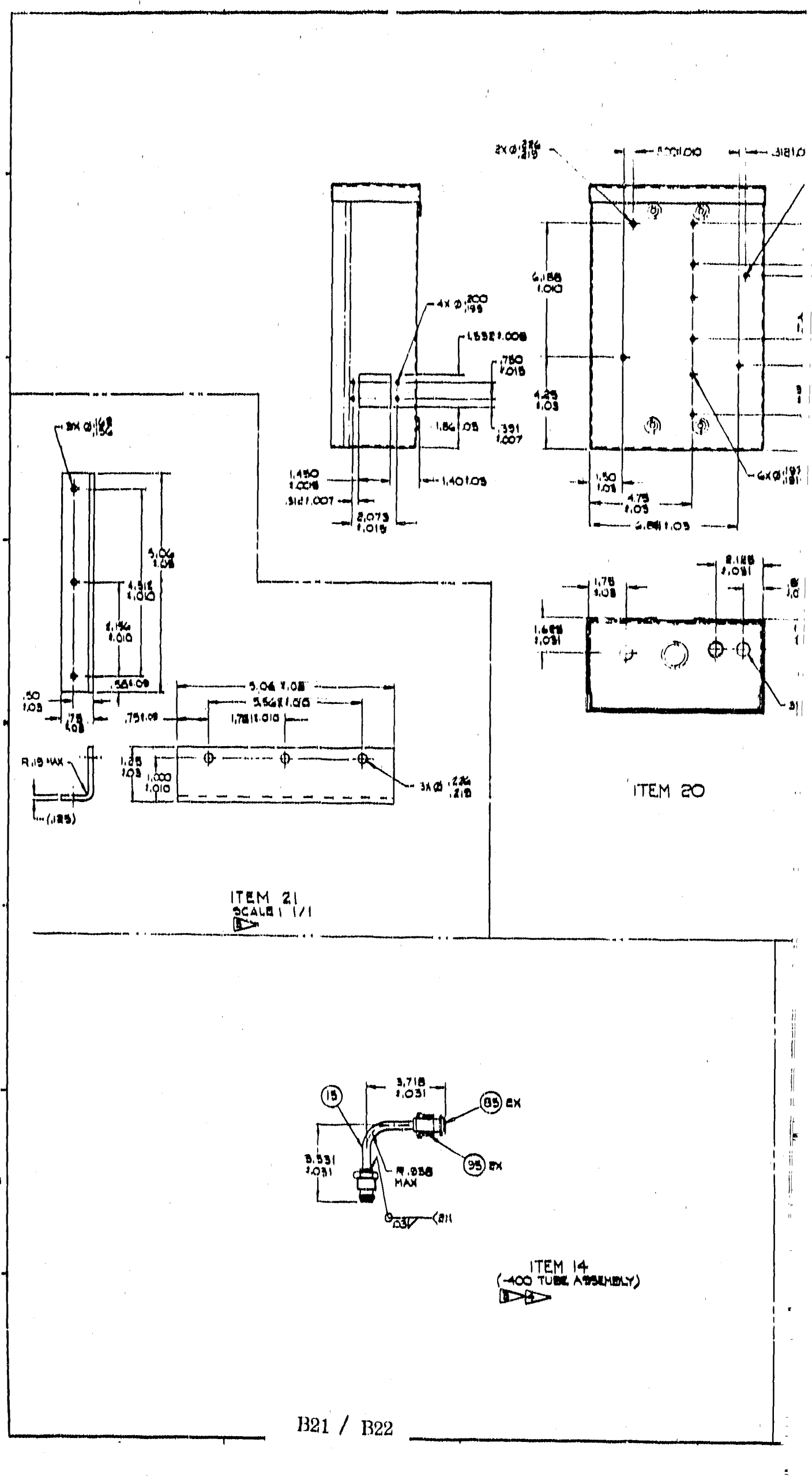



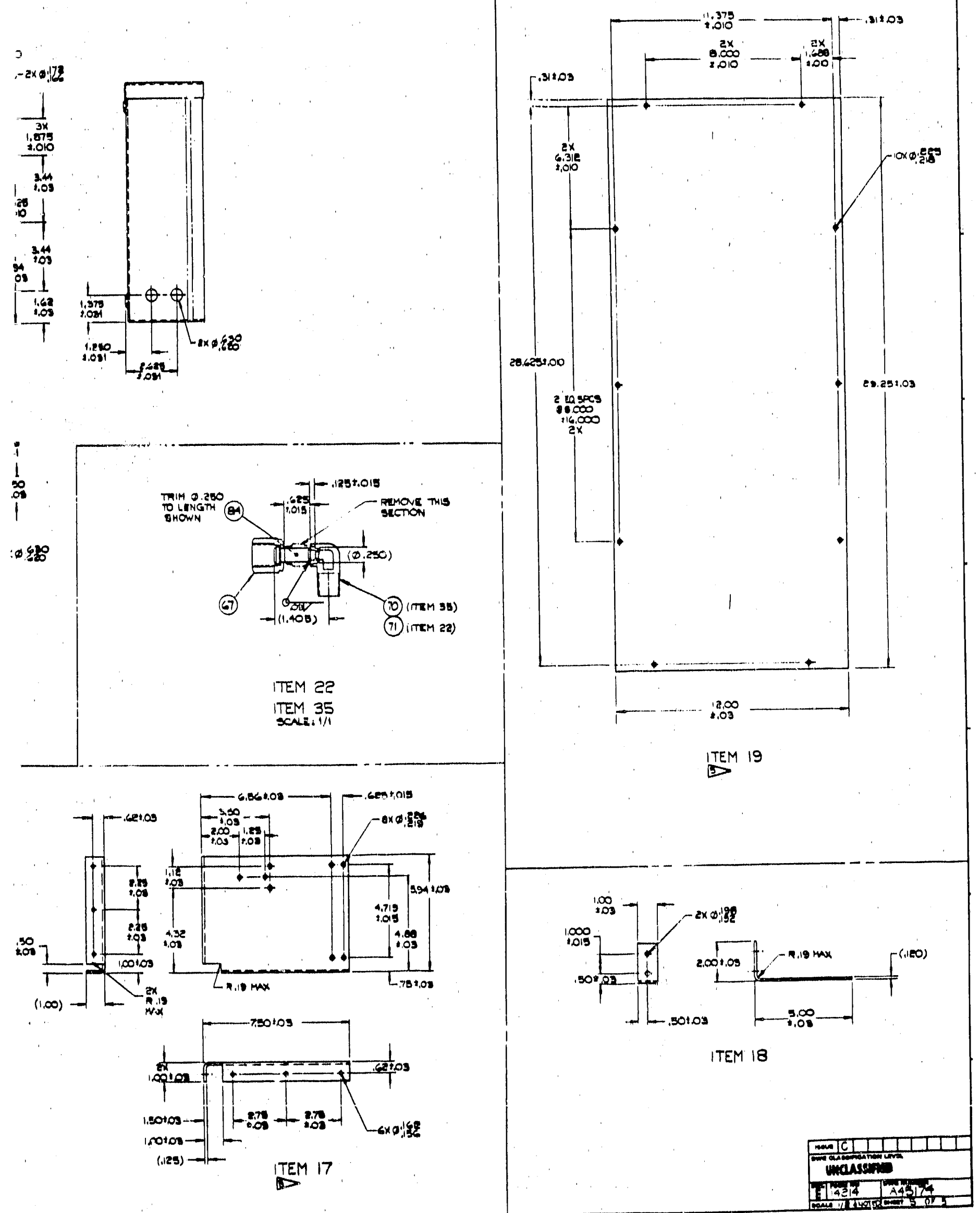

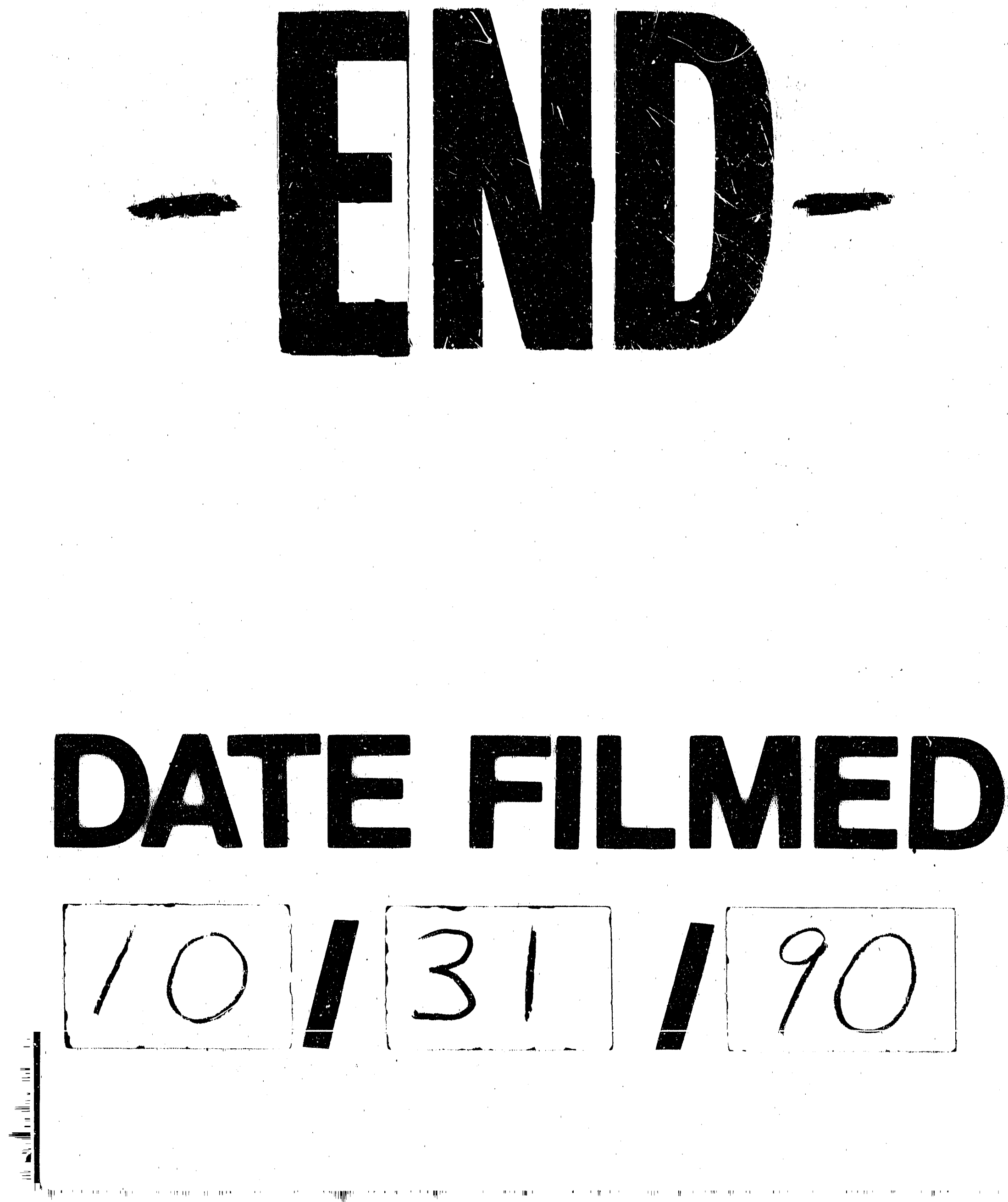
